Florida International University FIU Digital Commons

\title{
Negotiating Self: An Exploration of Women's Perceptions of Their Feminist and Submissive Identities
}

Carolyn Meeker

Florida International University, cmeek001@fiu.edu

DOI: $10.25148 /$ etd.FIDC004093

Follow this and additional works at: https://digitalcommons.fiu.edu/etd

\section{Recommended Citation}

Meeker, Carolyn, "Negotiating Self: An Exploration of Women's Perceptions of Their Feminist and Submissive Identities" (2018). FIU Electronic Theses and Dissertations. 3690.

https://digitalcommons.fiu.edu/etd/3690 


\section{FLORIDA INTERNATIONAL UNIVERSITY}

Miami, Florida

\section{NEGOTIATING SELF: AN EXPLORATION OF WOMEN'S PERCEPTIONS OF THEIR FEMINIST AND SUBMISSIVE IDENTITIES}

A dissertation submitted in partial fulfillment

of the requirements for the degree of

DOCTOR OF EDUCATION

in

ADULT EDUCATION \& HUMAN RESOURCE DEVELOPMENT

by

Carolyn Meeker

2018 
To: Dean Michael R. Heithaus

College of Arts, Sciences and Education

This collected papers dissertation, written by Carolyn Meeker and titled Negotiating Self: An Exploration of Women's Perceptions of Their Feminist and Submissive Identities, having been approved in respect to style and intellectual content, is referred to you for judgment.

We have read this collected papers dissertation and recommend that it be approved.

$\begin{array}{r}\hline \text { Hilary C. Landorf } \\ \hline \text { Laurie Shrage } \\ \hline \text { Thomas G. Reio, Jr. } \\ \hline \text { Tonette S. Rocco, Major Professor }\end{array}$

Date of Defense: March 20, 2018

The dissertation of Carolyn Meeker is approved.

Dean Michael R. Heithaus College of Arts, Sciences and Education

Andres G. Gil Vice President for Research and Economic Development and Dean of the University Graduate School

Florida International University, 2018 
(C) Copyright 2018 by Carolyn Meeker

All rights reserved. 


\section{DEDICATION}

This dissertation is dedicated to everyone who seeks courage within yourself to live life as you choose, while striving to do no harm to others.

This dissertation is dedicated to every kinkster who's been told that you're not enough:

- every submissive who's been told that you're not a twue submissive

- every Dominant who's been told that you're not Dominant enough

- every switch who's been told that you need to choose

- every person who's been told that you are too old, too young, too thin, too big

This dissertation is dedicated to every community member who creates and supports safe spaces where people learn about BDSM/Leather/kink.

This dissertation is dedicated to everyone who creates and supports shared spaces where anyone is welcome regardless of sex, gender, gender expression, side of the slash, relationship status, ability, age, size, race, ethnicity, and every other way in which people are marginalized within society.

This dissertation is dedicated to everyone who creates and supports sacred spaces where people with similar characteristics or interests create community. Thank you TNG and TOG; sub, Dom, and switch roundtables; venues for our Leathermen and Leather women; groups for our trans members, People of Color, critters, littles, rope, whips, and so many more.

This dissertation is dedicated to the 23 women who shared your stories. Your willingness to speak about your identities, experiences, and challenges was a gift to me, as it will be for others. I admire your courage in living life as you choose (to the extent possible) and your willingness to share your knowledge in the support of others. 


\section{ACKNOWLEDGMENTS}

I first acknowledge my Major Professor, Dr. Tonette S. Rocco, for being readily accessible, including students in projects, and creating peer support groups. I also acknowledge Dr. Thomas G. Reio, Jr., whose welcoming smile opens the door to questions such as: What about curiosity? Dr. Laurie Shrage was recommended as a potential committee member on the basis of her research interests. I left our first meeting with a video, two articles, and introductions to two other researchers. I was nervous to approach Dr. Hilary Landorf because I did not know her well. However, my research was soon improved because of her thoughtful questions and feedback. All of my committee members demonstrate genuine care for students and I am blessed.

I must also acknowledge my peers. Dr. Gisela Vega, Dr. Craig Michael McGill, and Chaundra Whitehead: Thank you for being my foundation over the years. Yselande Pierre, Sabrena O’Keefe, and Christina Reddick: Thank you for providing structure in this final year. Dr. Valerie Morgan, Dr. Sue Gallagher, and Dr. Michael Whitt: While not peers in this process, I appreciate your encouragement and feedback.

I would also like to acknowledge Dr. Richard Sprott, my CARAS Mentor and Executive Director of the Community-Academic Consortium for Research on Alternative Sexualities (CARAS). Thank you for helping me to get organized, graduate, and identify a research agenda. Your breadth of experience is very helpful.

My final acknowledgement is for my family and friends who have supported me throughout this process. Thank you Mom, Dad, Lily, and Julie. Thank you Joel. Thanks to all of my friends, to Michelle Phelan, Rosie Cruz, and Stephanie Strange, for your patience in sharing my time with a million other things and people that are not you. 


\section{ABSTRACT OF THE COLLECTED PAPERS DISSERTATION \\ NEGOTIATING SELF: AN EXPLORATION OF WOMEN'S PERCEPTIONS OF \\ THEIR FEMINIST AND SUBMISSIVE IDENTITIES}

by

Carolyn Meeker

Florida International University, 2018

Miami, Florida

\section{Professor Tonette S. Rocco, Major Professor}

As women navigate the intersecting meanings of feminism and submission, some struggle to reconcile their feminist politics and submissive practice (i.e., belief in equality and desire to yield authority). Bondage/discipline, dominance/submission, and sadism/masochism (BDSM) has been examined through diverse feminist lenses, including radical feminism, postcolonial world-travelling, and a sex-critical approach. However, scant empirical research focuses on the intersection of feminist and submissive identities. The purpose of this collected papers dissertation was to better understand the identity navigation of women in the BDSM community who identify as feminist and submissive. Two studies were conducted to explore this gap.

Study \#1, a structured literature review of BDSM, examined how feminism and submission are discussed related to women who are feminist and submissive. Data were collected through a library database search, Google Scholar, reference scans, and Google Scholar Cited by. Important segments of data were identified and analyzed. Four themes emerged: feminism in the context of BDSM, normalization of BDSM, navigating identities, and power as transgressive. Implications focus on three areas: the importance 
of consent, transgression, and diversity; helping women understand and navigate identities; and reducing stigma through education.

Study \#2, a phenomenological study, explored how 23 women in the BDSM community perceive and navigate their feminist and submissive identities. Data were collected through interviews. Inductive analysis revealed six themes: feminist identity as distinct from feminist values, the complexity of submissive identity, women learn to accept their submissive identity in different ways, BDSM community perceived as generally accepting of feminist identity, feminist community perceived as not very accepting of submissive identity, and being out as feminist and as submissive. Implications focus on four areas: exploring how women challenge oppressions; understanding how women understand and negotiate consent; learning about how individuals learn about, develop, and engage in BDSM D/s relationships; and examining how college women experience these identities, feminism, submission, consent, and abuse while they develop as individuals.

The findings can apply to counseling, feminism, sex education, higher education, adult education, and human resource development through incorporation into curriculum, training, and policies. Research and practice can be enhanced through exploring how consent is understood, operationalized, and violated; broadening discussions about identity development; and increasing awareness of how adults learn. 


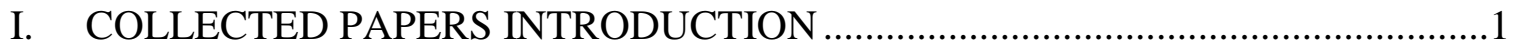

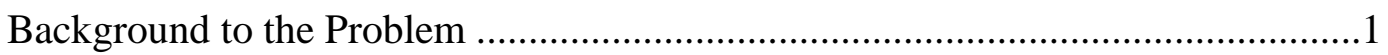

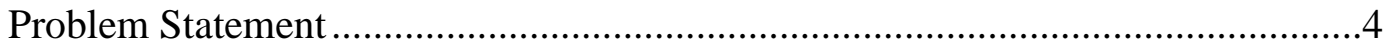

Purpose of the Collected Papers ....................................................................4

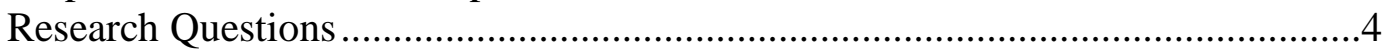

Overarching Conceptual Framework .....................................................................

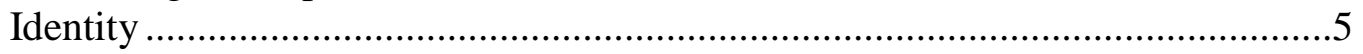

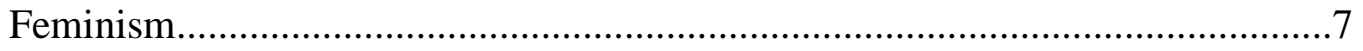

Bondage and Discipline, Dominance and submission, Sadism and Masochism

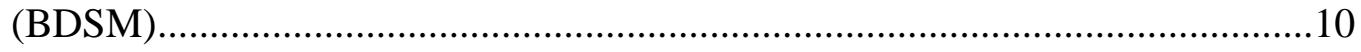

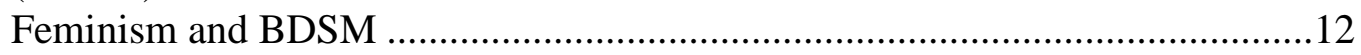

Significance of the Study ...............................................................................12

Description of the Collected Papers.................................................................13

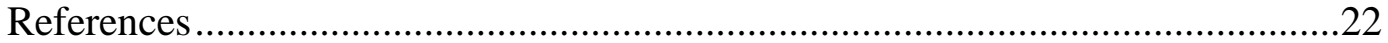

II. STUDY \#1: STRUCTURED LITERATURE REVIEW - NAVIGATION OF FEMINIST AND SUBMISSIVE IDENTITY BY WOMEN IN THE BDSM

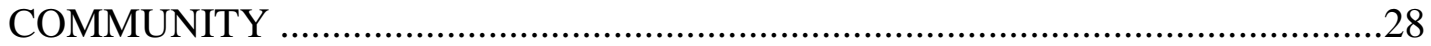

Purpose and Research Questions ……………….........................................

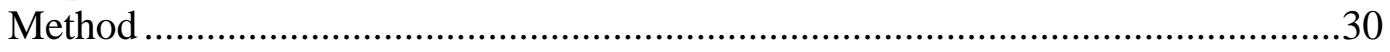

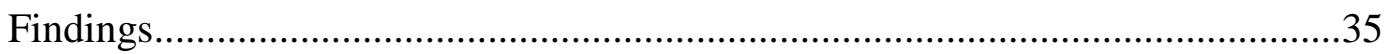

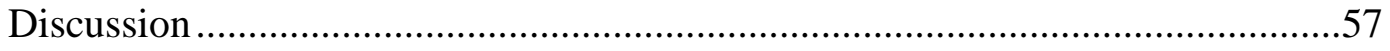

Implications for Future Research and Practice ...................................................61

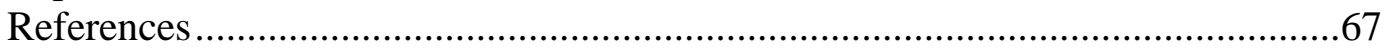

III. STUDY \#2: PHENOMONOLOGY - NEGOTIATING SELF: WOMEN'S NAVIGATION OF FEMINIST AND SUBMISSIVE IDENTITIES ........................78

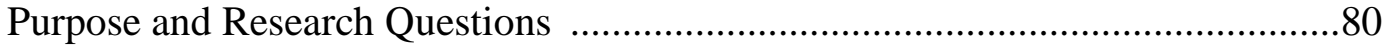

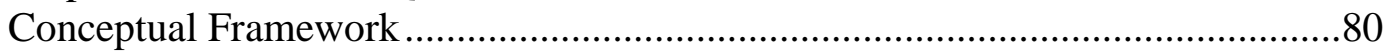

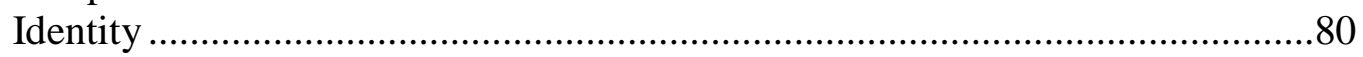

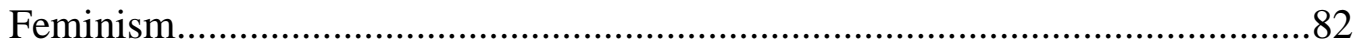

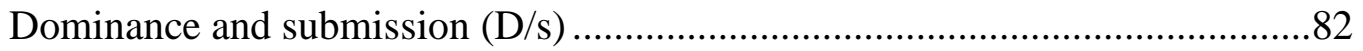

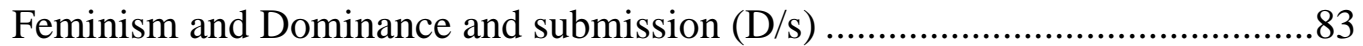

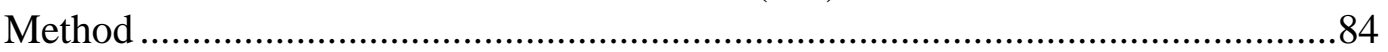

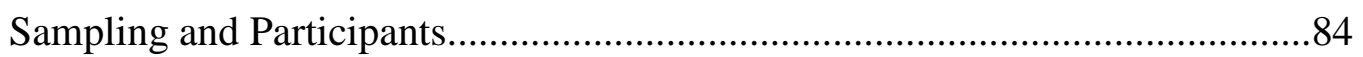

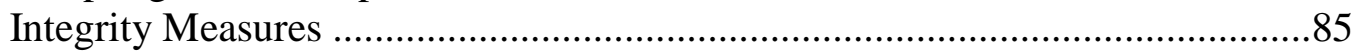

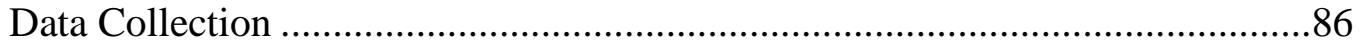

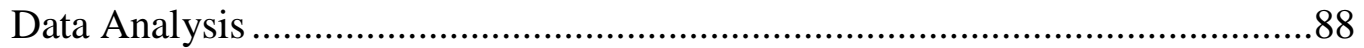

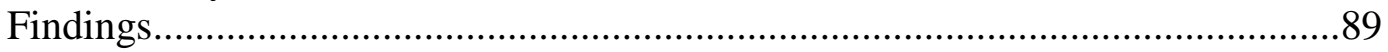

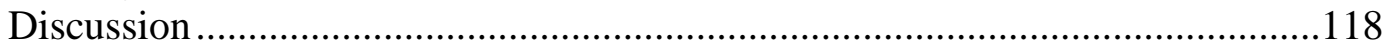

Implications for Future Research and Practice ………...................................125

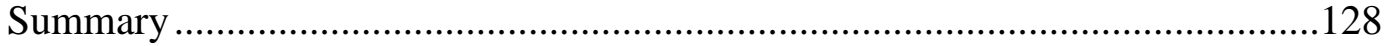




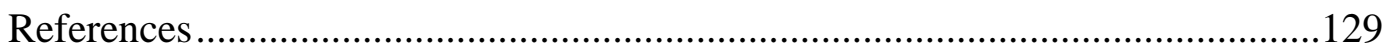

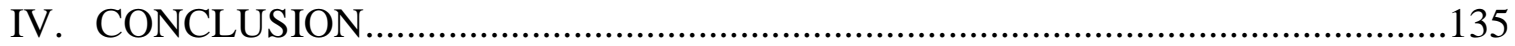

Overview of the Findings Related to Purpose of the Collected Papers ..............135

How Feminism and Submission are Discussed in the Scholarly Literature

on BDSM, Related to Women who Identify as Feminist and Submissive .........136

How Women in the BDSM Community who Identify as Feminist and

Submissive Perceive These Identities

How Women in the BDSM Community who Identify as Feminist and

Submissive Navigate These Identities ........................................................139

Discussion and Implications for Future Research and Practice..........................142

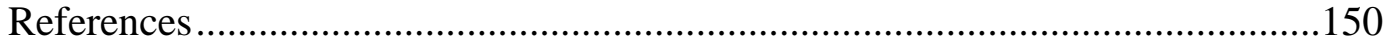

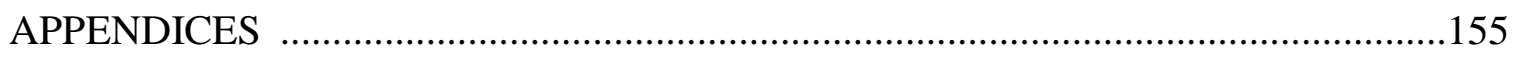

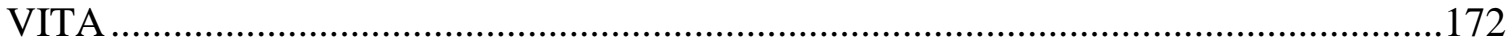




\section{LIST OF TABLES}

TABLE

PAGE

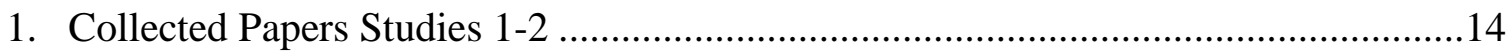

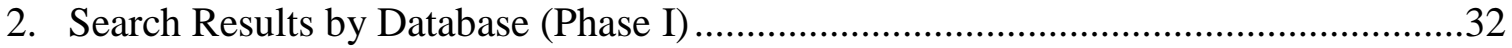

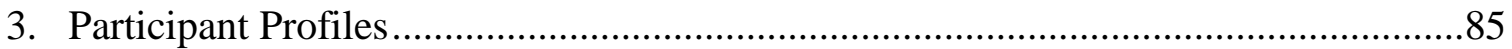

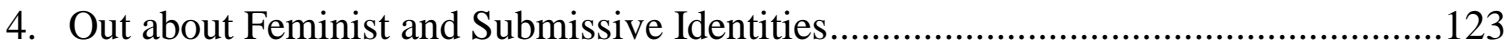

5. Out about Feminist and Submissive Identities....................................................143 


\begin{tabular}{ll}
\multicolumn{2}{l}{ ABBREVIATONS AND ACRONYMS } \\
Bondage/Discipline, Dominance/submission, Sadism/Masochism & BDSM \\
Dominance and submission & D/s \\
Master and slave & M/s \\
Risk aware consensual kink & RACK \\
Safe, Sane, and Consensual & SSC \\
Sadism and masochism or sadomasochism & SM or S\&M
\end{tabular}




\section{CHAPTER I}

\section{COLLECTED PAPERS INTRODUCTION}

This collected papers dissertation explored the identity navigation of women who are feminist and submissive, and active in the bondage/discipline, dominance/submission, and sadism/masochism (BDSM) community. The background to the problem, problem statement, purpose of the collected papers, research questions, and overarching conceptual framework are presented first. Then, the significance of the study, description of the proposed papers, and potential implications are provided, before concluding with the structure of the dissertation and references.

\section{Background to the Problem}

Identity shapes how people make sense of the world and their experiences, including their interactions with other people (Burke, 2007). An identity is "the set of meanings that define who one is when one is an occupant of a particular role in society, a member of a particular group, or claims particular characteristics that identify him or her as a unique person” (Burke \& Stets, 2009, p. 3). Individuals' identities are complex, as people claim various roles and affiliations (Stryker, 2002), such as: family role, gender, nationality, occupation, political affiliation, race, ethnicity, religious affiliation, sexual orientation, and social class. Some identities reinforce each other; others might not (Reitzes \& Mutran, 1995; Thoits, 1983; Wiley, 1991).

Identities and behaviors are connected through the meanings they share, yet "identities influence behavior only to the extent that the meanings of the behavior and the meanings in the identity standard are the same" (Burke \& Stets, 2009, p. 82). An identity standard is the set of meanings that defines the character of an identity. Individuals act or 
behave in ways to verify their identities, where their perceived meanings are consistent with their identity standard (Powers, 2005). If an identity is not verified by other people, then negative emotions may be produced, such as frustration, anger, and depression; and if no identities are verified, then anxiety, panic, and identity crisis might occur (Burke, 2007). For example, some women experience a struggle between their White, Mexican, and indigenous identities, where "commonly held beliefs of the white culture attack commonly held beliefs of the Mexican culture, and both attack commonly held beliefs of the indigenous culture" (Anzaldúa, 2007 p. 100). This "attack on ourselves and our beliefs" (Anzaldúa, 2007, p. 100) creates an "inner war" and "cultural collision," which can lead to the formation of a new, Latina identity.

Individuals' multiple identities can create polyrhythmic realities (Brown, 1989; Sheared, 1999), where their different understandings of their identities cause them to do "different, seemingly contradictory things, simultaneously" (Brown, 1989, p. 929). For example, a mother who advises her daughter to put husband and family before everything else might send that daughter money to pay for her college tuition, even though college will take time and attention away from husband and family. Women who are feminist and submissive can experience polyrhythmic realities if commonly held beliefs about feminism attack commonly held beliefs about submission, and vice versa.

Dominance and submission (D/s) is a relationship style that focuses on power exchange, where power exchange refers to "an interpersonal association in which the participants mutually consent to assume or yield authority" (Harrington \& Williams, 2012, p. 245). In D/s, or power exchange, relationships, the Dominant partner takes psychological and/or physical control over their submissive partner (Ortmann \& Sprott, 
2012). This power exchange might be perceived as incompatible with feminist values, such as the belief that individuals are inherently of equal worth and deserve the same rights and freedoms (Freedman, 2002). The concepts of intersecting identities and polyrhythmic realities can be useful in understanding the seemingly opposing identities as a system of simultaneous, complex, and interrelated identities. Feminist views on BDSM, which includes Dominance and submission (D/s), range from rejection to celebration, and can create polarizing frameworks. Some feminists argue that feminism and BDSM are mutually exclusive because BDSM promotes misogyny, exploitation, and violence against women (Dworkin, MacKinnon, 1985; Jeffreys, 2003; Linden, 1982). In fact, BDSM is viewed as "a lifestyle and approach to the world which glorifies and legitimates violence" (Jeffreys, 1993, p. 188). Other feminists argue that BDSM is a valid form of feminism and sexual freedom (Califia, 2002; Green, 2015; Queen, 1997a, 1997b; Rubin, 2011) and challenge theories of sexuality that define some forms of sex as "good," normal, and legitimate, or as "bad," abnormal, and illegitimate (Rubin, 1984). These opposing views can be problematic for women who are feminist and submissive.

As women navigate the intersecting meanings and expectations of feminism and submission, their polyrhythmic realities can lead to internal and external conflicts of identity. For example, a woman who believes in equality (feminist identity) might struggle to accept her desire to give up power to a Dominant partner (submissive identity). She might also experience conflict when one identity, or both, are not verified or accepted by other people. For example, she might feel positively about an identity because of her own regard for it, yet feel negatively about the identity as a consequence of a parent's negative attitude toward it. She might view herself as "wrong, other" or be 
viewed by others as "wrong, other" and struggle to avoid blaming, hating, and terrorizing herself or other people (Anzaldúa, 2007).

\section{Problem Statement}

Recent interest in studying BDSM in non-pathological ways has increased, as researchers seek to understand diverse people, identities and practices (Langdridge \& Barker, 2007; Turley, 2016; Weiss, 2011). Studies have explored BDSM and psychopathology (Cross \& Matheson, 2006; Powls \& Davies, 2012; Weinberg, 2006; Williams, 2006), BDSM cultural norms and characteristics (Langdridge \& Barker, 2007; Ortmann \& Sprott, 2015; Stiles \& Clark, 2011; Weinberg \& Newmahr, 2015), BDSM normalization (Barker, 2013a; Downing, 2012; Dymock, 2012; Musser, 2015; Weiss, 2011) and sexual citizenship (Chatterjee, 2012; Langdridge, 2006). BDSM has been examined through diverse feminist lens, including radical feminism (Linden, 1982), postcolonial feminism (Deckha, 2011), and a sex-critical approach (Downing, 2012; Tsaros, 2013). However, little research has explored the lived experiences and identity navigation of women who are feminist and submissive (Dymock, 2011).

\section{Purpose of the Collected Papers}

The overarching purpose of this collected papers dissertation is to explore the identity navigation of women in the BDSM community who identify as feminist and submissive. This will be explored through two studies: structured literature review and a phenomenological inquiry.

\section{Research Questions}

The dissertation was guided by the following primary research question: How do women in the BDSM community who identify as feminist and submissive navigate these 
identities? Subsidiary questions were: How are feminism and submission discussed in the literature on BDSM, particularly as related to women who identify as feminist and submissive? How do women who identify as feminist and submissive perceive these identities? How do women who identify as feminist and submissive navigate these identities?

\section{Overarching Conceptual Framework}

Perceptions of identity inform how individuals make sense of their world and their interactions with other people. Individuals understand themselves through intersecting roles and affiliations, which have socially constructed meanings and expectations of behavior (Burke \& Stets, 2009). This study explored the phenomenon of feminist and submissive identity, within the context of the BDSM community and (D/s) relationships, through a lens which integrates concepts of identity, feminism, and BDSM.

\section{Identity}

Meaning is a response to socially defined objects (Stryker, 2002). These responses are shared, which allows people to understand, predict, and come to expect actions from others. Positions, "which are the relatively stable, morphological components of social structure... carry the shared behavior expectations that are conventionally labeled 'roles'” (p. 54). Roles, such as mother, teacher, and athlete are perceived, reacted to, and labeled within society: people expect a mother to behave like a mother; a teacher to behave like a teacher. Individuals also apply a reflexive aspect of the self, naming themselves. For example, a mother will name herself as a mother; a teacher will name herself as a teacher. These labels, with their attached meanings and expectations, become internalized, and are known as identities. 
A role identity is the internalized meanings of a specific role that an individual applies to herself or himself (Stryker, 2002). To maintain congruency between the sets of meanings, an individual will exhibit appropriate role behavior. A social identity relates to an individual's identification with a social group (Stryker, 2002). To maintain congruency between the sets of meanings, an individual will exhibit behavior that maintains the group boundaries and divisions within the social structure. The person identity is the set of meanings that define a person as a unique individual, as opposed to a role or group member (Stets, 1995; Stets \& Burke, 1994).

Three key concepts of identity theory are prominence, commitment, and salience (Burke \& Stets, 2009; McCall \& Simmons, 1978). A prominence hierarchy of identity (McCall \& Simmons, 1978) refers to how important an identity is to an individual, depending on her desires or ideals, and how she wants to be seen by others. The higher an identity is in the prominence hierarchy, the more important it is to the individual. Commitment refers to how invested an individual is in the identity; how embedded she is within the social structure. Identity salience is the likelihood that an identity will be activated; the more salient an identity, the more likely it is to be activated in any given situation. Activation means that the identity is attempting to verify itself, and that perceptions of meanings are being made and compared to the identity standard. If more than one identity becomes activated in a situation, the identity with the highest prominence and commitment will guide the behavior (Burke \& Stets, 2009; McCall \& Simmons, 1978).

Problems develop when two or more identities conflict. If the meanings of identities are inconsistent with each other, or at least not independent from each other, 
serious problems may result, such as identities changing or someone leaving the situation, either of which lead to negative emotional reactions. Prolonged conflict may lead to forms of psychological stress such as anxiety, depression, confusion, and vacillation. However, if the identities change and verify each other, the individual will feel good and work to maintain the situation.

Conflict can occur in environments where one identity, or both, are not verified by other people. For example, a woman whose submissive identity is very important to her (high in the prominence hierarchy) and who is committed to the submissive identity, might not allow that identity to be activated (salience) when she is with a parent who has a negative attitude toward it. Similarly, if she is at a BDSM event where submissives are expected to behave in a certain manner (e.g., speaking only when spoken to), this expectation might conflict with one of her feminist values (e.g., the right to speak freely). In such situations, identity prominence and commitment will guide her behavior; she will prioritize one identity over the other, which could lead to internal and/or external conflict.

As women navigate their intersecting identities and polyrhythmic realities by acting in ways to verify or change their identities, they might hide identities that are perceived as carrying stigma. Stigma occurs when an individual is rejected for having an attribute deeply discredited by society (Goffman, 1963). To some extent, both feminist and submissive identities are stigmatized.

\section{Feminism}

Feminism is "an understanding that women have suffered forms of subordination or oppression because of their sex, and an advocacy of ways to overcome them to achieve better lives for women, and for men, within the family and society” (Badran, 2009, p. 
18). Yet being a feminist does not mean that one has to make feminist projects and advocacy one's life work; rather, "it's about finding the cause that works for you, and makes you happy, and doing something about it... even if it's as simple as speaking up" when someone tells a sexist joke (Valenti, 2007, p. 17). Feminism includes "a wide range of theoretical and political perspectives that value women and their experiences" (Ferber, Holcomb, \& Wentling, 2009, p. 554); thus, making feminism and feminist identity difficult to define and measure.

Many feminist perspectives are grouped into categories, such as liberal feminism; radical feminism; Socialist-Marxist feminsm; womanist feminism; and multicultural, global, or postcolonial feminism (Tong, 2009; Zucker \& Bay-Cheng, 2010). Liberal feminism (Nussbaum, 2005; Steinem, 1988) relates to the understanding that social and legal constraints block women's entrance into and success in the public world. Advocacy focuses on education, voting rights, equal pay for equal work, sexual harassment, domestic violence against women, affordable child care and healthcare, and reproductive and abortion rights. To achieve equality, women must have as much chance to succeed as men do, which can be achieved through legal means and social reform. Radical feminism (Dworkin \& MacKinnon, 1985; Griffin, 1982; Jeffreys, 1993) relates to the belief that sexism is the fundamental cause of human oppression; that systems of patriarchy (power, dominance, hierarchy, and competition) cannot be reformed, and emphasizes that gender is a social construction. To obtain equality, society must be uprooted and changed at its core, through legal and political structures as well as social and cultural institutions. Socialist-Marxist feminism (Haraway, 2003 ; Jagger, 1994) relates to the belief that capitalism and patriarchy are the primary sources of women's oppression and that 
sexism, classism, and racism are fundamentally intertwined. It is impossible for anyone to achieve true freedom in a class-based society, where wealth is in the hands of a powerful few. Womanist feminism (Walker, 2004; Ogunyemi, 1985) addresses racism within traditional feminist movements by focusing on poverty, ethnocentrism, and racism as equally important and as intertwined with sexism. White, racist society is the primary oppressor of women; men of color suffer as much as women of color in terms of discrimination. Multicultural, global, or postcolonial feminism (Mohanty, 2003; Adichie, 2014; Harding, 2016) relates to the idea that women are not all alike and do not experience the same oppressions. Contextual factors, such as race, ethnicity, sexual identity, gender identity, age, religion, education, occupation, marital status, and health shape women's self-understanding of being oppressed or not oppressed.

Since its origins, the term "feminist" has remained a pejorative term, even amongst progressive reformers, suffragists, and socialists (Freedman, 2002). In some environments, and to some people, feminism is perceived and stigmatized as "super anti: anti-men, anti-sex, anti-sexism, anti-everything" (Valenti, 2007, p. 6) and as "trampling men's rights and their dignity into the ground" (Women Against Men, 2014, n.p.). For these reasons, an individual who believes strongly in feminist values (e.g., equal pay, political representation, sexual and reproductive choice) might not disclose to others her feminist identity, or even consider herself a feminist (Freedman, 2002).

However, feminist activism appears to be increasing, particularly in the United States, where movements seek to end sexual violence and harassment (\#MeToo, https://metoomvmt.org/) and educate college communities about sexual assault (It's On Us, http://www.itsonus.org/). In CNN's report Feminism in the age of Trump, feminist 
leaders spoke about how the face of the women's movement and the feminist movement is changing and women are working together more than they used to, "Our leadership looks different. We're younger. We're browner. We're more diverse. Many of us are trans. Many of us are queer, and that's really important" (Jessica González-Rojas, in "Feminism in the Age of Trump," 2017).

\section{Bondage and Discipline, Dominance and submission, Sadism and Masochism (BDSM)}

Bondage and discipline (BD), dominance and submission (D/s), and sadism and masochism (SM), collectively referred to as BDSM, is an umbrella term for "forms of sexuality that incorporate restraint, pressure, sensation, training, and elements of both erotic and nonerotic power exchange" (Ortmann \& Sprott, 2012, p. 15). The term" sadomasochism" (SM) is also used when referring to BDSM, though not all D/s relationships incorporate sadism and/or masochism. Leather, kink, and fetish are other terms used when referring to the BDSM umbrella.

Practitioners of BDSM are not a homogeneous enough group to be considered a unity (Stoller, 1991). However, there appears to be enough commonality amongst activities to suggest that SM is "constituted by a set of five social features which sustained a particular class of fantasies with erotic meanings: (a) dominance and submission, (b) role playing, (c) consensuality, (d) a sexual context, and (e) mutual definition" (Weinberg, Williams, \& Moser, 1984, p. 380). For many people, the kink community is a place to escape the "real world," where they can engage in fantasy, role play, and other experiences outside of the norm. For others, the kink community is the real world, where they can be themselves and choose their family, community, and 
identities. Some people seem to move between these worlds without boundaries (Harrington \& Williams, 2012).

Dominance and submission (D/s) refers to a relationship style that focuses on power exchange, where a submissive partner "willingly and consensually sublimates or bequeaths his or her power to a Dominant partner," thus allowing "the Dominant to take psychological or physical control” (Ortmann \& Sprott, 2012, p. 16). This control can include decisions, behaviors, and actions and can involve any aspect of life, such as communication, household responsibilities, and finances. It can be restricted to certain aspects of life or can encompass every aspect of life, as in "total power exchange". The term power exchange emphasizes that while D/s relationships are about power, they are also an exchange: "although dominant and submissive roles may be relatively stable, power is understood to be mobile, shared, or routed between practitioners during play (see also Langdridge and Butt 2005)" (Weiss, 2011, p. ix). Partners in a D/s relationship negotiate, or work together to establish, the parameters of their power exchange. Some relationship dynamics might be static, where the expectations never change; other relationship dynamics might be more flexible, where the expectations adjust depending on the environment or situation.

Policy, legal, and theoretical debates about the regulation of BDSM "are informed by heteronormative and gendered assumptions about power, agency, risk and responsibility" (Cowan, 2012, pp. 275-276). Groups and individuals who engage in BDSM have been marginalized and stigmatized by mental health professionals and society (Klein \& Moser, 2006) as both pathological and anti-feminist (Dworkin, 1974, 1989; Linden, 1982). Individuals experience discrimination, violence, loss of child 
custody, and loss of jobs and promotions because of their related activities (Wright, 2005); therefore, they continuously and strategically determine whether to disclose their identities or involvement in BDSM (Bezreh, Weinberg, \& Edgar, 2012; Brown, 2010; Wright, 2008).

\section{Feminism and BDSM}

People have different understandings of sex, sexuality, and sexual identities; therefore, "a complete account of sexual desire should leave room for diverse and incommensurable practices" (Shrage \& Stewart, 2015, p. 13). As a "particularly cultural practice" (Deckha, 2011, p. 141), BDSM can be viewed through a "world"-travelling approach (Lugones, 1987). A “world"-traveling approach "reveals the possibility and complexity of a pluralistic feminism," (Lugones, 1987, p. 3), allowing individuals to look beyond their "potentially misinformed assumptions" about BDSM (Deckha, 2011).

In a study about BDSM (Weiss, 2011), individuals spoke of their difficulty reconciling their (often feminist) politics and BDSM practice, and about freedom and choice as "freedom from social norms" (p. 164). Both identities can be stigmatized independently or as an intersection of identities - submissive identity, perceived as pathological and anti-feminist, and feminist identity, perceived as anti-everything, including men's rights.

\section{Significance of the Study}

Learning about sexual identities allows for the creation of new knowledge - about ourselves, about other people, and about how learning is created or suppressed in society (Edwards \& Brooks, 1999). Understanding women's experiences is crucial for professionals, educators, care givers, and other individuals who impact women's lives, so 
that these individuals can be better informed and able to serve or relate to them. This includes health care professionals who provide physical, psychological, and spiritual support; legal professionals who inform and enforce laws and policies; and educators who teach about topics such as identity, relationships, sexuality, feminism, health care, and law. A deeper understanding can also benefit individuals and groups who engage in BDSM, particularly women who are feminist and submissive, who seek to reflect upon their identities and experiences.

Furthermore, examining heterosexism, or the "system of oppression that reduces the experience of sexual minorities to medical or criminal causes while victimizing people who are seen as sexual minorities through violence or diminished opportunity," (Rocco \& Gallagher, 2006, p. 30) can help society learn how to create equitable systems and structures (Rocco \& West, 1998). This study was undertaken to advance the discussion about learning, identity, feminism, submission, and BDSM, and the findings can be applied in the field of adult education through incorporation into curriculum and training for psychologists, doctors, nurses, attorneys, and law enforcement officers. It can also inform educational platforms for parents, friends, and colleagues who interact with BDSM practitioners, and can be significant to all member of the BDSM community, in terms of understanding multiple identities.

\section{Description of the Collected Papers}

The overarching purpose of the collected papers dissertation was to explore the identity navigation of women who identify as feminist and submissive (submissive in the context of a Dominance and submission or power exchange relationship) and who are active in the BDSM community. Two studies were conducted: a structured literature 
review and a phenomenological inquiry. Table 1 presents the type of study, running title, intended journal, purpose statement, main research question, and subsidiary research questions for each study.

Table 1

Collected Papers Studies 1-2

\begin{tabular}{|c|c|c|}
\hline Study specifics & Study \#1 & Study \#2 \\
\hline Type of Study & Structured literature review & Phenomenology \\
\hline Running Title & $\begin{array}{l}\text { Navigation of feminist and } \\
\text { submissive identity by women in } \\
\text { the BDSM community }\end{array}$ & $\begin{array}{l}\text { Negotiating self: Women's } \\
\text { navigation of feminist and } \\
\text { submissive identities }\end{array}$ \\
\hline $\begin{array}{l}\text { Journal of } \\
\text { Intent (and } \\
\text { Publication } \\
\text { Style) }\end{array}$ & $\begin{array}{l}\text { Signs: Journal of Women in } \\
\text { Culture and Society (Chicago } \\
\text { Manual of Style, 16th ed.). }\end{array}$ & $\begin{array}{l}\text { Self \& Identity (Taylor \& } \\
\text { Francis) }\end{array}$ \\
\hline $\begin{array}{l}\text { Purpose } \\
\text { Statement }\end{array}$ & $\begin{array}{l}\text { The purpose of this structured } \\
\text { literature review (Rocco, Stein, } \\
\& \text { Lee, 2003) is to examine the } \\
\text { scholarly literature on women in } \\
\text { the BDSM community who } \\
\text { identify as both feminist and } \\
\text { submissive and how they } \\
\text { perceive and navigate those } \\
\text { intersecting identities. }\end{array}$ & $\begin{array}{l}\text { The purpose of this } \\
\text { phenomenology (van Manen, } \\
\text { 1997) is to understand the } \\
\text { experiences of women in the } \\
\text { BDSM community who identify } \\
\text { as feminist and submissive, } \\
\text { regarding their experiences } \\
\text { navigating these identities. }\end{array}$ \\
\hline $\begin{array}{l}\text { Research } \\
\text { Question }\end{array}$ & $\begin{array}{l}\text { How are feminism and } \\
\text { submission discussed in the } \\
\text { scholarly literature about BDSM, } \\
\text { particularly related to women } \\
\text { who identify as feminist and } \\
\text { submissive? }\end{array}$ & $\begin{array}{l}\text { How do women in the BDSM } \\
\text { community who identify as } \\
\text { feminist and submissive perceive } \\
\text { and navigate these identities? }\end{array}$ \\
\hline $\begin{array}{l}\text { Subsidiary } \\
\text { Research } \\
\text { Question }\end{array}$ & $\begin{array}{l}\text { How is the intersection of } \\
\text { feminism and submission } \\
\text { discussed in the literature? }\end{array}$ & \\
\hline
\end{tabular}




\section{Study \#1: Structured Literature Review}

Researchers have examined BDSM through diverse feminist lenses, including a radical feminist approach (Linden, 1982; Lorde \& Star, 1982), a postcolonial feminist “world-travelling” approach (Deckha, 2011), a sex-critical approach (Barker, 2013a; Downing, 2012; Tsaros, 2013); and Black female sexuality (Cruz, 2016). Agency and consent have been explored, as well (Beres \& MacDonald, 2015; Chatterjee, 2012; Cruz, 2015; Deckha, 2011; Dymock, 2012; Musser, 2015; Tsaros, 2013). However, scant empirical research has focused on the intersection of feminist and submissive identity (Dymock, 2011).

Purpose and research questions. The purpose of the structured literature review (Rocco, Stein, \& Lee, 2003) was to examine the scholarly literature on women in the BDSM community who identify as both feminist and submissive and how they perceive and navigate those intersecting identities. The current study was guided by the following primary research question: How are feminism and submission discussed in the scholarly literature about BDSM, particularly related to women who identify as feminist and submissive? A subsidiary question was: How is the intersection of feminism and submission discussed in the literature?

Method. The data collection involved four phases: database selection and search (Phase I), Google Scholar search (Phase II), scanning of reference lists (Phase III), and Google Scholar "Cited by" search (Phase IV). A university librarian was consulted to determine the most appropriate search terms and databases. Originally, nine databases were selected, however Contemporary Women's Issues was not available, leaving eight in the search: Criminology (Sage), Education Journals (ProQuest), GenderWatch 
(ProQuest), JSTOR, Project MUSE, ProQuest Dissertations \& Theses Database (PDTD), PsycINFO (ProQuest), and Sociological Abstracts (ProQuest). The databases were searched for full text scholarly journal articles and dissertations in English through May 2017. The primary search term was "BDSM", with variations of "sadomasochism," "kink," "leather," "dominance and submission," and "power exchange." Each term was combined in separate searches with the terms "woman," "feminism," "submissive," "identity," and "role," with every permutation available (i.e., woman, women, and identity, identities, identify, or identification). The process yielded 1,284 initial results. The title of each result was read, looking for relevance to the research questions, and when there was doubt, the abstract was read, or the article, if no abstract was available. From the 1,284 results, 1,173 were eliminated. The 111 publications that remained after the initial scan were downloaded and read to confirm fit with the study. Only 22 were relevant to the research questions; however, 10 of these were duplicates, leaving 12 publications in the sample. Subsequent searches resulted in an additional 15 publications: five from Phase II Google Scholar; eight from Phase III Scanning Reference Lists, and two from Phase IV Google Scholar "Cited By", resulting in a sample of 27 publications.

Analysis and findings. The publications were read twice and coded separately to identify themes. Initially, the publications were read without taking notes, to gain a sense of the material while avoiding "coding fetishism" (Richards, 2002) or over-coding. Then, the publications were scanned for "raw information" (Joffe \& Yardley, 2003, p. 57). Notes were made in the margins of the documents, pertaining to each important segment of data that provided insight into the identity-related experiences of women who are feminist and submissive. The notes were recorded onto Word documents, with supporting 
text, to be used in identifying key ideas and common themes. Codes were assigned to each important segment of data. The codes were then sorted and the publications revisited to check for appropriate evidence, to strengthen the claim that the publications were reviewed evenhandedly and that the codes are trustworthy (Krefting, 1991). The themes, or patterns, that emerged from the data included both manifest content (something directly observable) and latent content (something implicitly referred to; Boyatzis, 1998).

Four broad themes were identified: (a) feminism in the context of BDSM, (b) the normalization of BDSM, (c) navigating feminist and submissive identities, and (d) BDSM power as transgressive. Implications for future research and practice focus on three areas: (a) the importance of consent, transgression, and diversity within the BDSM community; (b) helping women understand and navigate their feminist and submissive identities; and (c) reducing BDSM social stigma through education.

Publication submission and formatting. This first study of the collected papers is intended for submission to Signs: Journal of Women in Culture and Society, which requires the paper to be formatted to Chicago Manual of Style (16th ed.).

\section{Study \#2: Phenomenological Inquiry}

When identities intersect, they can create polyrhythmic realities (Brown, 1989; Sheared, 1999), where an individual's understandings of their different identities cause them to do "different, seemingly contradictory things, simultaneously" (Brown, 1989, p. 929). Intersecting identities can create borderlands fraught with tension and oppression, where an individual might view herself as "wrong, other" or be viewed as "wrong, other" by society (Anzaldúa, 2007). In these borderlands, the individual might struggle to avoid blaming, hating, and terrorizing herself and others. As women navigate the intersecting 
borderlands and meanings of feminism and submission, they might have trouble reconciling their (often feminist) politics and $\mathrm{D} / \mathrm{s}$ practice. The women might experience conflict, internally or from external entities. For example, a woman who believes in equality might struggle to accept her desire to yield authority to a Dominant partner. She might also experience conflict when one identity, or both, are not recognized or accepted by other people. If she perceives her intersecting identities as in conflict, then when the identities become activated simultaneously, she might have to choose which identity to prioritize, which could lead to further identity conflict.

Purpose and research questions. The purpose of the phenomenological study (van Manen, 1997) was to understand the experiences of women in the BDSM community who identify as feminist and submissive, regarding their experiences navigating these identities. The study was guided by the following research question: How do women in the BDSM community who identify as feminist and submissive perceive and navigate these identities?

Method. The study utilized a phenomenological approach (van Manen, 1997) to explore the perceptions of women regarding the phenomenon of having feminist and submissive identities, specifically how they experience and navigate these identities. Twenty-three participants were interviewed in person. The responsive interviewing model (Rubin \& Rubin, 2012) was used to obtain rich, in depth data about how the participants make meaning of their identities and experiences as feminist and submissive. Responsive interviewing, which treats the interviewees more like conversation partners than research subjects, calls for the interviewer to elicit examples, narratives, histories, stories, and explanations which are grounded in the experiences of the interviewees. 
The participants answered questions in three parts during the summer of 2017. First, before each interview, the participant verbally agreed to consent to participate in the research study (Appendix A), selected an alias, and completed a demographic survey (Appendix B). Second, each participant responded to an interview guide (Appendix C, Creswell, 2013) with 27 open-ended questions during a semi-structured interview, which was audio recorded. Third, after an initial review of the transcripts, each participant answered 17 follow up questions (Appendix D) to clarify or deepen the understanding of a concept. After the recordings were transcribed, they were organized, stored, and password-protected on the researcher's computer and thumb drive, as back up. All data will be kept for three years after the conclusion of the study.

Strategies used to increase the rigor and integrity of this research enhanced the study's credibility, confirmability, and dependability. Credibility was increased through member checking (Creswell, 2009), where the participants were asked follow-up questions (Appendix D). All of the participants offered to answer follow up questions through a Qualtrics form, to help confirm the accuracy of the findings and to add depth to a concept. For example, during the interviews, some participants expressed that they are not only submissive to their Dominant(s), but also to people who they care about. A follow up question asked "Which best describes your submissive identity?" with response options of (a) Only submissive to a Dominant partner(s) which 13 participants selected, (b) Submissive to a Dominant partner(s) AND to people I care about (friends, community) which seven participants selected, and (c) Submissive in general (with friend, at work, etc.) which three participants selected. Engaging in epoche and journaling throughout the study helped the researcher to stay grounded in the 
work and decrease personal bias, in order to view the data with a fresh perspective. Confirmability was increased though maintaining an audit trail of data collection, analyses, and decisions made through the study (Lincoln \& Guba, 1985). Dependability was increased through peer debriefing (Creswell, 2009), as peers and dissertation committee members confirmed that the assumptions, proposal, and methods were congruent with the research purpose.

Analysis and findings. Data analysis was an ongoing, iterative, process that involved "continual reflection about the data, asking analytic questions, and writing memos throughout the study" (Creswell, 2009, p. 184). After the transcripts were checked for accuracy, they were uploaded into the Nvivo software program, which was utilized to uncover and identity patterns, assist with organizing the codes, and manage the data. Inductive analysis was used to find meaning in the data by noting the patterns, categories, and themes that emerged, as suggested by Creswell's (2013) simplified version of Moustakas' (1994) modification of the Stevick-Colaizzi-Keen method.

The first step in this process was to engage in epoche (Moustakas, 1994), setting aside preconceived notions, understandings, and judgements of the phenomenon. This was done in a reflective journal, maintained throughout the study. The next step in the process was horizontalization (Creswell, 2013; Moustakas, 1994), through which was developed a list of significant statements from the interview transcripts, representing how the participants experience the phenomenon. Each statement was treated as having equal worth and the list of statements were reduced until it consisted of "nonrepetitive, nonoverlapping statements" (Creswell, 2013, p. 193). The significant statements that remained were clustered into larger meaning units or themes. Next, themes were 
identified that were common across the transcripts, and from them, composite textural, structural, and textural/structural descriptions were created of the participants' experiences.

Six broad themes emerged from the data: (a) feminist identity is distinct from feminist values; (b) complexity of submissive identity; (c) women learn to reconcile and navigate feminist and submissive identities in different ways; (d) the BDSM community as generally accepting of feminist identity and values; (e) the feminist community as not very accepting of submissive identity and values; and (f) being out as a feminist and as a submissive. Implications for future research and practice focus on four areas: (a) exploring how women challenge oppressions; (b) learning about how women understand and negotiate consent; and (c) understanding how individuals learn about, develop, and engage in BDSM D/s relationships; (d) examining how college women experience these identities, consent, and abuse while developing as individuals.

Publication submission and formatting. This second study of the collected papers is intended for submission to Self \& Identity, which requires the paper to be formatted to standards set by Taylor \& Francis.

\section{Structure of Collected Papers Dissertation}

This doctoral dissertation follows the FIU College of Arts, Sciences and Education's guidelines for the "Collected Papers" dissertation format. It consists of an introductory and a closing chapter written for the dissertation, as well as one chapter for each of the two studies outlined above, which are intended for journal submissions. The dissertation chapters are as follows:

Chapter I: Introduction, related literature review, research rationale 
Chapter II: Paper I: "Navigation of feminist and submissive identity by women in the BDSM community"

Chapter III: Paper II: “Negotiating self: Women's navigation of feminist and submissive identities"

Chapter IV: Conclusions, cross-paper implications, directions for future research and practice

\section{References}

\#MeToo. (n.d.). Retrieved from https://metoomvmt.org/

Adichie, C. N. (2014). We should all be feminists. London, UK: Harper Collins.

Anzaldúa, G. (2007). Borderlands: The new mestiza = La frontera . San Francisco, CA: Aunt Lute Books.

Badran, M. (2009). Feminism in Islam: Secular and religious convergences. Oxford, UK: Oneworld Publications.

Bezreh, T., Weinberg, T. S., \& Edgar, T. (2012). BDSM disclosure and stigma management: Identifying opportunities for sex education. American Journal of Sexuality Education, 7, 37-61. doi: 10.1080/15546128.2012.650984

Brown, E. (1989). African-American women's quilting: A framework for conceptualizing and teaching African-American women's history. Signs, 14(4), 921-929. Retrieved from http://www.jstor.org/stable/3174693

Brown, T. O. L. (2010). If someone finds out you're a perv (Masters thesis). Retrieved from OhioLINK ETD Center. (Document number: ohiou1279225927)

Burke, P. J. (2007). Identity control theory. In G. Ritzer, (Ed.), The Blackwell encyclopedia of sociology (pp. 2202-7). Oxford, UK: Wiley-Blackwell. Retrieved from http://wat2146.ucr.edu/Papers/05d.pdf

Burke, P. J., \& Stets, J. E. (2009). Identity theory. Oxford, UK: Oxford University Press.

Califia, P. (2002). Speaking sex to power: The politics of queer sex. San Francisco, CA: Cleis Press. 
Cowan, S. (2012). To buy or not to buy? Vulnerability and the criminalisation of commercial BDSM. Feminist Legal Studies, 20(3), 263-279. doi: 10.1007/s10691-012-9209-6

Deckha, M. (2011). Pain as culture: A postcolonial feminist approach to S/M and women's agency. Sexualities, 14(2), 129-150. doi: 10.1177/1363460711399032

Dworkin, A. (1974). Woman hating. New York, NY: Dutton.

Dworkin, A. (1989). Pornography: Men possessing women. New York, NY: Plume.

Dworkin, A., \& MacKinnon, C. (1985). The reasons why: Essays on the new civil rights law recognizing pornography as sex discrimination. Pornography Resource Center: Minneapolis, MN.

Edwards, K., \& Brooks, A. K. (1999). The development of sexual identity. New Directions for Adult and Continuing Education, 84, 49-57. Retrieved from http://eds.b.ebscohost.com.ezproxy.fiu.edu/ehost/pdfviewer/

Feminism in the age of trump. [Video file]. (2017, July 7). Retrieved from https://www.cnn.com/videos/politics/2017/07/06/feminist-leaders-after-2016election-orig-bw.cnn

Ferber, A. L., Holcomb, K., \& Wentling, T. (2013). Sex, gender, and sexuality: The new basics: An anthology. Oxford, UK: Oxford University Press.

Freedman, E. B. (2002). No turning back: The history of feminism and the future of women. New York, NY: Ballantine Books.

Goffman, E. (1963). Stigma: Notes on the management of spoiled identity. Englewood Cliffs, NJ: Prentice-Hall.

Green, L. (2015, February 20). BDSM 101! YouTube video by Laci Green retrieved from https://www.youtube.com/watch?v=lqNEAMLjC2Q

Griffin, S. (1982). Sadomasochism and the erosion of self: A critical reading of Story of O. In R. R. Linden (Ed.), Against sadomasochism: A radical feminist analysis (pp. 184-201). San Francisco, CA: Frog in the Well.

Haraway, D. J. (1988). Situated knowledges: The science question in feminism and the privilege of partial perspective. Feminist Studies, 575-599. doi: 10.2307/3178066

Haraway, D. J. (2003). The Haraway reader. New York, NY: Routledge. 
Harding, S. (2016). Whose science? Whose knowledge?: Thinking from women's lives. Ithaca, N.Y: Cornell University Press.

Harrington, L., \& Williams, M. (2012). Playing well with others: Your field guide to discovering, exploring and navigating the kink, leather and BDSM communities. San Francisco, CA: Greenery.

It's On Us. (n.d.). Retrieved from http://www.itsonus.org/

Jagger, A. M. (1994). Living with contradictions: Controversies in feminist social ethics. Boulder, CO: Westview Press.

Jeffreys, S. (1993). The lesbian heresy: A feminist perspective on the lesbian sexual revolution. North Melbourne, Vic, AUS: Spinifex Press.

Jeffreys, S. (2003). Unpacking queer politics: A lesbian feminist perspective. Cambridge, MA: Polity Press in association with Blackwell Pub.

Klein, M., \& Moser, C. (2006). SM (sadomasochistic) interests as an issue in a child custody proceeding. Journal of Homosexuality, 50(2-3), 233-242. doi: $\underline{10.1300 / J 082 v 50 \mathrm{n} 02 \_11}$

Langdridge, D., \& Butt, T. (2005). The erotic construction of power exchange. Journal of Constructivist Psychology, 18(1), pp. 65-73. Retrieved from http://dx.doi.org/10.1080/10720530590523099

Linden, R. R. (1982). Against sadomasochism: A radical feminist analysis. East Palo Alto, CA: Frog in the Well.

Lugones, M. (1997). Playfulness, "world"-travelling, and loving perception. In D. T. Meyers (Ed.), Feminist social thought: A reader, (147-159). New York, NY: Routledge.

MacKinnon, C. (1987). Feminism unmodified: Discourses on life and law. Cambridge, MA: Harvard University Press.

McCall, G. J., \& Simmons, J. L. (1978). Identities and interactions: An examination of human associations in everyday life. New York, NY: Free Press.

Mohanty, C., T. (2003). Under western eyes: Feminist scholarship and colonial discourses. In C. T. Mohanty, (Ed.), Feminisms without borders: Decolonizing theory, practicing solidarity (pp. 17-42). Durham, NC: Duke University Press. 
Moser, C. \& Kleinplatz, P. J. (2006). Introduction: The state of our knowledge on SM. In P. J. Kleinplatz \& C. Moser, (Eds.), Sadomasochism: Powerful pleasures. New York, NY: Harrington Park Press.

Nussbaum, M. C. (2005). Cultivating humanity: A classical defense of reform in liberal education. Cambridge, MA: Harvard University Press.

Ogunyemi, C. O. (1985). Womanism: The dynamics of the contemporary Black female novel in English. Signs: Journal of Women in Culture and Society, 11(1), 63-80.

Ortmann, D., \& Sprott, R. A. (2012). Sexual outsiders: Understanding BDSM sexualities and communities. New York, NY: Rowman and Littlefield.

Powers, W. T. (2005). Behavior: The control of perception ( $2^{\text {nd }}$ ed.). New Canaan, CT: Benchmark.

Queen, C. (1997a). Sex radical politics, sex-positive feminist thought, and whore stigma. In B. Ryan, (Ed.), Identity politics in the women's movement (pp. 92-102). New York, NY: New York University Press.

Queen, C. (1997b). Real live nude girl: Chronicles of sex-positive culture. Pittsburgh, PA: Cleis Press.

Reitzes, D. C., \& Mutran, E. J. (1995). Multiple roles and identities: Factors influencing self-esteem among middle-aged working men and women. Social Psychology Quarterly 57(4), 313-325. Retrieved from http://www.jstor.org/stable/2787158

Richards, L. (2002). Qualitative computing - A methods revolution? International Journal of Social Research Methodology, 5(3), 163-276.

Rocco, T. S., \& Gallagher, S. J. (2006). Straight privilege and moral/izing: Issues in career development. New Directions for Adult \& Continuing Education, 112, 2939. doi: $10.1002 /$ ace. 234

Rocco, T. S., Stein, D., \& Lee, C. (2003). An exploratory examination of the literature on age and HRD policy development. Human Resource Development Review, 2(2), 155-180. doi: 10.1177/1534484303002002004

Rocco, T. S., \& West, G. W. (1998). Deconstructing privilege: An examination of privilege in adult education. Adult Education, 48(3), 171. doi: $10.1177 / 074171369804800304$

Rubin, G.. (1984). Thinking sex: Notes for a radical theory of the politics of sexuality. In C. S. Vance, (Ed.), Pleasure and danger: Exploring female sexuality (pp. 267319). Boston, MA: Routledge. 
Rubin, G. (2011). Deviations: A Gayle Rubin reader. Durham, NC: Duke University Press.

Rubin, H. J., \& Rubin, I. S. (2012). Qualitative interviewing: The art of hearing data ( $3^{\text {rd }}$ ed.). Thousand Oaks, CA: Sage.

Sheared, V. (1999). Giving voice: Inclusion of African American students' polyrhythmic realities in adult basic education. New Directions for Adult and Continuing Education, 82, 33-48. doi: 10.1002/ace.8203

Shrage, L., \& Stewart, R. S. (2015). Philosophizing about sex. Tonawanda, NY : Broadview Press.

Steinam, G. (1983). Outrageous acts and everyday rebellions. New York, NY: Holt, Rinehart, and Winston.

Stets, J. E. (1995). Role identities and person identities: Gender identity, mastery identity, and controlling one's partner. Sociological Perspectives, 38(2), 129-150. doi: $10.2307 / 1389287$

Stets, J. E., \& Burke, P. J. (1994). Inconsistent self-views in the control identity model. Social Science Research, 23(3), 236-262. doi:10.1006/ssre.1994.1010

Stoller, R. J. (1991). Pain \& passion: A psychoanalyst explores the world of S\&M. New York, NY: Plenum Press.

Stryker, S. (2002). Symbolic interactionism: A social structural version. Caldwell, NJ: Blackburn Press.

Thoits, P. A. (1983). Multiple identities and psychological well-being: A reformulation and test of the social isolation hypothesis. American Sociological Review, 174187. Retrieved from http://www.jstor.org/stable/2095103

Tong, R. (2009). Feminist thought: A more comprehensive introduction. Boulder, CO: Westview Press.

Valenti, J. (2007). Full frontal feminism: A young woman's guide to why feminism matters. Emeryville, CA: Seal Press.

Van Manen, M. (1997). Researching lived experience: Human science for an action sensitive pedagogy. London, Ontario, Canada: Althouse Press.

Walker, A. (2004). In search of our mothers' gardens: Womanist prose. Orlando, FL: Houghton Mifflin Harcourt. 
Weinberg, M. S., Williams, C. J., \& Moser, C. (1984). The social constituents of sadomasochism. Social Problems, 31(4), 379-389. doi: 10.2307/800385

Weinberg, T. S., \& Newmahr, S. (2015). Selves, symbols, and sexualities: An interactionist anthology. Los Angeles, CA: Sage.

Weiss, M. D. (2011). Techniques of pleasure: BDSM and the circuits of sexuality. Durham, NC: Duke University Press.

Wiley, M. G. (1991). Gender, work, and stress: The potential impact of role identity salience and commitment. The Sociological Quarterly, 32, 495-510. doi: 10.1111/j.1533-8525.1991.tb00150.x

Women Against Men. (2014). Retrieved from http://www.womenagainstmen.com/about

Wright, S. (2005). Discrimination of SM-identified individuals. Journal of Homosexuality, 50, 217-231. doi: 10.1300/J082v50n02_10

Wright, S. (2008). Second national survey of violence \& discrimination against sexual minorities. Retrieved from:

https://ncsfreedom.org/images/stories/pdfs/BDSM_Survey/ 2008_bdsm_survey_analysis_final.pdf

Zucker, A. N., \& Bay-Cheng, L. Y. (2010). Minding the gap between feminist identity and attitudes: The behavioral and ideological divide between feminists and nonlabelers. Journal of Personality, 78(6), 1895-924. doi: 10.1111/j.14676494.2010.00673.x 
CHAPTER II

\section{STUDY \#1: STRUCTURED LITERATURE REVIEW - NAVIGATION OF FEMINIST AND SUBMISSIVE IDENTITY BY WOMEN IN THE BDSM COMMUNITY}

Overlapping cultures or identities create borderlands, which can be fraught with tension and oppression (Anzaldúa, 2007). In these borderlands, where one views herself as "wrong, other" or is viewed as "wrong, other" by society (Anzaldúa, 2007), an individual might struggle to avoid blaming, hating, and terrorizing herself or others. Women who live in such borderlands can internalize expectations, criticisms and hatred, or conversely, reject the devaluation of who they are by a culture that will never accept them (Anzaldúa, 2007). Women who identify as feminist and submissive can experience such a borderland of intersecting identities, where commonly held beliefs about feminism conflict with commonly held beliefs about submission.

Feminism is "an understanding that women have suffered forms of subordination or oppression because of their sex, and an advocacy of ways to overcome them" (Badran, 2009, p. 18). Areas of oppression include lack of ability to vote in elections, control over one's body, resources to overcome domestic violence, property rights, and equal pay for equal work. Different feminist perspectives focus on different concerns, and some perspectives view the same issues with vastly different lenses (Tong, 2009). Additionally, some individuals who have feminist attitudes and values may not label, or even consider, themselves feminists (Ramsey et al., 2007; Zucker \& Bay-Cheng, 2010).

Relationships of Dominance and submission (D/s) utilize power exchange, where partners "mutually consent to assume or yield authority" (Harrington \& Williams, 2012, 
p. 245). In a D/s, or power exchange, relationship, the Dominant partner takes psychological and/or physical control over their submissive partner (Ortmann \& Sprott, 2012). Common traits of $D / s$ relationships include the use of rules, rituals, and protocols and modes of conduct, such as how to behave when in certain environments (Ortmann \& Sprott, 2012). Some people perceive this as incompatible with feminist values, such as the belief that individuals are inherently of equal worth and deserve the same rights and freedoms (Freedman, 2002). They see D/s relationships as inherently unequal, even when the submissive partner has chosen to allow their Dominant partner to make decisions for them and establish expectations for their conduct and behavior.

Recent scholarly interest has grown in studying BDSM in non-pathological ways, aimed at understanding its diverse people and practices (Langdridge \& Barker, 2007; Turley, 2016; Weiss, 2011). Interest in BDSM cannot be explained solely by psychopathology (Cross \& Matheson, 2006; Powls \& Davies, 2012; Weinberg, 2006; Williams, 2006) or as motivated by childhood abuse (Sandnabba, Santilla, Alison, \& Nordling, 2002) or anti-feminist attitudes (Cross \& Matheson, 2006; Prior, 2013). BDSM has been described as a community with cultural norms and characteristics (Langdridge \& Barker, 2007; Ortmann \& Sprott, 2015; Stiles \& Clark, 2011; Weinberg \& Newmahr, 2015), where members seek opportunities to learn and socialize (Barker, 2007; Ortmann \& Sprott, 2012). The normalization of BDSM has also been explored, related to neoliberal values (Barker, 2013a; Downing, 2012; Dymock, 2012; Musser, 2015; Weiss, 2011) and sexual citizenship (Chatterjee, 2012; Langdridge, 2006).

The topic of BDSM has been examined through diverse feminist lenses, including a radical feminist approach (Linden, 1982; Lorde \& Star, 1982), a postcolonial feminist 
“world-travelling” approach (Deckha, 2011), a sex-critical approach (Barker, 2013a; Downing, 2012; Tsaros, 2013); and Black female sexuality (Cruz, 2016). Agency and consent have been explored, as well (Beres \& MacDonald, 2015; Chatterjee, 2012; Cruz, 2015; Deckha, 2011; Dymock, 2012; Musser, 2015; Tsaros, 2013). However, scant empirical research has focused on the intersection of feminist and submissive identities (Dymock, 2011).

\section{Purpose and Research Questions}

The purpose of the structured literature review (Rocco, Stein, \& Lee, 2003) was to examine the scholarly literature on women in the BDSM community who identify as both feminist and submissive and how they perceive and navigate those intersecting identities. This study was guided by the following primary research question: How are feminism and submission discussed in the scholarly literature about BDSM, particularly related to women who identify as feminist and submissive? A subsidiary question was: how is the intersection of feminism and submission discussed in the literature? The remainder of this paper is organized by methods, findings, discussion, and implications for future research and practice.

\section{Method}

A structured literature review method was followed to identify and make meaning of the selected literature (Rocco et al., 2003). This section describes the data collection, data organization, and data analysis procedures employed. 


\section{Data Collection}

The data collection involved four phases: database selection and search (Phase I), Google Scholar search (Phase II), scanning of reference lists (Phase III), and Google Scholar "Cited by" search (Phase IV).

Phase I: Database selection and search. A university librarian was consulted to determine the most appropriate search terms and databases. Originally, nine databases were selected, however Contemporary Women's Issues was not available, leaving eight in the search: Criminology (Sage), Education Journals (ProQuest), GenderWatch (ProQuest), JSTOR, Project MUSE, ProQuest Dissertations \& Theses Database (PDTD), PsycINFO (ProQuest), and Sociological Abstracts (ProQuest).

The databases were searched for full text scholarly journal articles and dissertations in English through May 2017. "BDSM" was the primary search term, with variations of "sadomasochism," "kink," "leather," "dominance and submission," and "power exchange". Each term was combined in separate searches with the terms "woman," "feminism," "submissive," "identity," and "role," with every permutation available (i.e., woman, women, and identity, identities, identify, or identification). This process yielded 1,284 initial results (See Table 2 for results per database).

The title of each result was read, looking for relevance to the research questions, and when there was doubt, the abstract was read, or the article, if no abstract was available. From the 1,284 results, 1,173 were eliminated for three reasons. First, non-peer reviewed publications (e.g., book reviews, magazines, and business reports) were excluded. Second, in some publications, the search terms referred to unrelated topics, such as BDSM for Birth Defects Systems Manager. Third, some publications about 
BDSM did not fit the research questions, such as articles focused on drag kings or on BDSM and feminism, but not women who are feminist and submissive. The high number of results and eliminations in JSTOR ( 886 and 868 , respectively) related to the fact that approximately $10 \%$ of JSTOR publications provide abstracts; therefore, the terms were searched within full text, and many did not fit the current study. The 111 publications that remained after the initial scan were downloaded and read to confirm fit with the study. Only 22 were relevant to the research questions; however, 10 of these were duplicates, leaving 12 publications in the sample. The low number of publications that fit the sample illustrates the dearth of BDSM research focused on the experiences of women who are feminist and submissive.

Table 2.

Search Results by Database (Phase I)

\begin{tabular}{lccc}
\hline Database & Total Hits & $\begin{array}{c}\text { Results of } \\
\text { First Scan }\end{array}$ & Accepted \\
\hline Criminology: A Sage full-text collection & 2 & & \\
Education Journals ProQuest & 67 & 5 & 2 \\
GenderWatch ProQuest & 45 & 22 & 3 \\
JSTOR & 886 & 18 & 3 \\
Project MUSE & 166 & 12 & 3 \\
ProQuest Dissertations \& Theses Database & 22 & 9 & 6 \\
(PDTD) & 65 & 27 & 2 \\
PsycINFO ProQuest & 36 & 21 & 3 \\
Sociological Abstracts ProQuest & 1,289 & 115 & $\mathbf{2 2}$ \\
Totals & & & 10 \\
Duplicates & & & $\mathbf{1 2}$ \\
TOTAL & & & \\
\hline
\end{tabular}


Phase II: Google Scholar search. Given the low number of results produced in Phase I, the search was expanded by adding three phases. In phase II, Google Scholar was searched using the keywords and the process from Phase I. This yielded 59 results, 38 of which remained after the initial scan. After downloading and reading new articles, five were accepted, resulting in a sample of 17 publications after Phase II.

Phase III: Scanning of reference lists. In Phase III, the reference sections of the 17 accepted publications were scanned. Potential additions were put through the established process of scanning and reading. This resulted in eight additional publications and 25 in the sample. During this phase, two book chapters were identified as relating directly to the research questions and were included.

Phase IV: Google Scholar "Cited By". The Google Scholar function "Cited By" allows researchers to see who has cited publications. In Phase IV, the 25 accepted publications were entered into Google Scholar and their citations were searched. The process of scanning and reading resulted in two additional publications, including one book chapter, and a final sample of 27 publications.

The sample. The sample of 27 publications included 15 journal articles, seven dissertations, three book chapters, and two non-dissertation student papers. Research addressing women's feminist and submissive identity navigation is sparse but increasing. One publication was published in 2003, five between 2005 and 2009, fourteen between 2010 and 2014, and six since 2015. The year with the most publications (5) was 2012, a year after the book Fifty Shades of Grey (James, 2011) was released. The Fifty Shades trilogy (James, 2011, 2012a, 2012b) lead to a flurry of publications focused on BDSM, feminism, consent, and abuse, such as Barker's (2013a) comparison of understandings of 
consent in Fifty Shades and on the BDSM blogosphere. Sixteen of the publications were empirical studies and four were conceptual pieces. Seven were autoethnographic essays, perhaps reflecting a reaction to what Holt (2015) sees as female submissives' struggle to reconcile feminism with their sexuality: women are seeking a more prominent role in creating their own narratives of sexuality.

\section{Data Organization}

An Excel document was used to record citation information (i.e., title, author, year, journal); type of study (i.e., conceptual, empirical); type of publication (e.g., dissertation, journal article); and search phase. Publications were downloaded and saved in files according to database searched. Word documents were kept for making notes about the publications, observations, and possible themes.

\section{Data Analysis}

The publications were read twice and coded separately to identify themes. Initially, the publications were read without taking notes, to gain a sense of the material while avoiding "coding fetishism" (Richards, 2002) or over-coding. Then, the publications were scanned for "raw information" (Joffe \& Yardley, 2003, p. 57). Notes were made in the margins of the documents, pertaining to each important segment of data that provided insight into the identity-related experiences of women who are feminist and submissive. The notes were recorded in Word documents, with supporting text, to be used in identifying key ideas and common themes. Codes were assigned to each important segment of data. The codes were then sorted and the publications revisited to check for appropriate evidence, to strengthen the claim that the publications were reviewed evenhandedly and that the codes are trustworthy (Krefting, 1991). 
The themes, or patterns, that emerged from the data included both manifest content (something directly observable) and latent content (something implicitly referred to; Boyatzis, 1998). At the manifest level, patterns were identified in the surface content of the literature, to create a sense of the broad meanings and implications (Patton, 1990). For example, there was a clear pattern within the literature to discuss feminism in terms of freedom to make choices. At the latent level, the literature was explored in depth, to examine the underlying ideas, assumptions, and meanings (Taylor \& Ussher, 2001) of that term; in other words, the contexts in which freedom was discussed, and the stories or experiences that were used in the discussions.

\section{Findings}

Four broad themes were identified: feminism in the context of BDSM, the normalization of BDSM, navigating feminist and submissive identities, and BDSM power as transgressive.

\section{Feminism in the Context of BDSM}

Concepts of agency, power, and consent were present in all publications. Agency refers to an ability to freely make decisions for oneself. Power was understood as a dynamic process; "a product of a social relationship, a characteristic of interaction" that is not owned by anyone (Newmahr, 2006, p. 57). Consent can be perceived as "an ongoing, relational, negotiation in which the conditions under which a 'no' is possible need to be created, by everyone involved, in order for a 'yes' to count”' (Barker, 2013b, p. 908).

Agency. Women's ability to freely make decisions was a focus of debate in the polarizing sex wars and continues to be debated. Some people argue that women have freedom to freely choose options while other people argue that women lack the ability to 
freely choose options, given existing systems of capitalism, patriarchy, and heteronormativity (Barker, 2013a; Chatterjee, 2012).

Bondage/discipline, dominance/submission, and sadism/masochism (BDSM) has been described as preventing individuals from "liberating themselves from oppressive relationships" (Marion, 2016, p. 191); however Marion found that women can employ a sense of agency in negotiating the level of power that they will consent to cede to their partners.

Power. Engaging in BDSM provides opportunities "where collaborative power creates the sense of inequality and where that inequality is eroticized and romanticized" (Newmahr, 2006, p. 57). This collaborative power is deliberate and careful. Many BDSM practitioners view power as equal, but as exchanged. A common expression was stated by one submissive, who described: "subs have the power, dom(me)s have the control" (Hébert \& Weaver, 2015, p. 53). Similarly, J. M. (2014) described the D/s dynamic as a "powerful unconscious alliance" (p. 25). These examples support prior research in which BDSM relationships were described as negotiated exchanges of power, as opposed to inherently of unequal power (Ritchie \& Barker, 2005). Conversely, some members of the BDSM community argue that submissives hold more power than dominants (Raab, 2013) because they set the boundaries, establish limits, and can leave at any time. Other practitioners disagree, stating that all partners should engage equally in the negotiation, establish limits together, and be able to leave. All of the women in Prior's (2013) study discussed power exchange as having core concepts of commitment, trust, negotiation, consent, give and take, giving up, education, and being sexual, but with room for 
"personal, intimate nuances" specific to their individual relationships and behaviors (p. 17).

Consent. Practitioners apply consent in different ways, and even in relationships where consensual nonconsent (agreement that consent is not required) has been negotiated, the partners establish together what consent means to them. People who engage in BDSM often require different levels of consent, depending on who they are playing with. For example, consent is often discussed more frequently when a relationship is new, as opposed to long-standing. One submissive explained, "Being a feminist affects the level of consent I require, from myself and others, the circumstances I consider acceptable for that consent to be given, and also my style of submission" (Martinez, 2011, pp. 58-59).

Discussions about consent tend to polarize people into an agency (third wave, sex-positive, or neoliberal) feminist position or a radical (sex-negative) feminist position (Barker, 2013a). In framing a more "sex-critical” position, Downing (2012) has rejected the rhetoric of neoliberal choice. Similar to Millbank (2012b), Downing critiqued the "sex-positive" position as having a tendency to make sex an imperative, which may exclude people who do not want sex. Millbank (2012a) also critiqued the model of enthusiastic consent (i.e., yes means yes) as problematic, as women are encouraged to respond enthusiastically, even when they might not be enthusiastic. This critique of the model of enthusiastic consent stems from a Foucauldian understanding of freedom, in which people have options, but the options are limited within a field of power.

Submissive women in Rivoli’s (2015) study claimed to experience empowerment through consent and perceived consent as being highly esteemed within the BDSM 
community, where "there is a zero tolerance policy for violating standards of consent" ( $p$. 27). However, other practitioners argued that incidents of abuse and consent violations within the BDSM community are not rare (Barker, 2012; Stryker, 2011) and victims are silenced and marginalized (Thompas, 2012; Pervocracy, 2011, 2012; Williams, 2011).

Comments abound regarding what victims should have done to avoid abuse (Veaux, 2012) and that if the victim did not go to the police, then it must not have been abuse (MacAulay, 2012). Victims tell themselves that it was their fault because they did not say no or insist forcefully enough (Williams, 2011). However, discussion in the blogosphere about abuse within BDSM reflects a shift in where responsibility is being located - from the individual to the community - and in understanding how consent operates (Barker, 2013a). This shift in the conversation about sexual consent as a collective and social phenomenon reflects a shift of responsibility from the individual submissive's need to say "no" or use a safeword to a focus on mutual responsibility and creating cultures where the model of "no means no" shifts to "yes means yes" (MacAulay, 2012), and "yes" is established before engaging in play.

\section{The Normalization of BDSM}

Bondage/discipline, dominance/submission, and sadism/masochism (BDSM) is described as a culture with five social features present in most BDSM interactions (Weinberg, Williams, \& Moser, 1984). These features are: (a) dominance and submission, or the appearance of rule and obedience; (b) consensuality, or voluntary agreement enter into a BDSM relationship and abide by the established limits; (c) sexual content, or the presumption that the activities will have a sexual or erotic context; (d) mutual definition, or the assumption of a shared understanding that the activities are 
somehow BDSM-related; and (e) role playing, or recognition that the roles assumed are not reality. The BDSM community functions as a community of practice (Busbee, 2008), where members share specialized knowledge, such as a shared vocabulary and terms for self-identification, technical knowledge about activities, negotiation skills, and the locations of safe spaces to interact.

Safe, Sane, and Consensual. The norms of a subculture serve to define members' expectations and control their interactions. For the BDSM community, these norms include safety and trust (Ernulf \& Innala, 1995; Weinberg, 2006) and adherence to guidelines of "Safe, Sane, and Consensual" (Weinberg, 1987). In the context of BDSM, "safe" means being free from harm and knowledgeable about the skills, techniques, and risks related to one's activities, "sane" means able to recognize the difference between fantasy and reality, and "consensual" means that adults negotiate and respect the limits established by each partner (Cross, 2010). Consent is considered a key difference between rape and abuse and consensual BDSM activities. Standards of 'Safe, Sane, and Consensual' (SCC) are seen by many practitioners as allowing the community to focus on health, safety, and the creation of ethical subjectivity (Weiss, 2011). However, recent discourse incorporates a critique of how SCC is used to police the BDSM community, members, and practices.

The Consequences of Normalization. In establishing "Safe, Sane, and Consensual," some practitioners perceive the BDSM community as having sacrificed its potential for resistance to and radical challenge of normative sexuality (Downing, 2012). The BDSM community is seen by some as having lost its sense of validity and authenticity (Dymock, 2011). One cost of this normalization is that some members 
choose to leave the BDSM community. Relatedly, Parchev and Langdridge (2017) argued that "the security politics of BDSM communities are not cost free, calling for what appears at times to be an excessive embrace of neoliberalism" (p. 14). In considering the popular trilogy Fifty Shades of Grey (James, 2011, 2012a, 2012b), Musser (2015) noted another cost: the consolidation of heterosexual privilege and Whiteness; the "shoring up normative models of intimacy and monogamy," placing the couple as the locus of intimacy (p. 129). In this way, neoliberalism works to privilege the individual and personal rights and responsibility, making it more difficult to recognize problems "as a matter of scale and structure rather than issues of an individualised, specific register" (Musser, 2015, p. 129). With this in mind, researchers warn against a "heteropatriarchal" version of BDSM, where "SM-normativity" (Wilkinson, 2009) dictates what forms of BDSM are acceptable.

Legal findings constrain what individuals can legally consent to; in fact, "law's current prohibitions on what constitute sex, consent, and pleasure limit what a woman may desire along benevolently paternalistic, but ultimately misogynistic, lines" (Downing, 2012, p. 65). The community standards of "Safe, Sane, and Consensual" operate as an internal disciplinary mechanism, where BDSM play and female masochism "outside the legal and clinical binary of health and harm" (Dymock, 2012, p. 55) are marginalized, even within the already marginalized BDSM community. In the context of this normalization, a woman who chooses to play beyond what society deems safe or reproductive "must display a greater degree of self-assertion, not only in disavowing her own safety, but in an active disavowal of the prohibitions imposed on her sexuality" (Dymock, 2012, p. 64). 


\section{Navigating Feminist and Submissive Identities}

Historically, BDSM has been relegated to the 'outer limits' of sexuality abnormal, unnatural, and bad, as opposed to the "charmed circle" of sexuality - normal, natural, and good (Rubin, 1993). Practitioners of BDSM encounter stigma-related issues similar to those of other sexual minorities (Chaline, 2007; Weiss, 2006; Wright, 2006). Current dilemmas and concerns that members of the BDSM community experience include: (a) stigma and prejudice; (b) increased mainstream attention, particularly in response to the Fifty Shades of Grey trilogy; (c) legal issues related to consent; (d) the loss of a generation due to AIDS; (e) lack of inclusion of transgender individuals; (f) coming out as kinky; and (g) lack of racial and ethnic diversity (Sprott, 2014).

Problematic assertions that BDSM practitioners encounter and learn to manage, include: (a) BDSM perceived as a lifestyle, not an orientation; (b) practitioners should hide it/keep it in the bedroom; (c) BDSM is violence; (d) BDSM is physically dangerous; (e) BDSM makes it hard to fight violence against women; and (f) D/s relationships are violations of consent (Sprott, 2014). These concerns, dilemmas, and assertions contribute to women's often challenging identity navigation as feminist and submissive.

Women in BDSM who identify as feminist and submissive find different ways of navigating and reconciling these identities. Some women see no need to navigate or reconcile these identities at all. Other women experience the reconciliation as a difficult, even violent, process. Still others see it as an ongoing struggle. Additionally, some women recognize a trend within the BDSM community 'to define 'submissive' in a particular way, and to cast all those not fitting in with that definition as 'not real submissives' - it strongly reminds me of debates around the term 'feminist"' (Walters, 
2012, p. 160). As their understanding of what it means to be submissive evolves, these women come to view the term as simplistic.

Submission as a Natural, Inherent Part of Self. A common theme from Rivoli's (2015) exploration of female submissive identity was that while the women do not consider their desires "normal," they do view their submission as "a natural, inherent part of themselves" (p. 47). Participants in Hébert and Weaver's (2015) exploration of dominant and submissive roles expressed that aspects of their submissive identities are even reflected in their careers. One submissive female spoke about thriving in the service that she provides; that she enjoys making people happy and doing things for them, both as a submissive and at work. However, just because submission might be an inherent part of self, that does not mean that a submissive always takes on a submissive role. For example, Queen (2002) recognized that although she desires to be sexually submissive, she does not want to be non-sexually submissive.

Submission as Replication. One participant spoke about replicating selfdestructive patterns in her relationships with men, through enacting elements of the coercive relationship she had with her father (Marion, 2016). This replication resulted in shame and self-hatred, and her need to behave perfectly in response to her fear of abandonment. She worked hard to keep her appearance the way her partner liked, to be open to whatever he wanted from her physically, and to avoid disappointing him at all costs. She endured activities that were humiliating, physically exhausting, and void of pleasure for her. She "dutifully" took on her partner's desires as her own and worked hard "to convince herself that their scenes are 'fun' rather than traumatizing" (Marion, 2016, p. 111). When she started to protest the treatment she received, she began with an 
attack on herself by shaving her head, which her partner would view as ugly. Her protest escalated until she reached her limit: "Once she realizes how traumatizing the relationship was for her, she switches into a mode of defiance, arguing with him online and posting public notes about how he violated her consent” (Marion, 2016, p. 112).

Marion (2016) perceived this participant's use of sex as a way of seeking validation, as motivated by a lack of self-worth. Engaging in a relationship with her partner allowed the participant to (at first) "validate her legitimacy as a hardcore bottom" and "feel special because someone who could choose anyone chose her" (Marion, 2016, pp. 112-113). However, when she failed to meet her partner's (or her father's) expectations, the participant felt shame, broken, and "like I can't even do a simple thing" (p. 113). Marion perceived the participant as moving forward, by learning about why she wants to please others, by setting limits, and by practicing saying "no." She is creating an ideal of submission as "structured less around enduring cruelty and violation, and more around providing care to a partner who shows his appreciation for what she offers" (Marion, 2016, p. 112). This understanding of submission is echoed by Queen (2002), who argued that it is not a bottom's responsibility "to find a way to eroticize what the top wants, no matter what pesky or heinous new ideas Sir or Madam has had today" (p. 175).

Submission as Simulation. In framing submission as consensual and empowering, some participants described two paradoxes around their submissive desires. One paradox was wanting to feel "dominated" or "forced" during BDSM play, while understanding that they do not actually want to be forced to do something that they do not want. Marion (2016) described this as a submissive wanting to be "subjected to her partner's desires against her will, even though what they are playing out is in reality a 
mutually-negotiated scenario" (p. 74). Playing out this scenario requires a "willing suspension of disbelief" (Coleridge, 1817), where the submissive, and her partner, suspends logic and critical thinking to believe and enjoy that which is unbelievable. Another paradox was wanting to feel "used" or "degraded" during BDSM play. One submissive described feeling "used" as a turn-on if she perceived her partner as "doing what you want with my body because you want me that badly" but as damaging if she perceived her partner as conveying, "you're worthless, you don't mean anything to me" (Marion, 2016, p. 75).

Submission as Feminist. Queen (2002) claimed that sexual submission is her deepest and most guilty pleasure, and that it has reinforced her strength and self-esteem in two ways. First, she understands her experience of "learning to negotiate with my pleasure" as a feminist process, and second, she considers that however one's desires are shaped, "getting what we want sexually helps us move towards what Maslow termed selfactualization" (Queen, 2002, p. 176).

Distance from Feminism. Many women who identify as submissive also identify as feminist. The two participants from Prior's (2013) study who did not identify as feminist described their understanding of feminism from its radical perspective, which they saw as anti-male and anti-sex. Similarly, while all of Surprise's (2012) participants expressed interest in equality and egalitarianism (feminist values), they overwhelmingly did not identify as feminist. One participant stated that, "it seems like most of the feminists that I encounter are kind of the second-wave feminists where it's like no, we need to be on top. And I'm like no, we all just need to be equal"' (Surprise, 2012, p. 67). Another said that "obviously" she is for equal rights, but she is not a man hater. Surprise 
suggested that this desire to separate oneself from (radical) feminism reflects a misunderstanding, or limited and damaging definitions of feminism.

Raab's (2013) participants claimed various views about feminism. Some claimed both feminist values and feminist identity; some claimed feminist values but did not claim a feminist identity; and some claimed neither. Most agreed that feminism should, and does, have a role within the BDSM community, though they perceived the role in different ways. Participants expressed that to some extent, feminism has been rejected within the BDSM community and that potential allies have been lost, because of the stigma associated with the label of feminism (Surprise, 2012).

These responses echo prior research showing that feminist identity and feminist attitudes are distinct constructs (Eisele \& Stake, 2008; Zucker \& Bay-Cheng, 2010) and that some individuals who have feminist attitudes or values do not claim feminist identity (Ramsey et al., 2007; Zucker \& Bay-Cheng, 2010). It is also possible that some women who have feminist values may not identify as feminist because they perceive feminism as racist and classist (Allison, 1994; hooks, 2000; Hurtado, 1989).

Feminism as Space for Self-Awareness. Martinez (2011) found that her participants who identified as queer also voiced a preference for queer feminist politics and were more willing to critique BDSM. The participants were able "to practice BDSM while being more conscious of what I'm doing, what power I want to relinquish and what power I want to retain, and how to negotiate that" (Martinez, 2011, p. 58). Another participant plays in private spaces, where she knows everyone, "so that she could have a better idea of the message the other participants were taking away from the scene" (Martinez, 2011, p. 59). This awareness of other people illustrates that some BDSM 
practitioners realize that individuals with similar political views would understand that as women in the bottom (submissive) role, they are simulating - not replicating - patriarchy (Martinez, 2011). Additionally, they are subverting heteronormativity, by playing with all genders and through the intent to gain sexual pleasure rather than reproduction.

Practitioners of BDSM emphasized the importance of submissives knowing themselves, being able to articulate their desires and limits, take an active role, and claim their sexuality (Raab, 2013). Similarly, Weiss (2011) emphasized the importance of “mastery of the self” for all BDSM practitioners (p. 87).

Feminism as Empowering. Many submissive women see feminism as freedom, that "the choice to submit [is] a very feminist thing because I am taking my lifestyle and my sexuality into my own hands... it was very empowering to be able to express that facet of my being" (Surprise, 2012, p. 69). Most participants in Raab's (2013) exploration of gender-power dynamics also described feminism as empowering; feminism helped them realize that "there are other ways to do things" (p. 56). Matthew's (2005) found three major themes related to the impact of BDSM on women's lives. Self-empowerment included building self-esteem, developing an identity, and emotional healing. The women also noted that their BDSM play lead to improved relationships, by learning to communicate better, learning to trust others, and learning to be non-judgmental. Prior (2013) concluded that third wave feminism, particularly, provides space where submissive women can express themselves fully "as integrated, well-balanced, and powerful, women” (p. 18). Rivoli’s (2015) participants also claimed to find empowerment through consent. 
Young argued that "sex positive feminism embraces the entire range of human sexuality and bases itself on the idea that sexual freedom is an essential component of women's freedom" (Young, 2009, p. 55). Submissives are "strong and powerful wo/men" (p. 56) who, in their desire to give their power to a dominant partner and be vulnerable and open to new experiences, take control of and embrace their sexuality; in fact, validating their sexuality through submission. Marion (2016) also found that some participants utilized their submissive roles to overcome culturally-induced shame or guilt about their sexual assertiveness. For example, one submissive woman shared that having partners who expected her "to fully express what I wanted" (p. 64) caused her to learn about what she liked and disliked.

Feminism and Submission as Mutually Supportive. BDSM is seen as enriching, empowering, and providing space to feel on a deeper level:

I embrace my submission and feel empowered and humbled at the same time by these experiences. I feel that any woman who is embracing her sexuality and actively pursuing genuine pleasure for both herself and her partners is participating in a form of feminism. (Young, 2009, p. 60)

Each of Prior's (2013) participants perceived feminist identity as supporting identities of submissive and slave. However, while BDSM play can be an important aspect of a woman's feminism and a mechanism for finding power (Easton, in Barker, 2005), some women struggle to reconcile their feminist and submissive identities.

Overcoming Internal Conflict with Feminism. Queen (2002) spoke about her "Inner Feminist" as having struggled with her desires and pleasure in taking a subordinate sexual position, especially when submitting to a man. She described her 
strain of feminism (at that time) as fostering self-doubts "in a petri dish of sex-negativity" and as "ignorant of much of human life's sexual possibility" (Queen, 2002, p. 170).

Some practitioners believe that shame and guilt can be particularly strong for female submissives in heterosexual relationships, as they might feel anti-feminist (Hébert $\&$ Weaver, 2015). One participant stated, "I thought maybe there was something wrong with me for being this way. It took me a long while to actually realize it's okay to be like this" (Hébert \& Weaver, 2015, p. 59). Another came to recognize her right to choose, "if I'm this way I can choose to act on it or not. I can choose how important it is to me, and then, once I've made those choices, well it's my choice to have the kind of sex life I wanna have" (p. 59). The BDSM community, particularly the blogosphere, provides space where women work to understand, reconcile, and navigate their identities. In exploring how female sex bloggers discuss their BDSM practices to construct their identities, Walters (2012) referred to Subversive Submissive's reasons for blogging and stopping:

When I first began writing here, all I wanted was to give voice to the thoughts I'd been wrestling with for so long and to find support from others who thought like me - to find reassurance that I wasn't alone. Thanks to this blog and that support from everyone who's read it over the last few years, I've gotten exactly what I wanted: I no longer feel overwhelmingly ashamed or afraid of my desires; I feel confident in my sexuality; I have a better understanding of different BDSM subcultures and histories and can articulate both defenses and critiques of them. (Walters, 2012, pp. 157-158).

However, as kink became a normal part of her life, blogging lost its excitement;

Subversive Submissive no longer wanted "to process, dissect, analyse, and share with others" (Walters, 2012, p. 158). 
Ongoing Tension Between Submissive and Feminist Identities. Some women experience ongoing tension between their feminist and submissive identities, even when they accept each identity on its own. A participant in Raab's (2013) exploration of gender-power dynamics said about her feminist identity, "It's not something which I fully manage to reconcile. It makes it harder to bottom, it makes it harder to submit, it definitely makes it harder to accept discipline" (p. 53). Even given the right to choose, the main challenge for submissives was accepting the consequences of their chosen roles. Participants experienced difficulty in several ways: in having to do what their dominants command, in dropping whatever they were doing to attend to their dominants' wishes, and in accepting some of the decisions that were made for them. One female submissive shared that "there's also times like where I'm tired or I don't want to do something or [laughs], but, you know, it's kind of not within the terms of the relationship I'm gonna' say no to things" (Hébert \& Weaver, 2015, p. 59).

\section{BDSM Power as Transgressive}

Another theme in the literature situates BDSM as a site for transgression. Engaging in BDSM involves the "joint boundary transgression of personal boundaries between people of hegemonic social and ethical boundaries, and often physiological boundaries" (Newmahr, 2011, p 163). This is an important topic in the online BDSM community, where members discuss how BDSM power dynamics mirror nonconsensual power dynamics within society (pepomint, 2007a). Bondage mirrors restraint and the use of cages mirrors imprisonment. Dominance and submission (D/s) mirrors the exercise of and submission to authority. Sadism and masochism (SM) mirror the giving and receiving of violence. Mastery and slavery (M/s) mirrors extreme forms of control. Role 
play also mimics power dynamics, such as uniform play (i.e., military, police), daddy or mommy play (i.e., parent/child), and teacher/student play. Sexism is mirrored in dirty talk, rape play, and forced feminization, to name a few activities. Racism is mirrored in race play and conceptually in $\mathrm{M} / \mathrm{s}$ dynamics. In effect, BDSM practitioners sandbox, or play around with, power dynamics (pepomint, 2007a). Tools used to sandbox power dynamics include forms of consent such as safewords, contracts, consensual non-consent, and positive consent, as well as the ability to eroticize things that were not previously erotic and make pleasurable that which was not.

Young (2009) described how feminists play with and transgress power structures while striving to live life fully:

As queers, as feminists, as kinky persons, and sexual outlaws we have always been breaking the rules. We go outside of the designated sexual norms as we search for connection, community, and fulfillment in our sexual lives and identities. Our sexual selves were not handed to us, so we have eroticized the disassembling of traditional power structures and protocols and have built our own to use as our sex toys. (pp. 52-53)

Catharsis. One way that BDSM practitioners transgress norms is through catharsis. BDSM is not therapy; however, in some contexts, BDSM appears to have the potential to be psychically and psychologically therapeutic (Easton, 2007; Lindemann, 2011; Woody, 2014). BDSM also helps participants grow as individuals and as partners (Rivoli, 2015; Woody, 2014). In a conversation with a friend, Woody (2014) expressed a concern that talking to a therapist about BDSM and past trauma is problematic. The friend asked, "But what if it is about trauma, and what if that's actually okay?" (p. 97). Woody came to realize that: "My path lies in forgiving myself for loving what I love, for kinking what others find unfathomable, and for taking pleasure in the subversion of my 
trauma history" (p. 97). In these ways, BDSM challenges the traditional medical model of BDSM (Chatterjee, 2012).

Similarly, Marion's (2016) participants demonstrated that while some women's BDSM practices might involve elements of traumatic repetition, they also involve elements of positive developmental growth, pleasure-seeking, and psychological healing. Specifically, their BDSM practices may "provide sensory and affective stimulation or soothing" and help them to defend against or "overcome barriers to intimacy" and “"rescript' past experiences of violation" (p. 6). Marion (2012) also found that when a bad reaction is triggered, or a prior trauma recalled, it is not necessarily the activity itself that triggered the reaction or recall. Sometimes, a bad reaction can be triggered by a relational experience, such as feeling like what was happening was not mutual or feeling disconnected from or disrespected by a partner; like they were not invested in what they were doing (Marion, 2016). Despite these claims that BSDM can be felt as therapeutic, Barker and Langdridge (2009) caution that placing emphasis on healing or therapeutic narratives can underscore the false understanding of BDSM as founded in trauma.

\section{Cultural Trauma Play: Transgressions within BDSM. Some BDSM}

practitioners speak about "cultural trauma play" where they transgress cultural and national boundaries, categories, and roles through "performances of the self in ways that deploy, recreate or reanimate existent social forms" (Weiss, 2006, p. 48). Such types of play include Nazi play, race play, rape play, forced feminization, interrogation scenes (Weiss, 2006), as well as consensual nonconsent (Luminais, 2012). Even within BDSM, these types of activities can be stigmatized as "edge" status because they play with issues of oppression. In exploring transgression within the dyke BDSM community, Bauer 
(2008) found that "the possibility of playing with, experiencing, transgressing, and transforming the stereotypes and dynamics associated with categories of social hierarchy in a pleasurable way" (p. 247) seems to depend on one's lack of oppressed identity. For example, within the dyke community, where there were no straight (and mostly no male) privilege, gender play was common. However, most of the members' racial privilege, as White, seemed to keep them from playing with race in a comparable way (Bauer, 2007).

Master/slave Relationships. A Master/slave dynamic, also known as Total Power Exchange, can be seen as a D/s relationship with fewer limits, where the slave might allow their owner to control every aspect of their life (Dancer, Kleinplatz, \& Moser, 2006). This control can involve daily activities (e.g., the ability to go out alone, what to wear, where to sit, when and what to eat, household chores) and larger aspects of life (e.g., employment, finances, who to talk to, sexual activities). Sometimes, the slavery might be less formal or more relaxed, as when visiting family, working, or sick, but a slave is always a slave, regardless of environment. One slave explained, "i am never out of role but that doesn't mean that everyone around me knows i'm a slave. i serve my owner at work but no one there has any idea of my slavery" (Dancer et al., 2006, p. 89).

Some BDSM practitioners view M/s relationships as likely abusive and/or a sign of mental illness: "if something causes you distress... you probably need therapy more than you need BDSM" (Rivoli, 2015, p. 39). In this statement, the participant questioned the ability of a slave to retain their sense of agency and ability to exit the relationship. These concerns contribute to why M/s relationships are seen by some as transgressive not always in a positive way - even within the BDSM community. Individuals who engage in $\mathrm{M} / \mathrm{s}$ relationships can be at even greater risk of mockery, shunning, and 
discrimination than partners who engage in D/s, as discussed by Master Skip Chasey in

his Keynote Address at the 2008 Master/slave Conference:

$\mathrm{M} / \mathrm{s}$ is still virtually always a disqualifying taboo. Because of the heightened scrutiny we receive from the powers that be, many in the leather community would like nothing better than to sever the link between them and us. If you think I'm simply paranoid, then perhaps you're unaware that at the 1998 Leather Leadership Conference, a policy statement on the issue of "SM vs. Abuse" was drafted containing some imprecise verbiage that could be interpreted as a condemnation of the dynamic that underlies virtually every Master/slave relationship. And when a few years later that problem was brought to the attention of the kink community's leading national advocacy organization, who at the time was widely promoting that policy statement, their leadership responded by saying, and I quote, "Those people"- meaning us - "are on the fringe. We don't care about them." (n.p.)

$\mathrm{M} / \mathrm{s}$ relationships provide space to transgress social norms, both inside and outside of the BDSM/Leather/kink community.

Gender Play. Bondage/discipline, dominance/submission, and sadism/masochism (BDSM) provides space for practitioners to actively resist gender norms through genderswitching, switching gender-based styles depending on the gender of a play partner, and rejecting gender altogether (Simula, 2012). In fact, BDSM practitioners are able to create identities that are fluid and ever-changing. Similarly, female participants in Taylor and Ussher's (2001) exploration of BDSM discourse spoke about BDSM as pro-sex feminism, where members transgress norms of heterosexuality and parody dynamics of subjugation, oppression, and exploitation. They spoke about being able to wield a "cock", penetrate a partner, and not have penetrative sex in their BDSM play. They also spoke about being able to hold power over and dominate men. BDSM was seen as exposing, ridiculing, undermining, and destroying oppressive systems of patriarchy. In these ways, BDSM has the potential to be a liberating and disruptive sexuality, by placing the 
practitioner in a state of constant reflexivity and challenging boundaries of gender, (dis)ability, sexuality, self, and other (Chatterjee, 2012).

In talking about gender-based slurs, BDSM educator Midori linked humiliation to self-esteem (Scott, 2012a). She suggested that a woman who might have internalized the idea that "good girls don't" and who enjoys her sexuality, might also enjoy being called a "slut" by her boyfriend, if he sees her in all of her complexity. In calling her a slut, "he is freeing her of the social expectations of having to be modest" (Midori, in Scott, 2012a, n.p.). Being called "slut" during BDSM play can be humiliating and empowering, and very different from being called a "slut" by a stranger or in anger. Midori also pointed out that this form of BDSM play may not be enjoyable to "women of other generations, for whom the word slut is painful to hear" (Scott, 2012a, n.p.).

Race Play. Race play causes intense emotion for some practitioners, due to its use of racialized imagery (Scott, 2012a). On one hand, some BDSM practitioners feel that if you want to engage in race play, then you should. Mike Bond, a Black man who teaches about race play, expressed, "I have been floored when people have criticized me by saying [that] not everyone agrees with my fetish. So what? Not everyone likes cheese" (in Scott, 2012a, n.p.). In exploring Black female sexuality, Cruz (2015) quoted Portillo regarding the politically incorrect nature of BDSM, "especially for me as a black woman who plays with white tops (occasionally a white male top), people say that because of history I shouldn't be enjoying this, let alone wanting it" (Cruz, 2015, p. 413). Cruz continued, arguing that mutually consensual pleasure should be what matters "regardless of whether such rapture is linked to the internationalization and/or perpetuation conscious, unconscious, or subconscious - of oppressive white heteropatriarchal 
supremacist structures and values" (p. 413). In listening to the voices of Black women who practice BDSM and race play, Cruz (2015) found that:

their pleasure, highly conflicted, is informed by the history of racism, interracial sexual violence, and racialized exchanges of power. If BDSM might not heal a historical wound and/or allow for some kind of redress, actual or symbolic, for Black women, it might serve as a stage or, better yet, a ring to replay and to reimagine scenes of Black/white sexual intimacy and the imbrications of pleasure, power, race, and sex. (p. 435)

When Chen (2012) asked Williams, "How do you reconcile the fact that even in a consensual space, we bring that baggage?" (n.p.), Williams replied that it is not possible to be fully reconciled. The baggage is ugly, difficult, and painful, "but consent makes the ugliness beautiful and turns the profanity of derision to a sacred interaction that permits us to dive deep into the bullshit, the terribleness of these things, and survive them" (Williams, in Chen, 2012, n.p.). When Plaid (2009a) asked Williams, "How can we move the conversation within our communities so we can talk about BDSM and race play as sexual/erotic possibilities?" (n.p.), Williams replied that people who participate in race play need to come out of that closet, and people within the community need to end their "us vs. them" mentality. She argued that "there has to be room in the dungeon for everyone's emotional play" and that "every person who is ashamed of their desires is another person we damage indirectly with our scathing commentary and harsh judgments" (Williams, in Plaid, 2009c, n.p.). In seeming contrast, Williams also stated that "I make it bloody fucking clear it is NOT ACCEPTABLE for you to EVER ask someone to bottom to you in that type of scene. I feel it really has to come from the person being the "victim" (Plaid, 2009b, n.p.). 
That begs the question, how does someone who wants to engage in race play from the dominant position seek a partner? Consider this comment to Scott's (2012a) post:

I'm a white man who generally pairs up with white women. I generally avoid black women for the very reason that it would seem "wrong" for me to dominate them... I find other races attractive, but I can't playfully smack black women around because of the history between our races. I'm curious about whether it is only "socially acceptable" for white men to dominate white women. I wonder if Asian and Hispanic women would be as willing to let me choke them, spank them, pull their hair, etc. as white women are." (n.p.)

These examples prompt questions. Would it be a form of shaming to tell this White male dominant that he should never ask a bottom to engage in race play? Might concealing his desires eliminate opportunities for submissives who enjoy race play? How is it possible to know if his desires are motivated by racist fantasies?

Some BDSM practitioners are repulsed by race play and do not want their race to be eroticized at all. In responding to Plaid's (2009a) interview with Williams, LeatherTbird argued that "abolition of racial and cultural discrimination is the only way to purge it from society. To make a game out of our on going struggle for [the sake of] sexual satisfaction is to make a mockery of all efforts toward that end" (n.p.). Another example is Chupoo, a submissive in an M/s relationship with a Black man. Chupoo can accept what Scott (2012) refers to as the "transgressive appeal of erotic language that seems to degrade women" (e.g., being called "bitch" or "slut"); however, race play goes too far. She feels like her (Black) Master understands that they have a partnership and respects her. However, when considering race play, she recalls that "I have people in my family who had to submit to that, where they had no choices. It's too close to home for 
American black people" (Scott, 2012, n.p.). The acceptance of "slut" and rejection of "nigger" supports Bennett's (2015) argument that BDSM is context dependent.

Regardless of one's stance on race play, some BDSM practitioners believe that many people in the community ignore race and racism and falsely claim that race is not an issue; that everyone is treated the same. One of Luminais' (2012) participants expanded:

there [are] a lot of white dominant/white submissive males and females that are looking for a black stallion to come in and rape the girl. It would feel very progressive and edgy, if it wasn't like these people had come full circle. It's like, this is how they see, this is truly how they feel about black men - that their goal is to find all of the vulnerable white women and rape them. It perpetuates this idea of what black men are. The same thing is true of black women being depicted as dominatrices or slave girls, very plantation slave girls. (in Luminais, 2012, pp. 246)

Like other forms of power play, race play is an ideal site for critical reflection. Regardless of where you play, Williams suggests that practitioners ask themselves, "Do you know in your guts of guts that [racism] is not their point of view?" (Scott, 2012a, n.p.). Have BDSM practitioners asked themselves if their race play desires are not, in fact, fueled by racism, sexism, self-hatred, and/or prior trauma?

\section{Discussion}

Analysis of the publications identified four broad themes: (a) feminism in the context of BDSM, (b) the normalization of BDSM, (c) navigating feminist and submissive identities, and (d) BDSM power as transgressive. These themes provide the foundation of answering the research question: How are feminism and submission discussed in the scholarly literature about BDSM, particularly related to women who identify as feminist and submissive, and are active in the BDSM community? 


\section{Feminism}

Bondage/discipline, dominance/submission, and sadism/masochism (BDSM) was discussed in terms of agency, power, and consent; and as both replicating and simulating systems of patriarchy. It was also conceptualized as transgressing systems of patriarchy, which supports the argument within feminist discourse that theorists, researchers, and practitioners would do well to discard binary thinking (e.g., healthy/unhealthy, good/bad, freedom of choice/lack of ability to choose) and instead seek more comprehensive, and perhaps complex, understandings of what BDSM is and why people engage in it. Some people replicate past trauma and destructive or maladaptive behaviors within D/s relationships; some do not. Some people use BDSM activities as a way of reenacting or reshaping past experiences; some do not. Some people have thought critically about what motivates their sexuality, desires, decisions, and behaviors; some have not. Chancer (2000) wrote that, "feminists share interests in both criticizing systemic subordination and respecting individual diversities" and argued that a greater awareness of false dichotomies can perhaps "ensure the realization of increasingly multifaceted goals in a not-too-distant feminist future" (p. 87).

Some BDSM practitioners claim that the BDSM community is a safe space where feminism has a place, equality is the norm, and queering gender is possible. Others disagree and argue that the BDSM community does not accept feminism and that both sexism and racism thrive. They question if people are just replicating gender norms that they are used to, without critically thinking about their desires and choices.

Racism was also discussed as being largely ignored within the BDSM community, which is supported by the privileges of Whiteness. Neoliberalism (i.e., the 
increase of individualization and professionalization) within the BDSM community can block potential members who do not have sufficient capital, whether social or financial (Parchev \& Langdridge, 2017). However, the lack of presence of People of Color in the BDSM community can also be understood as a result of the discrimination and discomfort that they experience when engaged in the community.

Of critical importance in this discourse is how people perceive and enact the ability to replicate, simulate, and/or transgress boundaries and oppressions through BDSM play; how they sandbox power dynamics and fashion tools such as negotiation, safewords, contracts, consensual non-consent, and positive consent to eroticize and tame issues of power that were not previously pleasurable (pepomint, 2007a).

\section{Submission}

Some women perceive submission as a natural and inherent part of their identity, and some consider themselves to be submissive in general (even in their career choices) while some express their submission in a sexual context only. D/s relationships, in which partners negotiate the parameters of their power exchange, allow room for diverse structures of power and consent.

Submissives experience challenges related to stigma due to their BDSM interests, relationship problems, and desires. They encounter risks and challenges related to being vulnerable, interacting with bad (abusive) dominants, and following orders and accepting decisions made by someone else. There is also the risk of interacting with people in the community who have unstable personalities or who threaten the cohesion of the community. A major challenge that many practitioners observe is that new people, 
particularly young submissive women, are viewed as naïve or needing to be protected, and may be exploited; often by male dominants.

Submissives benefit from receiving pleasure from pleasuring others; physical

pleasure and arousal; psychological release; fun and variety; personal growth; improved romantic relationships; community involvement and belonging; freedom from day-to-day roles; and being yourself. They also benefit from giving up power to a trusted dominant partner and by being asked by their partner(s) exactly what they want, having their limits respected, being paid close attention to, and being cared for when a scene was over. Access to peers and education, including the ability to learn about BDSM practices, consent, power, and self-advocacy were two other ways that submissives benefit from the BDSM community.

\section{The Intersection of Feminism and Submission}

Many women who identify as submissive also identify as feminist, while others have feminist values, but do not label themselves as feminist. Women perceived submission as empowering, as expressed through stories of freedom to choose, freedom to be, and increased awareness of self and esteem.

Some women who identify as feminist and submissive do not experience conflict between these two identities and feel no need to navigate or reconcile them. Women who do experience conflict related to these identities learn to navigate and reconcile them in several ways. The reconciliation can be a difficult, even violent, process, and reconciliation can be an ongoing struggle. Some women who experience shame related to their BDSM interests find comfort in and begin to reconcile their identities through engagement in the BDSM community. 
Women recognize the importance of self-awareness; of being aware of what you want and why, both as a BDSM practitioner and as a submissive. Some women also recognize a need to be cognizant of how their actions affect other people.

As Marion (2016) argued, consent is complicated by the fact that, "the real, preexisting power dynamics that exist between players will always frame and partially determine the meaning of what happens in a scene" (p. 189). This is true even for people outside of a play scene. Some BDSM practitioners who observed scenes of reenacted trauma or oppression (e.g., race play, rape play, slavery) experienced the scenes as harmful. In fact, many people are uncomfortable with such types of play.

To resist falling into a polarized either/or position of neoliberal sex-positive choice or sex-negative lack of ability to choose, Downing (2012) suggests applying a sexcritical approach, through which to critically assess all forms of sexuality and the ideologies upon which they are formed. Instead of discussing whether BDSM should be understood as a sexual practice that supports feminist goals, conversations should explore "the variety of ways that BDSM participants support or resist normative conceptualizations of gender and sexuality (Simula, 2012, p. 502).

\section{Implications for Future Research and Practice}

Implications for future research and practice focus on three areas: (a) the importance of consent, transgression, and diversity within the BDSM community; (b) helping women understand and navigate their feminist and submissive identities; and (c) reducing BDSM social stigma through education. 


\section{Consent, Transgression, and Diversity within the BDSM Community}

Consent, power, and agency are critical components of feminism within the context of BDSM. Feminist discourse within the BDSM community calls for all members to reflect upon how they employ these concepts in their actions relationships and to examine how groups support or reduce oppressions. For example, a submissive woman may benefit from reflecting upon why she submits or if she employs agency when choosing to give informed consent.

One area of opportunity is to examine the extent to which "Safe, Sane, and Consensual" (SSC) protects or marginalizes members of the BDSM community, and to provide strategies through which the community can be more inclusive of individuals and practices. Understanding "safe" as welcoming diversity can become a vehicle for encouraging inclusion in terms of race, ethnicity, class, sex, gender, gender expression, age, (dis)ability, shape, and size. Setting aside the "us vs. them" mentality within consensual relationship dynamics and discussing contested dynamics and forms of play (e.g., M/s relationships, race play) instead of ostracizing them can also lead to increased diversity and acceptance. Awareness of how race and gender are experienced and how racism and sexism are employed, particularly unintentionally, can help the BDSM community to understand its lack of diversity and ways to counter this problem.

Another area for exploration is to apply a sex-critical approach (Downing, 2012) to BDSM interests, roles, and practices. How do practitioners look beyond the binary of freedom of choice vs. lack of ability to choose? How do individuals, partners, and groups understand, discuss, and utilize agency, power, and consent? BDSM practitioners and groups might benefit from asking themselves tough questions (pepomint, 2007b). Are 
their desires fueled by oppressive attitudes, such as ableism, homophobia, racism, and sexism? Are they using BDSM to access power in ways that they would normally eschew as oppressive? If yes, then are they using BDSM to subvert these oppressive forms of power? What effect does their BDSM have on the world? Are they using BDSM in a way that resists or perpetuates oppression?

\section{Helping Women Understand and Navigate Their Feminist and Submissive Identities}

Research and practice can also focus on how women who are feminist and submissive understand, navigate, and sometimes struggle with these identities. Existing research shows that women who identify as feminist and submissive find different ways of perceiving, navigating, and reconciling these identities.

The BDSM community is a thriving site of education where practitioners learn about themselves, other people, and practices. BDSM practitioners experience this education on their own or with and from other people. They learn through a variety of formats, including books, such as Different Loving: The World of Sexual Dominance and Submission (Brame, Jacobs, \& Brame, 1998), Domination \& Submission: The BDSM Relationship Handbook (Makai, 2014), Playing Well with others: Your Field Guide to Discovering, Exploring and Navigating the Kink, Leather and BDSM Communities (Harrington, \& Williams, 2012), and The S\&M Feminist (Thorn, 2012). Books also provide guidance for people outside of BDSM, such as When Someone You Love is Kinky (Easton \& Liszt, 2000) and Health Care Without Shame (Moser, 1999). Additionally, the blogosphere provides a wealth of posts and reader comments about BDSM, submission, and feminism; for example, The Pervocracy: Sex. Feminism. BDSM. And Some Very, Very Naughty Words (Pervocracy, http://pervocracy.blogspot.com/) and The Submissive 
Guide: Helping You Find Yourself (lunaKM, https://submissiveguide.com/). In fact, one of the most comprehensive blogs about BDSM (Ranai, 2011) provides content in 23 languages, and 38 links to resources in English about feminist perspectives. Many of these resources direct people to find more information and groups through FetLife "the Social Network for the BDSM, Fetish \& Kinky Community" (https://fetlife.com). FetLife has various online groups for feminists, including: BDSM and Feminism, $21^{\text {st }}$ Century Feminism and Womanism, Feminist Submissives, Feminist BDSM Lesbian femmes and butches, and regional groups, such as Feministas BDSM Brasil and Glasgow Feminist Munch. These resources provide a wealth of information for women who want to understand themselves better. Research can explore how women access these and other resources to better understand their identities, desires, and limits and claim their BDSM sexuality.

\section{Reducing BDSM Social Stigma through Education}

Another avenue of research and practice relates to educating people about BDSM sexuality. Academic research on women in BDSM is lacking. However, researchers who explore BDSM hope that their findings can have a positive impact on the effectiveness of educators, counselors, therapists, doctors, and other professionals who interact with members of the BDSM community (Barker, 2007; Nichols, 2006; Rehor, 2015). The need for professionals to be educated about BDSM has been recognized by the BDSM community, as demonstrated by the Kink Aware Professionals Directory (KAP), where individuals can find psychotherapeutic, medical, legal, and other professionals who are sensitive to diverse expressions of sexuality (NCSF, n.d.). 
A key to increasing this effectiveness is to educate the professionals about BDSM so that they have a better understanding of BDSM interests; identities; and "Safe, Sane, and Consensual". Education can occur within higher education courses; professional associations and training (e.g., Academy of Human Resource Development, Collins, Meeker, Whitehead, \& Rocco, 2012; American Psychological Association, Kolmes Sprott, \& Witherspoon, 2013; National Conference on LGBT Equality, Sprott 2014); and other settings where adults learn, including the BDSM community (CARAS, 2012).

Through higher education, individuals gain formal learning, such as vocational training, certifications, and degrees (e.g., bachelor's, master's, doctorates). This is where many professionals learn about their fields and prepare for careers. Professional training and associations provide ongoing education for professionals to expand their knowledge and expertise. Adults learn in a variety of other settings, as well. Adult education is a practice in which, and a field that addresses how, adults gain new knowledge, skills, attitudes, or values outside of higher education (Merriam \& Brockett, 2007). This education occurs in settings such as literacy programs, recreational programs, recovery programs, rehabilitation centers, prison education, and community organizations. Each of these settings provides opportunities for professionals to learn about BDSM.

Higher education can provide education through academic services, such as classroom instruction and educational seminars, and through student services, such as student clubs and diversity initiatives. Professional training and associations can provide ongoing or topic-specific education. For example, healthcare professionals (e.g., nurses, doctors, therapists) can attend seminars to learn about BDSM-related issues, such as how to respond if a patient shares that sometimes they have bruises as a result of bondage, or 
that they are having difficulty telling a partner about their fantasies. Legal professionals (e.g., law enforcement, attorneys, judges) can attend seminars to learn about how consent is utilized within BDSM relationships, and perhaps gain insight into how to distinguish between abuse and kink. Educators (i.e., professors, trainers, social justice advocates) can attend seminars to learn about these same issues and gain insight into how to respond to a student who expresses interest in BDSM practices and sexuality.

In their content analysis of Adult Learning publications from 2006 to 2010, Cherrstrom, Robbins, and Bixby (2017) asserted that "Adult Learning reflects the field of adult and continuing education and strives to meet the practitioner-oriented needs of adult educators across diverse audiences, purposes, and contexts" (pp. 10-11). However, BDSM has been largely ignored by the field of adult education. A keyword search for BDSM-related terms (e.g., BDSM, sadomasochism, sadomasochistic, dominance and submission, power exchange, fetish, kink, kinky, Leather) within five adult education journals (Adult Education Quarterly, Adult Learning, AERA Open, Emerging Adulthood, and the Journal of Adult and Continuing Education) identified zero publications. The absence of scholarly publications within Adult Learning and similar journals demonstrates a missing opportunity for inclusion within the field of adult education. Future research can advance discourse about learning, identity, feminism, submission, and BDSM, can be incorporated into curriculum and training, and can inform other educational platforms for parents, friends, and colleagues of BDSM practitioners.

In a presentation at the 2014 National Conference on LGBT Equality, Sprott (2014) provided several reasons why BDSM should be included in the LGBTQ discourse. First, some LGBTQI individuals also identify with BDSM/Leather/kink as an 
aspect of their sexuality, and it is "hard to ask people to leave one part of their sexuality at the door when the issues are directly about sexual health, rights, freedom" (slide 33). Also, issues related to BDSM can provide bridges to other people and potential allies outside of LGBT communities and increase understanding. Furthermore, BDSM communities and practitioners have wisdom and experience regarding consent and can provide insight into power and power dynamics (slide 33). Considering these arguments, research and practice focusing on LGBTQ issues can be enhanced by, and should be inclusive of, research and practice focusing on BDSM.

A final note for researchers and feminists is that those who recoil at the idea of sexuality pared with pain and domination can apply a "world"-travelling approach (Deckha, 2011) to understanding BDSM. This can help them look beyond their potentially misinformed assumptions and reduce the possibility of viewing BDSM practitioners as the sexual Other.

\section{References}

Allison, D. (1994). A question of class. In D. Allison, Skin: Talking about sex, class, and literature (pp. 13-36). Ithaca, NY: Firebrand Books.

Anzaldúa, G. (2007). Borderlands: The new mestiza = La frontera San Francisco, CA: Aunt Lute Books.

Badran, M. (2009). Feminism in Islam: Secular and religious convergences. Oxford, UK: Oneworld Publications.

Barker, M. (2005). On tops, bottoms and ethical sluts: The place of BDSM and polyamory in lesbian and gay psychology. Lesbian and Gay Psychology Review, 6(2) pp. 124-129. Retrieved from

http://www.bps.org.uk/pss/pss_review/pss_review_home.cfm

Barker, M. (2007). Turning the world upside down: Developing a tool for training about SM. In D. Langdridge \& M. Barker, (Eds.), Safe, sane and consensual 
contemporary perspectives on sadomasochism (pp. 261-270). Basingstoke, UK: Palgrave Macmillan.

Barker, M. (22 October 2012). Consent and abuse of power in kink and other sexual communities, Rewriting the Rules. [Blog post]. Retrieved from http://rewritingthe-rules.com/sex/consent-and-abuse-of-power-in-kink-and-other-sexualcommunities/

Barker, M. (2013a). Consent is a grey area? A comparison of understandings of consent in Fifty Shades of Grey and on the BDSM blogosphere. Sexualities, 16(8), 896914. doi http://dx.doi.org/10.1177\%2F1363460713508881

Barker, M. (2013b). Rewriting the rules: An integrative guide to love, sex and relationships. New York, NY: Routledge.

Bauer, R. (2008). Transgressive and transformative gendered sexual practices and white privileges: The case of the Dyke/Trans BDSM communities. Women's Studies Quarterly, 36(3-4), 233-253. Retrieved from http://ezproxy.fiu.edu/login?url=http://search.proquest.com.ezproxy.fiu.edu/docvi ew/61787493? accountid=10901

Bennett, T. (January 01, 2015). Persecution or play? Law and the ethical significance of sadomasochism. Social and Legal Studies, 24(1), 89-112.

Beres, M. A., \& MacDonald, J. E. (2015). Talking about sexual consent: Heterosexual women and BDSM. Australian Feminist Studies, 30(86), 418-432.

Boyatzis, R. E. (1998). Transforming qualitative data: Thematic analysis and code development. Thousand Oaks, CA: Sage.

Brame, G. G., Jacobs, J., \& Brame, W. G. (1998). Different loving: The world of sexual dominance and submission. London, UK: Arrow.

Busbee, E. R. (2008). Power exchange: Interaction and identity in a BDSM community (Order No. 3317068). Available from ProQuest Dissertations \& Theses A\&I; ProQuest Dissertations \& Theses Global. (304399461). Retrieved from http://ezproxy.fiu.edu/login?url=http://search.proquest.com.ezproxy.fiu.edu/docvi ew/304399461 ? accountid=10901

Chaline, E. (2007). On becoming a gay SMer: A sexual scripting perspective. In D. Langdridge \& M. Barker, (Eds.), Safe, sane and consensual contemporary perspectives on sadomasochism (pp. 155-176). Basingstoke, UK: Palgrave Macmillan. 
Chasey, S. (2008). The rise and fall of the M/s community: A cautionary observation. Keynote Address to the 2008 Master/slave Conference. Washington, DC.

Retrieved from http://masterslaveconference.org/documentation/2008-masterskip-chasey-the-rise-and-fall-of-the-ms-community/

Chatterjee, B. B. (2012). Pay v UK, the probation service and consensual BDSM sexual citizenship. Sexualities, 15(5-6), 739-757.

doi:http://dx.doi.org.ezproxy.fiu.edu/10.1177/1363460712446279

Chen, V. (2012). Kink, Race, and College: A Discussion with Mollena Williams, Equal Writes: Feminism and Gender Issues at Princeton University. Retrieved from https://equalwrites.wordpress.com/2012/03/11/kink-race-and-college-adiscussion-with-mollena-williams/

Coleridge, S. T. (1817). Biographia Literaria, Chapter XIV. Retrieved from http://www.english.upenn.edu/ mgamer/Etexts/biographia.html

Collins, J. C., Meeker, C., Whitehead, C., Rocco, T. S. (2012). Disclosing "deviance" in the workplace: LGBT, BDSM, convicts, and the disabled. In Dirani, K. M., Wang, J., Gedro, J., Doshy, P. (Eds.), Academy of Human Resource Development Conference Proceedings (p. 50). Denver, CO: Academy of Human Resource Development.

Community-Academic Consortium for Research on Alternative Sexualities (CARAS). (2012, April). The CENA Project: BDSM Educational Needs Assessment. Presentation at the Leather Leadership Conference XVI, Nashville, TN.

Cross, P. A., \& Matheson, K. (2006). Understanding sadomasochism: An empirical examination of four perspectives. Journal of Homosexuality, 50(2-3), 133-166. doi:http://dx.doi.org.ezproxy.fiu.edu/10.1300/J082v50n02_07

Cruz, A. (2015). Beyond black and blue: BDSM, Internet pornography, and Black female sexuality. Feminist Studies, 41(2), 409-436.

Cruz, A. (2016). Playing with the politics of perversion: Policing BDSM, pornography, and Black female sexuality. Souls: A Critical Journal of Black Politics, Culture, and Society, 18(2-4), 379-407. doi https://doi.org/10.1080/10999949.2016.1230817

Dancer, P. L., Kleinplatz, P. J., \& Moser, C. (2006). 24/7 SM slavery. Journal of Homosexuality, 50(2-3), 81-101. doi:http://dx.doi.org/10.1300/J082v50n02_05

Deckha, M. (2011). Pain as culture: A Postcolonial feminist approach to S/M and women's agency. Sexualities, 14(2), 129-150. doi: 10.1177/1363460711399032 
Downing, L. (27 July 2012). What is 'sex critical' and why should we care about it? Sex Critical. [Blog]. Retrieved from http://sexcritical.glogsopt.co.uk/2012/07/what-issex-critical-and-why-should-we.html

Dymock, A. (2012). But femsub is broken too! On the normalisation of BDSM and the problem of pleasure. Psychology \& Sexuality, 3(1), 54-68. doi:10.1080/19419899.2011.627696

Easton, D. Shadowplay, (2007). S/M journeys to our selves. Safe, sane and consensual: contemporary perspectives on sadomasochism (pp. 217-228). London, UK: Palgrave,

Easton, D., \& Liszt, C. A. (2000). When someone you love is kinky. Emeryville, CA: Greenery.

Eisele, H., \& Stake, J. (2008). The differential relationship of feminist attitudes and feminist identity to self-efficacy, Psychology of Women Quarterly, 32(3), 233244. doi: 10.1111/j.1471-6402.2008.00432.x

Ernulf, K. E., \& Innala, S. M. (1995). Sexual bondage: A review and unobtrusive investigation. Archives of Sexual Behavior, 24(6), 631-654.

FetLife, (2017). Social Network for the BDSM, Fetish \& Kinky Community. https://fetlife.com/

Freedman, E. B. (2002). No turning back: The History of feminism and the future of women. New York, NY: Ballantine Books.

Harrington, L., \& Williams, M. (2012). Playing well with others: Your field guide to discovering, exploring and navigating the kink, leather and BDSM communities. San Francisco, CA: Greenery.

Hébert, A., \& Weaver, A. (2015). Perks, problems, and the people who play: A qualitative exploration of dominant and submissive BDSM roles. The Canadian Journal of Human Sexuality, 24(1), 49-62. Retrieved from http://ezproxy.fiu.edu/login?url=https://search-proquestcom.ezproxy.fiu.edu/docview/1667326462?accountid=10901

Holt, K. (2015). Negotiating limits: Boundary management in the Bondage/Discipline/Sadomasochism (BDSM) community (3703396). Available from ProQuest Dissertations \& Theses A\&I; ProQuest Dissertations \& Theses Global; Social Science Premium Collection. (1688330151). Retrieved from http://ezproxy.fiu.edu/login?url=https://search.proquest.com/docview/16883 $\underline{30151 \text { ? accountid }=10901}$ 
hooks, B. (2000). Feminist theory: From margin to center. Boston, MA: South End Press.

Hurtado, A. (1989). Relating to privilege: Seduction and rejection in the subordination of White women and women of color. Signs: Journal of Women in Culture and Society, 14, 833-855.

J. M. (2014). Coming up for air: Personal reflections on women's masochism, Feral feminisms, 2, 23-27. Retrieved from http://www.feralfeminisms.com/coming-up$\underline{\text { for-air/ }}$

James, E. L. (2011). Fifty shades darker. New York, NY: Vintage Books.

James, E. L. (2012a). Fifty shades of grey. New York, NY: Vintage Books.

James, E. L. (2012b). Fifty shades freed. New York, NY: Vintage Books.

Joffe, H., \& Yardley, L. (2004). Content and thematic analysis. In D. Marks \& L. Yardley (Eds.), Research methods for clinical and health psychology (pp. 56-68). London, UK: Sage.

Kleinplatz, P. J., \& Moser, C. (2006). Sadomasochism: Powerful pleasures. New York, NY: Harrington Park Press.

Kolmes, K., Sprott, R., \& Witherspoon, R. (2013, July). 50 shades of grey in therapy: Working with BDSM/kink sexualities and communities. Continuing Education Workshop presented at the American Psychological Association convention, Honolulu, HI.

Krefting, L. (1991). Rigor in qualitative research: The assessment of trustworthiness. American Journal of Occupational Therapy, 45(3): 214-222. doi: 10.5014/ajot.45.3.214.

Langdridge, D. (2006). Voices from the margins: Sadomasochism and sexual citizenship. Citizenship Studies, 10(4), 373-389.

doi:http://dx.doi.org.ezproxy.fiu.edu/10.1080/13621020600857940

Langdridge, D., \& Barker, M. (2007). Safe, sane, and consensual: Contemporary perspectives on sadomasochism. London, UK: Palgrave Macmillan.

LeatherTbird. (2009). "Race play: It[s] NOT a Game": A dissenting viewpoint. Retrieved from http://www.mollena.com/tag/andrea-plaid/

Lindemann, D. (2011). BDSM as therapy? Sexualities, 14(2), 151-172. doi:http://dx.doi.org.ezproxy.fiu.edu/10.1177/1363460711399038 
Linden, R. R. (1982). Against sadomasochism: A radical feminist analysis. East Palo Alto, CA: Frog in the Well.

Lorde, A., \& Star, S. L. (January 01, 1982). "Interview with Audre Lorde”. In Linden, Robin Ruth; Pagano, Darlene R.; Russell, Diana E. H.; et al. Against Sadomasochism: A Radical Feminist Analysis. San Francisco, CA: Frog in the Well. pp. 66-71.

Luminais, M. N. (2012). In the habit of being kinky: Practice and resistance in a BDSM community, Texas, USA (Ph.D.). Available from ProQuest Dissertations \& Theses A\&I. (1032783661).

lunaKM. (2017). The Submissive Guide: helping you find yourself. [Blog]. Retrieved from https://submissiveguide.com/

MacAulay, T. M. (23 March 2012). There's a war on part 1: Trouble's been brewing., Yes means Yes: Visions of female sexual power \& a world without rape. [Blog post]. Retrieved from https://yesmeansyesblog.wordpress.com/2012/03/23/theresa-war-on-part-1-troubles-been-brewing/

Makai, M. (2014). Domination \& submission: The BDSM relationship handbook. Los Gatos, CA: Smashwords.

Marion, J. (2016). Please hurt me: A feminist psychoanalytic study of women's consensual sadomasochistic sexual practices (Ph.D.). Available from ProQuest Dissertations \& Theses A\&I. (1812552153).

Martinez, K. (2011). Bound in theory and practice: A mixed-methods exploration of consensual sadomasochism (3468405). Available from ProQuest Dissertations \& Theses A\&I; ProQuest Dissertations \& Theses Global. (887901416). Retrieved from http://ezproxy.fiu.edu/login?url=https://search.proquest.com/docview/88790 1416? accountid=10901

Merriam, S. B., \& Brockett, R. G. (2011). The profession and practice of adult education: An introduction. New York, NY: John Wiley \& Sons.

Millbank, L. (2012a). Under duress: Agency, power and consent, part two: 'Yes'. A Radical Transfeminist, 23 January 2012. Available at: https://radtransfem.wordpress.com/2012/01/23/under-duress-agency-power-andconsent-part-two-yes/ (accessed 16 July 2017).

Millbank, L. (2012b). The ethical prude: Imagining an authentic sex-negative feminism. A Radical Transfeminist, 29 February 2012. Available at: 
https://radtransfem.wordpress.com/2012/02/29/the-ethical-prude-imagining-anauthentic-sex-negative-feminism/ (accessed 16 July 2017).

Moser, C. (1999). Health care without shame. San Francisco, CA: Greenery Press.

Musser, A. J. (2015). BDSM and the boundaries of criticism: Feminism and neoliberalism in fifty shades of grey and the story of O. Feminist Theory, 16(2), 121-136. doi:http://dx.doi.org.ezproxy.fiu.edu/10.1177/1464700115585723

Newmahr, S. (2006). Experiences of Power in SM: A Challenge to Power Theory. Berkeley Journal of Sociology, 50, 37-60. Retrieved from http://www.jstor.org.ezproxy.fiu.edu/stable/41035611

Newmahr, S. (2011). Rethinking kink: Sadomasochism as serious leisure. Qualitative Sociology, 33, 313-331.

Nichols, M. (2006). Psychotherapeutic issues with "kinky" clients: Clinical problems, yours and theirs. Journal of Homosexuality, 50(2-3), 281-300. doi:http://dx.doi.org.ezproxy.fiu.edu/10.1300/J082v50n02_14

Ortmann, D., \& Sprott, R.A. (2012). Sexual outsiders: Understanding BDSM sexualities and communities. New York, NY: Rowman and Littlefield.

Parchev, O., \& Langdridge, D. (2017). BDSM under security: Radical resistance via contingent subjectivities. Sexualities, (In-Press).

Patton, M. Q. (2002). Qualitative research and evaluation methods. Thousand Oaks, CA: Sage.

pepomint. (11 June 2007a). "Towards a general theory of BDSM and power" posted on the blog freaksexual. Retrieved from https://freaksexual.com/2007/06/11/towardsa-general-theory-of-bdsm-and-power/.

pepomint. (28 February 2007b). "Your kink does not get a free pass". Posted on the blog freaksexual. Retrieved from https://freaksexual.com/2007/02/28/your-kink-doesnot-get-a-free-pass/

Pervocracy. (10 March 2011). Rape culture: What is rape culture? Pervocracy, [Blog post]. Retrieved from http://pervocracy.blogspot.com/2011/03/rape-culture-onewhat-is-rape-culture.html (accessed 16 July 2017).

Pervocracy. (22 February 2012). Why I didn't just call the cops, Pervocracy. [Blog post]. Retrieved from http://pervocracy.blogspot.co.uk/2012/02/why-i-didnt-just-callcops.html 
Pervocracy, C. (2017). The Pervocracy: Sex. Feminism. BDSM. And some very, very naughty words. [Blog]. Retrieved from http://pervocracy.blogspot.com/

Plaid, A. (2009a). Race play interview - Part I. Interview with Mollena Williams. Retrieved from http://www.mollena.com/2009/04/race-play-interview-part-1/

Plaid, A. (2009b). Race play interview - Part III. Interview with Mollena Williams. Retrieved from http://www.mollena.com/2009/04/race-play-interview-part-iii/

Plaid, A. (2009c). Race play interview - Part IV. Interview with Mollena Williams. Retrieved from http://www.mollena.com/2009/04/race-play-interview-part-iv/

Portillo, T. (1991). "I get real: Celebrating my sadomasochistic soul”. In M. Thompson (Ed.) Leatherfolk: Radical sex, people, politics, and practice (pp. 49-55). Los Angeles, CA: Daedalus.

Powls, J., \& Davies, J. (2012). A descriptive review of research relating to sadomasochism: Considerations for clinical practice. Deviant Behavior, 33, 223234.

Prior, E. (2013) Women's perspectives of BDSM power exchange. Electronic Journal of Human Sexuality, 16. Retrieved from http://www.ejhs.org/volume16/BDSM.html

Prior, E. E., \& Williams, D. J. (2015). Does BDSM power exchange among women reflect casual leisure? An exploratory qualitative study. Journal of Positive Sexuality, 1(12), 12-15.

Queen, C. (2003). On being a female submissive (and doing what you damn well please). In C. Queen, Real live nude girl: Chronicles of sex positive culture, (pp. 173-176). San Francisco, CA: Cleis.

Raab, S. M. (2013). The perpetuation and subversion of gender-power dynamics in BDSM: An interview study in Central Pennsylvania. Dickinson College Honors Theses. Paper 50. Retrieved from http://scholar.dickinson.edu/cgi/viewcontent.cgi?article=1049\&context=student $\mathrm{h}$ onors

Ramsey, L. R., Haines, M. E., Hurt, M. M., Nelson, J. A., Turner, D. L., Liss, M., et al. (2007). Thinking of others: Feminist identification and the perception of others' beliefs. Sex Roles, 56, 661-616.

Ranai. (2011). Kink resources in many languages and kinky fiction. [Weblog]. Retrieved from https://ranai.wordpress.com/ 
Rehor, J. E. (2015). Sensual, erotic, and sexual behaviors of women from the 'kink' community. Archives of Sexual Behavior, 44(4), 825-836. doi:http://dx.doi.org.ezproxy.fiu.edu/10.1007/s10508-015-0524-2

Richards, L. (2002). Qualitative computing - A methods revolution? International Journal of Social Research Methodology, 5(3), 163-276.

Ritchie, A., \& Barker, M. (2005). Feminist SM: A contradiction in terms or a way of challenging traditional gendered dynamics through sexual practice? Lesbian and Gay Psychology Review, 6(3), 227-239. Retrieved from http://oro.open.ac.uk/id/eprint/17262

Rivoli, L. R. (2015). Liberation Through Domination: BDSM Culture and SubmissiveRole Women. Student Publications, 318. Retrieved from http://cupola.gettysburg.edu/student_scholarship/318

Rocco, T. S., Stein, D., \& Lee, C. (2003). An Exploratory examination of the literature on age and HRD policy development. Human Resource Development Review, 2(2), 155-180. doi: 10.1177/1534484303002002004

Rubin, G. (1993). Thinking sex: Notes for a radical theory of the politics of sexuality. In H. Abelove, M. A. Barale, \& D. M. Halperin (Eds.), The lesbian and gay studies reader (pp. 3-44). New York, NY: Routledge.

Sandnabba, K. N., Santtila, P., Alison, L., \& Nordling, N. (2002). Demographics, sexual behaviour, family background and abuse experiences of practitioners of sadomasochistic sex: A review of recent research. Sexual and Relationship Therapy, 17(1), pp. 39-55. doi https://doi.org/10.1080/14681990220108018

Scott, C. (August 6, 2012a) Thinking kink: Playing with race in BDSM. Online magazine Bitch: Feminist Response to Pop Culture. Retrieved from https://www.bitchmedia.org/post/thinking-kink-bdsm-and-playing-with-race-sexsexuality

Simula, B. L. (2012). A 'Different economy of bodies and pleasures'?: Gender, power, and sexuality in BDSM interactions (Order No. 3522289). Available from ProQuest Dissertations \& Theses A\&I; ProQuest Dissertations \& Theses Global. (1037419865). Retrieved from http://ezproxy.fiu.edu/login?url=http://search.proquest.com.ezproxy.fiu.edu/docvi ew/1037419865? accountid=10901

Sprott, R. A. (January 2014). Who are these leather people, and why do we need to include them? Kink history, culture, communities and dilemmas. Paper presented at the National Conference on LGBT Equality. Houston, TX. Retrieved on September 23, 2016 from 
https://carasresearch.org/images/uploads/main/Who_are_these_leather_people_A n_overview_and_introduction.pdf

Star, S. L. (January 01, 1982). "Swastikas: The Street and the University". In R. R. Linden, D. P. Pagano, D. E. H. Russell, et al. Against Sadomasochism: A Radical Feminist Analysis (pp. 131-6). San Francisco, CA: Frog in the Well.

Stiles, B. L., \& Clark, R. E. (2011). BDSM: A subcultural analysis of sacrifices and delights. Deviant Behavior, 32(2), 158-189. Retrieved from http://dx.doi.org/10.1080/01639621003748605

Stryker, K. (16 July 2011). Safe/ward: I wish I could use a safeword on rape culture, KittyStryker The Most Dangerous Liaison. [Blog post]. Retrieved from http://kittystryker.com/blog/posts/safeward-i-wish-i-could-use-a-safeword-onrape-culture/

Surprise, O. (2012). Screaming green: A topography and bourdieusian analysis of the model of sexual consent utilized by BDSM community members (1509152). Available from ProQuest Dissertations \& Theses A\&I; ProQuest Dissertations \& Theses Global. (1012364302). Retrieved from http://ezproxy.fiu.edu/login?url=https://search.proquest.com/docview/101236430 2? accountid=10901

Taylor, G. W., \& Ussher, J. M. (2001). Making sense of S\&M: A discourse analytic account. Sexualities, 4(3), 293. doi: 10.1177/136346001004003002

Thorn, C. (2017). S\&M Resources. [Blog]. Retrieved from http://clarissethorn.com/bdsmresources/

Tong, R. (2009). Feminist thought: A more comprehensive introduction. Boulder, CO: Westview Press.

Tsaros, A. (2013). Consensual non-consent: Comparing EL James's fifty shades of grey and Pauline Reage's story of O. Sexualities, 16(8), 864-879. doi:http://dx.doi.org.ezproxy.fiu.edu/10.1177/1363460713508903

Turley, E. L. (April 02, 2016). "Like nothing I've ever felt before": Understanding consensual BDSM as embodied experience. Psychology and Sexuality, 7, 2, 149162. doi https://doi.org/10.1080/19419899.2015.1135181

Veaux, F. (14 July 2012). Some thoughts on ethics, safety, and conduct in BDSM: Part I, Franklyn Veaux's Journal. [Blog post]. Retrieved from http://tacit.livejournal.com/382208.html 
Walters, C. J. (2012). Discourses of heterosexual female masochism and submission from the 1880s to the present day (Order No. U575177). Available from ProQuest Dissertations \& Theses A\&I; ProQuest Dissertations \& Theses Global. (1124095062). Retrieved from http://ezproxy.fiu.edu/login?url=https://search.proquest.com/docview/112409506 $\underline{2 \text { ? accountid }=10901}$

Weinberg, T. (2006). Sadomasochism and the social sciences: A review of the sociological and social psychological literature. Journal of Homosexuality, $50(2 / 3), 17-40$.

Weinberg, T. S., \& Newmahr, S. (2015). Selves, symbols, and sexualities: An interactionist anthology. Los Angeles, CA: Sage.

Weiss, M. (2006). Working at Play: BDSM Sexuality in the San Francisco Bay Area. Anthropologica, 48(2), 229-245. doi:10.2307/25605313

Weiss, M. (2011). Techniques of pleasure: BDSM and the circuits of sexuality. Durham, NC: Duke Univ. Press.

Williams, D J (2006). Different (painful!) strokes for different folks: A general overview of sexual sadomasochism and its diversity. Sexual Addiction \& Compulsivity, 13, 333-346.

Williams, M. (27 March 2011). Consent [Violated], The Perverted Negress. [Blog post]. Retrieved from http://www.mollena.com/2011/03/consent-violated/

Woody, I. A. (2014). It's the hard knock life: Sex, shame, and making meaning, Feral feminisms, 2, 92-97. Retrieved from http://www.feralfeminisms.com/its-the-hardknock-life-sex-shame-and-making-meaning/

Wright, S. (2006). Discrimination of SM-identified individuals. Journal of Homosexuality, 50(2-3), 217-231. doi:http://dx.doi.org.ezproxy.fiu.edu/10.1300/J082v50n02_10

Young. M. (2009). Thoughts on rope, submission and feminism. In L. Harrington (Ed.), Rope, bondage, and power (pp. 51-60). Las Vegas, NV: Nazca Plains.

Zucker, A. L., \& Bay-Cheng, L. Y. (2010). Minding the gap between feminist identity and attitudes: The behavioral and ideological divide between feminists and nonlabelers. Journal of Personality, 78, 1895-1924. doi:10.1111/j.14676494.2010.00673.x 


\section{CHAPTER III}

\section{STUDY \#2: PHENOMONOLOGY - NEGOTIATING SELF: WOMEN'S NAVIGATION OF FEMINIST AND SUBMISSIVE IDENTITIES}

When identities intersect, they create polyrhythmic realities (Brown, 1989; Sheared, 1999), where an individual's understandings of their different identities cause them to do "different, seemingly contradictory things, simultaneously" (Brown, 1989, p. 929). Intersecting identities can create borderlands fraught with tension and oppression, where an individual might view herself as "wrong, other" or be viewed as "wrong, other" by society (Anzaldúa, 2007). In these borderlands, the individual might struggle to avoid blaming, hating, and terrorizing herself and others. Women who are feminist and submissive can experience such a borderland of intersecting identities, where commonly held beliefs about feminism conflict with commonly held beliefs about submission.

Feminism is "an understanding that women have suffered forms of subordination or oppression because of their sex, and an advocacy of ways to overcome them" (Badran, 2009, p. 18). Areas of oppression include lack of property rights, resources to overcome domestic violence, ability to vote in elections, and control over their bodies. Feminism has been described in many ways: as a movement, as a set of attitudes or values, and as an explicit identity (Zucker \& Bay-Cheng, 2010). Not unexpectedly, feminists experience feminism in diverse ways (Freedman, 2002), making feminism difficult to define and measure. For example, feminist advocacy may become one's life work or can be as simple as speaking up when someone tells a sexist joke (Valenti, 2007). Within feminist perspectives, lines are drawn between what is acceptable and what is not (Tong, 2009). 
Dominance and submission (D/s) refers to a relationship dynamic where partners "mutually consent to assume or yield authority" (Harrington \& Williams, 2012, p. 245). This yielding of authority is also known as power exchange. In D/s relationships, the dominant partner takes psychological and/or physical control over their submissive partner, which can involve the use of rules, rituals, and protocols or modes of conduct, such as how to behave when in certain environments (Ortmann \& Sprott, 2012). Some people perceive this as incompatible with feminist values, and view D/s as glorifying and legitimizing violence against women (Jeffreys, 1993; 2003).

As women navigate the intersecting meanings of feminism and submission, they might have trouble reconciling their (often feminist) politics and D/s practice. The women might experience internal or external conflict. For example, a woman who believes in equality might struggle to accept her desire to yield authority to a dominant partner. She might experience further identity conflict when both identities become activated simultaneously. In these moments, she may have to choose which identity to prioritize, which means renegotiating her identity yet again. This can be exacerbated when one identity, or both, are not recognized or accepted by other people.

BDSM has been examined through diverse feminist lenses, including radical feminism (Jeffreys, 1993; Linden, 1982) a postcolonial "world-travelling" approach (Deckha, 2011), and a sex-critical approach (Downing, 2012). Feminism and power have also been examined through the lens of BDSM (Prior, 2013). For example, Prior (2013) found that women use BDSM as a vehicle for authentic expression and emotional and sexual fulfillment. Additionally, submissive women perceive feminist identity as supporting submissive identity. Prior concluded that "third wave feminism provides a 
space for women in BDSM communities to express their sexual identities fully, even when those identities seem counterintuitive to the ideals of feminism" (2013, p. 17). Although BDSM has been examined through a range of lenses, little research has explored the lived experiences and identity navigation of women who are feminist and submissive (Dymock, 2011).

\section{Purpose and Research Questions}

The purpose of this phenomenology (van Manen, 1997) was to understand the experiences of women in the BDSM community who identify as feminist and submissive, regarding their experiences navigating these identities. This study was guided by the following research question: How do women in the BDSM community who identify as feminist and submissive perceive and navigate their feminist and submissive identities?

\section{Conceptual Framework}

This research was guided by a conceptual framework integrating identity theory (Burke \& Stets, 2009), feminism (Badran, 2009; Freedman, 2002; Tong, 2009), and Dominance and submission (Deckha, 2011; Langdridge \& Barker, 2007) as they relate to women who are feminist and submissive (Thorn, 2012; Young, 2012).

\section{Identity}

Identity shapes how people make sense of the world and their experiences in it, including their interactions with other people (Burke, 2007; McCarthey \& Moje, 2002). Individuals understand their sense of self in relation to the roles they occupy in their social structure (Thoits \& Virshup, 1997). Roles such as mother, teacher, and athlete are perceived, reacted to, and labeled within society: people expect a mother to behave like a mother; a teacher to behave like a teacher. Individuals also apply a reflexive aspect of the 
self, naming themselves by the roles they occupy. For example, a mother will name herself as a mother; a teacher will name herself as a teacher. These labels, with their attached meanings and expectations, become internalized, and are known as identities.

A role identity is the internalized meanings of a specific role that an individual applies to herself or himself, such as being a student (McCall \& Simmons, 1978; Stryker, 2002). A social identity is based on an individual's identification with a social group, such as being a student at a specific high school (Burke \& Stets, 2009; Hogg \& Abrams, 1988). To maintain congruency between the meanings for each identity, individuals perform behaviors expected and appropriate for each role. These behaviors maintain the group boundaries and divisions within the social structure. A person identity is the set of meanings that define a person as a unique individual, as opposed to a role-holder or group member (Stets \& Burke, 2009).

Identities and behaviors are connected through the meanings they share, yet "identities influence behavior only to the extent that the meanings of the behavior and the meanings in the identity standard are the same" (Burke \& Stets, 2009, p. 82). An identity standard is the set of meanings that defines the character of an identity. Individuals act or behave in ways to verify their identities, where the perceived meanings of their identities are consistent with their identity standard (Powers 2005). When multiple identity standards have oppositional meanings, the identity standards must shift, as the identities change to remove the conflict (Burke \& Stets, 2009).

A prominence hierarchy of identity (McCall \& Simmons, 1978) refers to how important an identity is to an individual. The higher an identity is in the prominence hierarchy represents how much the identity resonates with the individual. Commitment 
refers to how invested an individual is in the identity; how embedded within the social structure. Salience is the likelihood that an identity will be activated; the more salient an identity, the more likely it is to be activated in any given situation. If more than one identity becomes activated in a situation, the identity with the highest prominence and commitment will guide the behavior (Burke \& Stets, 2009).

\section{Feminism}

Feminist identity and feminist attitudes are distinct constructs (Eisele \& Stake, 2008) and individuals who have feminist values do not necessarily claim a feminist identity (Ramsey et al., 2007; Zucker \& Bay-Cheng, 2010). For example, someone who has feminist values may not identify as feminist if they perceive feminism as racist and/or classist (Allison, 1994; hooks, 2000; Hurtado, 1989).

There are no definitive estimates for how many women in the U.S. are feminist or submissive. However, a recent poll of 1,000 American adults (Swanson, 2013) estimated that $23 \%$ of the women and $16 \%$ of the men surveyed consider themselves feminists; though $82 \%$ of the respondents believe that men and women should be social, political, and economic equals.

\section{Dominance and submission $(\mathrm{D} / \mathrm{s})$}

Some adults engage in an alternative sexual preference or have an identity or orientation toward bondage and discipline, dominance and submission, and/or sadism and masochism (Langdridge \& Barker, 2007; Weinberg, Williams, \& Moser, 1984). Bondage and discipline, dominance and submission, and sadism and masochism are collectively known as BDSM and often referred to as S\&M, Leather, kink, or fetish. Bondage, the physical restraint of a person, and discipline, the psychological restraint designed to 
control behaviors, are supported by established rules and enforceable by punishment (Harrington \& Williams, 2012). Dominance and submission (D/s), power exchange, and Master/slave (M/s) refer to relationships involving consensual exchange of power in terms of behaviors, actions, decisions, or other aspects of life. Sadism and masochism refer to providing (sadism) or receiving (masochism) intense sensation, pain, or suffering for sexual, sensual, or emotional gratification.

Research has estimated that 5-10\% of the U.S. population "engages in sadomasochism for sexual pleasure on at least an occasional basis" (Reinisch, Beasley, Kent, \& Kinsey Institute, 1990, p. 162). More recently, the Durex 2005 Global Sex Survey estimated that $10 \%$ of the adults in the U.S. engage in S\&M (5\% worldwide) and that $36 \%$ of adults in the U.S. have used masks, blindfolds, or other forms of bondage ( $20 \%$ worldwide). Another survey estimated that $1.8 \%$ of the population in Australia had engaged in BDSM activity with the last year (Richters, Visser, Rissel, Grulich, \& Smith, 2008). A survey of 3,058 BDSM practitioners on BDSM-related email listservs or online groups showed that slightly more than half $(51.1 \%)$ were female (Wright, 2008).

\section{Feminism and Dominance and submission (D/s)}

Feminist views on BDSM range from rejection to celebration and can create polarizing frameworks. Some feminists argue that the "sexual revolution" was not liberating for women because it was on men's terms (Jeffreys, 2003). From this perspective, engaging in $\mathrm{D} / \mathrm{s}$ is viewed as reproducing systems of patriarchy, abuse, and violence against women (Dworkin, 1974, 1989; Dworkin \& MacKinnon, 1985; Griffin, 1982; Jeffreys, 1993, 2003; Smash, 2013). On the other hand, some feminists criticize anti-pornography and BDSM feminists for supporting sexual puritanism, having an 
authoritarian stance, and being a potential threat to free speech (Willis \& Aronowitz, 2014). From this perspective, BDSM is viewed as a valid form of expression and of female sexuality (Califia, 2001; Rubin, 1984) and freedom and choice are viewed as "freedom from social norms" (Weiss, 2011, p. 164). As a "particularly cultural practice" (Deckha, 2011, p. 141), BDSM can be viewed through a "world-travelling" approach, revealing "the possibility and complexity of a pluralistic feminism" (Lugones, 1987, p. 3). Individuals can look beyond misinformed assumptions about BDSM (Deckha, 2011) and understand sex, sexuality, and sexual identities as "diverse and incommensurable practices" (Shrage \& Stewart, 2015, p. 13).

\section{Method}

A phenomenological study allows a researcher to understand the shared essence

of an experience shared by participants (Moustakas, 1994), in this case, the perceptions of women in the BDSM community who are feminist and submissive. This section describes the sampling procedures, integrity measures, data collection, and data analysis.

\section{Sampling and Participants}

Twenty-three women participated, falling within the accepted range for qualitative research (Creswell, 2013; Miller, Neil \& Salkind, 2002), as data saturation was achieved when no new themes or major concepts were identified (Guest, Bunce, \& Johnson, 2006). Each participant met the following criteria: 18 years or older; identified as a woman, feminist, and submissive; lived in Florida; and were active in the BDSM community. Seven of the women were known to the researcher from prior research, three were referred by friends, two were referred by a leader of a local BDSM group, and one 
was identified during a conversation at the Miami Beach Pride Parade. The other 10 women were identified through snowball sampling (Brown, 2005).

The participants represented a range of background and demographics

characteristics. Table 3 presents the profiles of the participants. Aliases are in lowercase to denote the submissive role, as is common practice within the BDSM community.

Table 3. Participant Profiles

\begin{tabular}{|c|c|c|c|c|c|c|c|c|c|}
\hline greta & 23 & 16 & 18 & 21 & 2 & Bisexual & White & Master's & Higher Education \\
\hline lili & 23 & 19 & 12 & 19 & 1 & Pansexual & White & High school & Stay at home mom \\
\hline hortense & 23 & 16 & 13 & 14 & 2 & Bisexual & Hispanic & Bachelor's & Operations Manager / Photographer \\
\hline nicole & 24 & 20 & 18 & 18 & 1 & Bisexual & Hispanic & Bachelor's & Office Manager \\
\hline diana & 30 & 15 & 16 & 18 & 2 & Queer & White \& Jewish & Bachelor's & Search Assessor \\
\hline julia & 30 & 12 & 16 & 20 & 1 & Queer & White \& Jewish & Bachelor's & Social Worker \\
\hline debby & 31 & 16 & 30 & 30 & 3 & Pansexual & White \& Jewish & Bachelor's & Student (Mental Health Counseling) \\
\hline cleo & 31 & 7 & 20 & 28 & 4 & Queer & White & Master's & Higher Education (Diversity) \\
\hline carmen & 34 & 13 & 29 & 29 & 3 & Pansexual & Hispanic & Master's & Higher Education (Financial Aid) \\
\hline iris & 37 & 21 & 16 & 23 & 5 & Bisexual & White \& Hispanic & Doctorate & Pharmacist \\
\hline joan & 42 & 7 & 41 & 19 & 2 & Bisexual & Native American / Multiple Cultures & Associate's & Paramedic (retired) \\
\hline frances & 42 & 24 & 24 & 33 & 1 & Heterosexual & White & Master's & Higher Education (Advising) \\
\hline irma & 48 & 15 & 11 & 35 & 3 & Bisexual & Black & Associate's & Boat Mechanic \\
\hline gabrielle & 49 & 7 & 15 & 33 & 1 & Heterosexual & White & Some college & Personal Trainer / Nutritionist \\
\hline michelle & 49 & 12 & 44 & 44 & 2 & Bisexual & White & Master's & Social Worker \\
\hline katia & 49 & 14 & 18 & 19 & 6 & Queer & White \& Jewish & Bachelor's & Senior Business Analyst (Taxonomy) \\
\hline helene & 50 & 18 & 36 & 20 & 2 & Lesbian & White & Trade school & Drafter \\
\hline ophelia & 50 & 21 & 18 & 20 & 3 & Heterosexual & White & Bachelor's & Behavior Analyst / Educator \\
\hline gloria & 54 & 15 & 40 & 40 & 2 & Pansexual & White & Master's & Yacht Chef (retired) \\
\hline claudette & 54 & 9 & 32 & 32 & 6 & Heterosexual & White & Master's & Social Worker (retired) \\
\hline cindy & 57 & 12 & 10 & 54 & 2 & Heteroflexible & White & License & Registered Nurse \\
\hline opal & 59 & 7 & 39 & 39 & 4 & Heteroflexible & White & Master's & Educator \\
\hline ella & 62 & 15 & 50 & 50 & 10 & Heterosexual & White \& Jewish & Some college & Graphic Artist (disabled) \\
\hline Average & 41 & 14 & 24 & 29 & 3 & & & & \\
\hline
\end{tabular}

\section{Integrity Measures}

Qualitative research techniques allows researchers "to share in the understandings and perceptions of others and to explore how people structure and give meaning to their daily lives" (Berg, 2001, p. 7). Multiple strategies were employed to enhance the integrity 
of this study, enhancing credibility, confirmability, and dependability. Credibility was increased through member checking (Creswell, 2009), where the participants were asked follow-up questions to confirm the accuracy of the preliminary findings and to add depth to a concept. Engaging in epoche (Moustakas, 1994) required the first author to set aside preconceived notions, understandings, and judgements of the phenomenon to help stay grounded in the work and decrease personal bias. This was done through reflection and recording thoughts about the topic, process, and interactions with participants in a researcher journal (Bogdan \& Biklen, 2006). The first author recognized the following assumptions: (a) individuals perceive identities and experiences in different ways, (b) feminism can mean different things to different people, (c) submission is experienced and given in diverse ways, (d) some women, but not all, have experienced conflict when accepting or navigating their feminist and submissive identities, and (e) the women would be willing to speak about their experience. Confirmability was increased though maintaining an audit trail of data collection, analyses, and decisions made through the study (Lincoln \& Guba, 1985). Dependability was increased through peer debriefing (Creswell, 2009), as peers and dissertation committee members checked whether the assumptions, proposal, and methods were congruent with the research purpose.

\section{Data Collection}

Each interview occurred in person; communication prior to and following the interviews was by email, text, or phone. Before the interviews, the participants received a description of the purpose and format of the research. At the beginning of the interview, participants had an opportunity to ask questions and gave adult verbal consent to be 
interviewed (Appendix A). After the recordings were transcribed, they were organized, stored, and password-protected on the first author's computer and thumb drive.

The responsive interviewing model (Rubin \& Rubin, 2012) was used to obtain rich, in-depth data about how participants make meaning of their identities and experiences as feminist and submissive. Responsive interviewing, which treats the interviewees more like conversation partners than research subjects, calls for the interviewer to elicit examples, narratives, histories, stories, and explanations grounded in the experiences of the interviewees. Participants answered questions in three phases during the summer of 2017.

First, before each interview, the participant selected an alias and completed a demographic survey of 11 questions to capture background information such as age, gender, and sexual orientation (Appendix B). Second, each participant responded to an interview guide with 27 open-ended questions during a semi-structured interview (Appendix C), which was audio recorded. The interviews lasted an average of 49 minutes, ranging from 23 to 121 minutes. Some women requested to use their BDSM scene name as their alias, claiming a desire to be authentic and not hide who they are. However, this would have made them, and occasionally other people in their community, identifiable; therefore, the researcher assigned a new alias to each participant, using the names of hurricanes that have hit Florida.

Third, all the participants offered to be contacted again via email if any questions later arose. After an initial review of the transcripts, an email was sent to each participant asking that they respond to 17 follow up questions (Appendix D) to clarify or deepen the understanding of a concept. For example, during the interviews, women spoke about 
being submissive to individuals, to their community, and in general; therefore, a follow up question asked if they see themselves as submissive (a) only to a Dominant partner(s), (b) to a Dominant partner(s) and to people they care about, or (c) in general. The participants answered the follow-up questions through a Qualtrics form and entered their alias, so that their new data could be matched with their interview transcript.

\section{Data Analysis}

Data analysis was an iterative, process that involved "continual reflection about the data, asking analytic questions, and writing memos throughout the study" (Creswell, 2009, p. 184). After the interview transcripts were checked for accuracy, they were uploaded into the Nvivo 11 software program, to uncover and identity patterns, assist with organizing the codes, and manage the data. Inductive analysis was used to find meaning in the data by noting patterns, categories, and themes that emerged, as suggested by Creswell's (2013) simplified version of Moustakas' (1994) modification of the Stevick-Colaizzi-Keen method.

Through the process of horizonalization (Moustakas, 1994), the researcher developed a list of significant statements from the interview transcripts, which represented how the participants experience the phenomenon of feminist and submissive identity. Each statement was treated as having equal worth and the list of statements were reduced until it consisted of "nonrepetitive, nonoverlapping statements" (Creswell, 2013, p. 193). The significant statements that remained were clustered into larger meaning units or themes. Next, the researcher identified six themes that were common across the transcripts and from them, created composite textural, structural, and textural/structural descriptions of the participants' experiences. The composite textural description describes 
what the participants experienced with the phenomenon, using verbatim examples. The composite structural description describes how the experiences happened; in other words, the setting and context of the experiences with the phenomenon. The composite textual/structural description captures the "what" and the "how," in other words, the "essence," of the participants' experiences with this phenomenon.

\section{Findings}

Six broad themes emerged from the data: (a) feminist identity as distinct from feminist values; (b) the complexity of submissive identity; (c) women learn to reconcile and navigate feminist and submissive identities in different ways; (d) the BDSM community as generally accepting of feminist identity and values; (e) the feminist community as not very accepting of submissive identity and values; and (f) being out as a feminist and as a submissive. These themes are supported by quotes from the interviews, and the quotes are numbered according to paragraph in the participant's transcript.

\section{Feminist Identity as Distinct from Feminist Values}

The distinction between feminist identity and feminist values emerged as the women described what feminism means to them, as an identity and/or as values. There was also a clear inability to articulate a shared sense of what the "feminist community" is.

Feminism described as values. The most common terms used to describe feminist identity were equality (17); challenging oppressions (12); autonomy, freedom, and choice (nine); strong (nine); and authentic (five).

All the women perceived feminism as calling for equal rights as individuals and as members of society. Seventeen spoke specifically about equality for women; "feminism means being an advocate for women, for women's safety, for women's rights, 
for equal pay, to not get the crap beaten out of you by your husband when you come

home at night" (michelle, para. 18). Some spoke in less binary terms:

To me, feminism is a way of looking at the world. It means that you recognize that people have different privileges and different oppressions. Not everyone is treated equal or given the same opportunities to vote; to work, equal pay for work; to even choose who they marry, if they marry; to choose if they are going to have children or how many children. It means an advocacy to fight for these issues: for equality, for all sexes, all genders, not just about women and girls. Equality across the board. Feminism is for everybody, right? bell hooks, that's what it is. (frances, para. 8)

Twelve women felt that feminists must challenge oppressive behaviors and decisions,

particularly related to gender norms and employment:

Feminism means everyone is equal, that boys should be allowed to have female qualities and females should be allowed to have boy qualities and not be looked down upon like we are. A strong business woman - when it's a male strong business man, he's considered this great leader; when it's a female strong business woman, she's considered a bitch. I think that's part of what feminism, it's making that bitch identity go away. No, she's just a strong business woman, and a guy is not weaker for crying. (debby, para. 24)

On the other hand, debby also recognized how easy it can be to fall into stereotypical patterns, as she did when she learned that she was going to have a new female boss:

It took a while for her to earn my respect, which I hate admitting. Because I had this pre-assumption about her that's she's going to be this total bitch. So, that was my pre-assumption I did against my feminist values. I associated her as a female bitch right off the bat and she actually turned out to be a pretty great boss. (para. 52)

All four Hispanic women discussed machismo in relation to feminism; nicole spoke about machismo as some people just not knowing any better:

I've been working on calling out things that aren't well thought-out or maybe intended to be complimentary or nice or any level of positive intentions, and calling them out anyway, in a way that's still positive. Because it's not that they are doing something horrible or that they are you know, oppressing me or something. It's just, they don't know any better. For me, it happens with my coworkers and my boss and these people because they are very, very, very, 
very Cuban. So, they are extremely machista. I had never really been around people on a regular basis that were such recent transplants from Cuba. I had been around people who had been there a much longer time ago, so it was always much easier to just kind of dismiss it as a generational thing. Now, it's more like, "No, this is a cultural thing. You have to deal with this." (para. 37)

Some women considered the elimination of any form of oppression to be a feminist goal.

Other women see oppressions as intersecting, but separate:

I would love to see equality across the board. I would love to see everybody who has to fight for equal rights and help each other out. That would be a dream, you know, that would be great if People of Color and gay people and disabled people and feminists and everybody else that feels wronged could all get together and demand equal rights across the board. But that's not going to happen because special interest groups generally stay to themselves mostly. But no, I don't think that feminism and gay rights are equal or are actually interlinked. I think there's just overlap sometimes with certain people. (helene, para. 47)

All the women valued feminism, but three thought that some feminists go too far and too politically correct. When her daughter calls her out for saying "ladies and gentlemen," claudette gets angry and bites back: "Come on off your high horse and stop using feminism as a bat to hit me with" (para, 14).

In contrast to frances, cleo argued that feminism does not mean equality. Rather, "feminism is freedom. For everybody. It's not just for women. It's not just for White cisgender heterosexual women, and I don't equate feminism with equality, nor necessarily with equity, because there's still boundaries with equity. It's just-- it's freedom" (cleo, para, 15). Diana spoke about it as "freedom of choice, freedom to live their happiest most satisfying, truest life" (para, 26). This advocacy for equality and freedom and fight against oppression requires strength.

Feminist identity was described as "being a strong, self-actualized, aware, human being. More than the sum of my parts. I'm not just breasts and I'm not just a receptacle. 
I'm a fully-functional human being" (ella, para. 18). This sentiment was echoed by others: feminist means "being strong and independent. Not relying on somebody else. Not relying on a man" (claudette, para. 32). Feminist identity was also seen as an everyday attitude and behavior: "I try to put it into everything that I have. One conversation with me and you are going to know who I am and what I stand for. I try not to hide that. I try to really be my authentic self with my staff, with my students, with my friends, family. I just really perceive it as a part of me" (greta, para. 14). These values were clearly articulated and important to the women in understanding their feminism. When asked what feminist activities they engage in, 22 women said that they speak up when they hear something offensive, 21 engage in self-reflection, 21 talk about issues, 21 read about issues, 20 vote, 7 participate in marches, and 4 join feminist groups.

Distinct feminist identity vs. feminist values. Interestingly, even though the participants agreed that they met the criteria for the study (e.g., identified as a feminist) when discussing what feminism means to them, five expressed that although they have feminist values, they do not see themselves as having a distinct feminist identity. Some women explained this as feminist values being intrinsic and not something that can be extracted. For example, cindy said, "I don't even think of it as being feminist identity. It's so much a part of the core of who I am and what I am” (para, 16). Similarly, nicole noted, "it's so intrinsically tied into everything else that is important to my sense of self that I don't feel it's important on its own; as its own separate identity" (para, 41). These statements reflect prior research about feminism and the BDSM community in which some submissive women who have feminist values do not identify as feminists (Prior, 2013; Raab, 2013; Surprise, 2012). One reason for this is because of the stigma 
associated with the label of feminism (Surprise). This also supports the findings outside of the BDSM community, that feminist identity and feminist values are distinct constructs (Eisele \& Stake, 2008), that some people have feminist attitudes but not a feminist identity (Ramsey et al., 2007), and that people with feminist values may choose to not identify as a feminist because they perceive feminism as racist and classist (Allison, 1994; hooks, 2000; Hurtado, 1989).

Inability to identify feminist community. Most women (14) consider themselves to be involved in the feminist community in a variety of roles: 12 consider themselves advocates who fight or speak up for rights, four are educators who teach about topics such as consent, communication, and skills (e.g., how to cane someone, slave positions), four are leaders who run or help to run groups or events, and three are mentors. The high number of advocates versus low numbers of other roles reflects the understanding of feminism as something - an attitude, a set of values, a way of living that exists at all times, not just in relation to a role or identity. Even amongst the women

who claimed multiple roles within the feminist community, there was no shared sense of what the "feminist community" is, what it looks like, or where to find it: "I'm not sure who the feminist community is. I think it's, you know, very individual" (gabrielle, para. 75). Although feminism, feminist values, and feminist identity are important, these women are not as invested in a feminist community.

\section{Complexity of Submissive Identity}

Submissive identity is complex. Although there are some common elements across all D/s relationships (i.e., consensual exchange of power), there are levels and 
forms of power exchange, roles, and communication. Furthermore, submission itself can mean different things. These women are submissive differently and to different people.

Submission described as values. The most common terms used to describe submissive identity were service (14); choice (9); trust (9); communication (8) and consent and negotiation (6); authenticity (6); and strong (6). In general, the women spoke about their submissive values as being "the same as anybody's values" (gabrielle, para. 39) and as the same as their feminist values. Fourteen women emphasized their need to provide service to a Dominant partner(s). For instance, frances spoke in terms of household chores and doing things that her Dominant did not like to do. However, she also shared that when she is not available, then her Dominant will do things himself, and sometimes, whoever is able to do something better does it.

Although she enjoys service, jess does not want to feel domesticated (e.g., cooking, cleaning, tending to family); debby likes to please people; making someone happy makes her happy, and she finds it easier to do things for someone else than for herself. She feels fortunate when she has a partner who recognizes this and uses it to help her grow as a person.

Sometimes the submission that women give to their Dominant is different from the submission they give their friends and community:

I'm not really sure how to explain it. It would be different because it's not my Dominant. If there's someone I view as a dominant person - and sometimes that just brings that role out in me - I still have the ability to say, "No, I don't agree" or whatever it may be, which is different than my D/s dynamic with my Dominant. (lili, para. 59)

This is because in most cases, lili would defer to her Dominant for answers and decisions but would not defer to her friends in the same way. Sometimes, her Dominant struggles 
with her submissive nature: "It's hard for him to see me in a submissive role to other people, even if it's not intentional, because I am his submissive, but he understands it's the type of person I am and sometimes it's unavoidable" (lili, para. 63). This was one example of the challenge that the women face in creating balance between what seems natural and/or desired and what seems practical and/or permitted.

Five women spoke about the challenge of anticipatory service, where they do something for their Dominant or environment before/without being told:

I do a lot of anticipatory service, and so I have to struggle to remember that it's not service if I choose it. It's service if it's something that is desired by the other person. Not just because - I can't pick and choose, like, "I think this is great service, so this is what you are going to get." That has been a stumbling block for me. To get to that point and say, "Okay, so maybe I don't perceive that as service, but if you perceive that as service, then that is service." (cindy, para. 61)

Four women spoke about giving too much. When katia first entered the BDSM community, she dove in. She still identifies as Leather and as service-oriented, but she has had to pull back because in serving others, she was neglecting herself. Others had similar experiences:

You know when your jug is empty and you have nothing left to refill it with. That's the beauty of a D/s relationship. I can pour out, pour out, pour out, but within that relationship, it's constantly pouring back in, so that lets me keep pouring it out. (cindy, para. 47)

Michelle also spoke about her struggle to do things for herself, instead of spending all her time and energy on other people and her communities. She struggles with this every day, and she feels fortunate that her Dominants help her to realize that she gives enough, and does enough, for others. This self-awareness helps the women to make informed choices about the submission and service that they provide. 
All the women perceived submission as a choice that they make, and nine were intentional in using the term. Some choose every day to submit to their partner, or before each D/s interaction; some made a choice once; and some struggle to come to terms with the choices that they, or their partners, make. For ella, submission is "a choice, number one. I choose to be submissive to very specific people. I'm not submissive to anybody else. My submission is a gift that I give them, just like their Dominance is a gift that they give me" ( para. 48). Five women described the choice as a feminist decision, "there is something freeing in that choice and something that is inherently feminist about it because I chose it. It wasn't forced upon me at any point" (greta, para. 173). The women felt that trust and communication were essential in their choice to submit to a Dominant partner(s).

Nine women spoke about the importance of trust in their D/s relationships. For example, julia said, "I have to be really certain that I trust you're going to make the right decisions, because if I don't, then I don't need you to do that. I can do it for myself"' (para. 213). Without trust, they felt like they would not feel safe to submit to a partner, physically, emotionally, or psychologically. The women need to trust that their Dominant(s) would respect their negotiated limits and recognize that even within their D/s dynamic, all partners should be valued, appreciated, and respected. Trust was established through communication, key for any successful relationship.

Eight women mentioned communication specifically related to D/s relationships, where things can go horribly wrong - physically, psychologically, emotionally, or socially. Communication was considered critical at all times, not just when negotiating consent: 
It just sounds really blasé the way it ends up getting said as often as it does, but for me personally, it's not even just communication to make sure that we are both doing what we want to do; it's more. There needs to be feedback and there needs to be a whole, like, post-orgasm "Let's have an entire conversation about what just happened here" conversation. Like, "we are going to dissect everything that just happened and I'm going to let you know, I liked x, y, and z. This could have been different for me. What was this like for you?" (nicole, para. 58)

Some women struggled with the level of communication required within $\mathrm{D} / \mathrm{s}$

relationships and the vulnerability is required:

There are four levels that we let people in at. We let them in through physical touch. We let them in through communication back and forth. We let them in through an emotional connection. And then we kind of let them in - the last one for me is like - letting somebody into my head. Like, I would have sex with someone well before I would ever let them into my head. Right? Because I'm much more comfortable on that physical connection. I can have an emotional connection with you, I'm fine with that. For me, it's like that mind connection is where you hit that spiritual connection and it's like, that's where I really let you into me, and so that's, for me, that's the hardest one. So submission for me was making that decision that - yeah, you really are going to let this person in, and not just to the good but, you know, the good, the bad, the ugly. (cindy, para. 58)

Along with trust and communication, consent was a crucial aspect of D/s:

I would say consent above all else is always a value for me. Whether that's with a vanilla partner or with a Dominant partner or another submissive - anything, anything that I do there has to be consensual and I need to hear it and I need to be asked for it, or we are not continuing. That's on both parties - for me to ask my partner and for my partner to ask me. (greta, para. 73)

Trust, communication, and consent were often discussed in relation together. To have a successful and satisfying D/s relationship, the women needed to feel like they can safely communication their wants, needs, and fears with their Dominant, and vice versa. They also need to trust that their Dominant(s) will understand and respect the limits that have been negotiated. Self-awareness was an important part of the women's ability to establish communication, trust, and consent. 
Six women spoke about the importance of self-awareness and being authentic,

both required and allowed the women to be strong:

Really knowing who you are at your core and being really comfortable with it, just may be where the feminism comes into it. I think it's just so important for us all to really know who we are, where we fit, you know, how we identify, and be very true to that, very authentic and not let anybody pull you away from that authenticity. So it kind of all comes back to this inner authenticity. (ophelia, para. 90)

Six women spoke about the need for submissives to be strong. For example, iris

perceives the submissive or slave as running the show:

We are the strength behind the partners that think that they are running it all. It's not true. They are not. We've taken this back-step to help put them up on the pedestal. We are happy there. We don't need reward, we don't need the show, we just need the love from them. (para. 41)

A part of this strength includes the abilities to be very patient, understanding, and accepting. A submissive needs to "put aside your emotional instinct with your partner, try to understand where they are coming from; be the one to step above it all and try to communicate" (iris). Some expressed the need for strong Dominant partner(s) who could work with them to maintain their D/s power exchange dynamic:

I know I am incredibly stubborn. And the reason that my relationship works is because [Master] is more stubborn than I am. When you boil it right down to the bottom layer, that's what it is. But for me, that's incredibly important, because otherwise I steam roll over the top of people. If I don't feel like you can stand up to me and hold that line, then I'm just going to go on and keep going. (cindy, para. 61)

Irma echoed this sentiment:

You have to be a true, true Alpha to get me to submit or else - it ain't going to go well. You know, as soon as you stop being an Alpha - I'm gone, and I did that with my last partner. She stopped and it's like, "Nope, bye" because I need an individual who can stoke that little thing inside of me, you know - it just completes me. And when it's not there, it just sucks. (para. 78) 
Self-awareness, authenticity, and strength, combined with trust, communication, and consent, formed the foundation of the women's ability to provide submission and service in healthy and satisfying ways.

Submissive in different ways and to different people. Participants experienced and expressed submission in different ways. Submission is not restricted to romantic or sexual partners. When asked to whom they are submissive, 13 identified as "only submissive to a Dominant partner(s)", but seven identified as "submissive to a Dominant partner(s) AND to people I care about (friends, community)", and 3 as "submissive in general (with friends, at work, etc.)". In terms of D/s relationships, 12 were submissive to one partner only, four submissive to multiple partners, two submissive only during play, and one was unsure; the other four women all reported that they are submissive to one partner but qualified their response. The comments included: submissive "as so inspired," "to community/ service," and "starting other relationships now". Thirteen participants reported that when in a D/s relationship, their power exchange dynamic is " $24 / 7$ " or all of the time, while seven reported "as often as possible, given the constraints of life" and three reported "only when in private or with close friends." No participants reported their D/s dynamic as "only in the bedroom" or "once in a while to spice things up."

One participant, opal, identified as a sexual submissive and a masochist with her primary Dominant:

I try to be a pleasing submissive. I'm also a sexual submissive, and I'm a masochist. And so I submit when I am being played with, and I need that power exchange. What I see as my submission is a power exchange going back and forth - this power from a Dom and taking my power and giving it to him. Not that I can't still do things, but then I give that power. I'm doing more and more of that today than I was before. I've been fighting it for a little bit, but it feels very, very 
good to get into that pocket of submitting to somebody and submitting to a particular special person. (para. 66)

This submission requires sexual and masochistic activity. However, greta's submission depends on who she is with, or what roles she and her Dominant(s) are enacting. One of opal's main partners likes two specific roles. The first, usually occurring in public, involves protocol for behavior and requires her to have a service-orientation, and she will probably get beat during a scene. The second occurs in private play, where she tends to be more bratty and engage in her little (younger than actual age) identity.

Submission was discussed as needing different things with different moods:

It's freedom. It's being able to just let go and relax, and let go of the of the tension and responsibility of handling things, you know. It could be play, it could be I really need to get flogged, or, you know, I want to get tied up, or it could be, 'Can I just sit at your feet for the next 45 minutes while you stroke my hair?' I just need to let go; it's meditative almost. It sends me to a meditative space. (diana, para. 59)

All the women identify as submissive in the context of D/s relationships and most perceive of themselves as always being a submissive, even when not in a relationship.

For instance, ella spoke about her submissive identity as existing beyond a sexual or romantic relationship:

It's not just male/female relationships. It's a world relationship. It's a family relationship. It's a co-worker relationship. I'm not afraid to say exactly how I feel, but I always look to see how other people are feeling, making them feel comfortable, because that's important to me, getting that feedback from all sorts of parts of my life. (para. 47)

Most women identified as a submissive even if not in a relationship:

If I was single, I would still be $a$ submissive, but I would not necessarily be submissive, because not just any Dominant could walk up and do something because they would get hurt. Whereas, in a relationship it's different. She does have the right and the ability to do what she wants in those situations as long as 
everything is done within our pre-determined, or pre-negotiated rules, so to speak. (helene, para. 56)

Submissive identity is sometimes restricted to romantic relationships; cleo is not in the $\mathrm{D} / \mathrm{s}$ closet, but she does not talk about it outside of the relationship: "if someone were to ask me my identity, I would say woman and White and feminist, but I wouldn't say submissive" (para. 48). Similarly, while julia considers herself service-oriented (e.g., she does the laundry, fetches water for her partner), she recognizes that her submissive identity is only salient and important when she is in a D/s relationship. Otherwise, she rarely thinks about being a submissive. When not in a D/s relationship, julia's manner of interaction is closer to, "Fuck you, get your own fucking water" (para. 316). Submission for both women is rather narrow compared to other women's, particularly those who identify as slave.

Six women identified as a slave, and several more provided reasons for why they would not choose to be a slave. For gabrielle, the difference between a submissive and a slave is a clearer distinction than it is for others:

I've heard people say, "Well, it's a really grey area." For me, it's not grey. When you are a submissive, each time somebody asks you to do something, you make a decision. You decide whether or not that's going to be something you do. I feel that as a slave, you decide up front that you are going to do whatever your Owner or Master or however you want to say it, asks of you. That's the defining area.

When you are a slave, you have already built up that trust, and you've already gone that far in your relationship that you know whatever that person asks of you, it is not going to be to your detriment. So, you never have to question, "Am I going to do it?" I'm sure there are some submissives that are like that, too, but I think, on the whole, as a submissive, you get to choose over and over again. Slavery, to me, is a no-brainer almost, because it's already been pre-determined. The power exchange is already mapped out, so there's no struggle. There's no, you know, power play, struggle going on. For me, it's a very soothing relationship to have. (para. 77) 
This understanding of a Master/slave relationship - the trust required and the expectation

of obedience without question - are two reasons why cindy does not identify as a slave:

For most slaves, their default position to their Master is obedience. Master says; you obey. That's a default position. And that is not my default position. My default position is always "who, what, where, when, why?" So, if I'm going to receive a command, then my response is not going to be obedience, necessarily. It's going to be further information seeking: "who, what, where, when, why?" (para. 51)

For irma, a slave identity does not work because she will always find loopholes and exit doors: "I like giving up control to a person, but I'm wrapped too tight to give up total control" (irma, para. 78). Irma also recognized that individuals continue to develop as people. Perhaps her submissive identity could also develop to encompass a slave identity, if she found a partner who was strong enough and who she trusted enough to give up total control.

\section{Women Learn to Accept and Reconcile Identities in Different Ways}

There was a general sense that the women's feminist and submissive identities do not inherently conflict with each other. However, many women recalled instances when they did struggle with their identities, and when their values did seem to conflict. These instances often related to overcoming societal expectations of "normal" sex vs. "kinky" sex; feminist attitudes and values that frame BDSM and D/s as violence and abuse; and setting aside a desire to speak, debate, or ask questions of their Dominant partner, when it interferes with a sense of submission.

For some, it was impossible to distinguish their identities well enough to discuss them as having separate sets of meanings and values. Identities were "so intertwined that it's hard to separate one from the other" (claudette, para 132). For gloria, "there's never 
been a time that I've thought, 'Okay, as a feminist I should do this. As a submissive, I should do that.' Maybe that's because, in terms of my identities - like I am a submissive - it's just something I am" (para. 171). For these women, their core values are consistent across all identities. In a follow-up question, all participants agreed with this statement:

Your core values are always a part of who you are, threaded throughout each identity like a tapestry. Sometimes, certain colors (identities/values) are more visible, but the other colors (identities/values) are still there in the background. In essence, your values are consistent, regardless of what you're doing, where you're at, or who you're with.

This was an important factor in understanding why some women perceive their identities as not conflicting: they see their values as constant and as supporting whatever role they are in. Yet, participants illuminated their perception of feminist and submissive identities as simultaneously supporting and conflicting with each other. Eight women perceived their identities and values as sometimes conflicting with each other, one as conflicting, and 14 as not conflicting. Anecdotes of supporting identities included submission as a feminist choice and feminism as accepting women's agency in choosing to submit. Anecdotes of conflicting identities and values included the internal struggle to accept and reconcile submissive desires with feminist values of equality, and experiences with other people who have negative perceptions of feminism and/or submission.

There was a general understanding that in choosing to be submissive, women enact their feminist identity and values; debby shared, "one of my feminist values is the right to choose, so as a feminist, I can be a complete submissive because I wasn't forced into it. I choose it. This is my choice and I believe feminism is all about the right to choose" (para. 97). Others agreed: 
there is something freeing in that choice [to be beat] and something that is inherently feminist about it because I chose it. It wasn't forced upon me at any point. Like I said, consent is very important, both with myself and the scene that I'm a part of" (greta, para. 137)

Another woman noted that it is important for submissive women to understand feminism and to value their ability to make choices:

I can only be submissive because I'm a feminist, because I believe in choice. Without that background, without that knowledge of feminism and what some of today's paradigms are, and without knowing more completely who I am, I wouldn't be able to release or reveal that submissive part of me, I would still be blocked from that. (michelle, para. 105)

Although some women spoke about feminism and submission as supportive from an internal perspective, this was not the case for everyone. Some women whose identities and values now exist in harmony experienced conflict in the past.

Some women struggled to become comfortable with their submissive identity. This often began before the women even knew what submission meant. On average, participants recognized their submissive identity at age 24 and entered the BDSM community at age 29. However, most women experienced submissive desires or behaviors at a much earlier age. They discussed their initial experiences with submissive desires and behaviors in four distinct ways: as inherent or always existing (six), as a part of becoming sexually active (five), as beginning with erotica or pornography (seven), and as unknowingly played out in their intimate relationships (six). When discussing the last two ways (erotica and pornography and unknowingly in relationships), women shared experiences of struggle. 
Participants learned about submission and BDSM through books, videos, and television. Seven recalled specific memories of being turned on, particularly while reading erotica and watching movies. For instance, ophelia first experienced submissive desires through erotica when she was 13. She expressed concern that the types of "heroes" in her books are not the nicest people:

Probably even before I was exploring sex myself. I'm going to say like 13. I was reading a lot and my mom had trashy romances, and I remember always just being incredibly aroused with the whole like, pirate in control-scenarios, you know. Those kinds of things just always did it for me. So, I knew even before, it was just - that was what melted my butter. I just always naturally became interested in that kind of a personality, to my detriment, because sometimes they are not the nicest people but, that always did it. That always melted my butter. (ophelia, para. 76)

Frances also recalled reading her mother's romance novels at age 12 or 13 . While she accepts her submissive identity and desires, she is concerned about what such books, images, and desires can do to a young person who is discovering her sexuality, especially if living in an environment where sexuality, sex, and kink are taboo subjects. She worries about how young women will develop as healthy individuals, with healthy relationships if they cannot speak openly and learn about their desires and issues of consent and communication with knowledgeable adults:

I really got turned on by some of the, you know, aggressive dominant male figures and the - not passive, but definitely the more submissive - female "heroines" I'll call them. Looking back, I think, "Wow, there are a lot of issues in what turns me on". I still get turned on by it. I still like some BDSM porn, stuff like that. In my head, it's all consensual, but in reality, if I were the 'heroine' of some of those books or the actress in the porn movies, I think it might be very different, because there was no negotiation about what is consensual in those stories. In my head, when I'm reading it or looking at it, I have this - I don't know if it's a dissonance or just like this willing suspension of disbelief, that what's happening is not really going against anyone's will, and then I can enjoy it. (frances, para. 45) 
Six women experienced what frances is afraid of, in relationship after relationship, where one or both partners engaged in forms of $\mathrm{D} / \mathrm{s}$ power exchange without awareness, negotiation, or emotional support. One descried a previous relationship:

It scared me a lot. It made me feel wonderful a lot. If the person wasn't trustworthy, it made me really miserable. But I realize that I would sort of secretly submit in relationships, where I would act a little bit more submissive, and they would bring out their dominance, and then I would actually pretend sometimes that they were making me do something that they weren't making me do. But I didn't know what that was. I didn't know where that came from, you know? Later, I knew that I was still in what one would call a vanilla relationship, but it wasn't, it was a man having control over me, but we never had the negotiations, so when I realized that negotiations are normal, and expected and really respected in the BDSM world, then I said "Okay, now I can let go of this, now I can be there," and so I was - and that was about 20 years ago. (opal, para. 94)

Claudette's marriage was falling apart when a friend suggested that a part of the problem might be due to inadvertent $\mathrm{D} / \mathrm{s}$ desires:

It was so simple. He said "You are both submissives and you are trying to out submit each other," and I said, "Huh?" and he explained it to me. I thought at first he was crazy, but the more he talked, the more it made sense, so I went home to my husband at the time, and I said, "I've got an idea: you be the Master, I'll be the slave. It will all work out and be hunky dory." And he said, "No, you are twisted and sick and perverted. That's never going to happen." (para. 112)

Frances' identities conflict when she is given an order at a time when it is not convenient:

Sometimes they might conflict like when my partner is like, "I want you to do this right now," and I'm like, "I can't do this right now because I'm in the middle of something else, so can I do it in five minutes?" He's okay with that, but the attitude that I get in my voice - my tone of voice - I have to be careful of. Yeah, they are separate, but they support each other. They make each other better. They question each other. (para 57)

Frances also spoke about an ongoing struggle to reconcile what "gets her hot" if she is not certain that it was consensual. She was one of the women who first experienced 
submissive fantasies while reading her mom's romance novels. A part of her feels guilty for liking some pretty aggressive pornography, and she wonders if a "willing suspension of disbelief" is sufficient, to consider herself a decent person, or if she should stop watching the films so that there is a smaller commercial market.

Cleo also struggled with desires and issues of consent, related to her love of consensual non-consent and rape fantasies and having been molested as a child:

Sometimes it pops in my mind, "Oh, this is kind of fucked up," because I don't believe that rape is okay, ever. But I go back to, "Okay, this is my desire, this is what I want, this is what gets me off," so it's okay. (para. 78)

Iris spoke about reframing her perception of submissive identity:

For a long time, I perceived that identity as one of my weakest ones. It was something very difficult to deal with. It was something kind of really odd, too. I felt like using the term "being submissive" meant you were a weaker being. That, in itself, has taken a lot to get around, so that's really why I don't even use the term slave or submissive, which is why our dynamic is King and Queen. How I identify it now is that I identify as a Queen. I am the Queen of my house. He is the King of our house and we are taking care of our kingdom. (para. 35)

Having a foundation of self-awareness, authenticity, strength, trust, communication, and consent is particularly helpful for the women when they struggle with submission.

Six women mentioned the importance of learning how to relinquish the need to argue, question, or provide insight, unless it is sought. Opal spoke about consciously choosing to defer to her Dominant's wishes. As an intelligent woman who enjoys playing devil's advocate, she likes to debate, but she found that debating with her Dominant has a negative impact on their D/s dynamic. She shared, "I usually always followed what he wanted, but had to put my two cents in. And now I realize that that's really getting in his 
way of feeling my submission" (opal, para. 82). She struggled to keep her opinions to

herself, but finds it rewarding, as it allows their D/s to be felt more strongly.

Gabrielle discussed how she handles situations where she does not understand

why she is being told to do something or when she thinks there might be a better way:

I guess it depends on what it is. Normally, I would do it first and then possibly ask for equal footing later, and maybe discuss it, if it was something that important to me. In general, if He asks me to do something, He's got a pretty good reason behind it, and so if I feel like I can do it better, that's a tough one, because how do you say to someone who owns you, "I can do it better?" In that instance, I'd probably do it to the best of my ability and then go back and say, "I did what you wanted, but I added this, because it would be to our benefit" and He would be okay with it, because He trusts me. He trusts me to make the right decision. (para. 79)

The women work through these challenges within their D/s relationships through communication, reflection, and sometimes changing their behaviors.

Joan spoke about "an inner battle to kneel at his feet and be quiet," which she has learned to get better at (para. 57). A strategy for getting better was to dress a particular way. As an exhibitionist, joan finds that when she covers her body with clothes, she behaves more appropriately than when naked or scantily clad. Opal spoke about the challenge of not debating an issue or asking questions when given an order:

I can say 'Could I give my opinion about this please?' And I've been told flat out 'No' a couple of times in the last couple of days. It's like, 'Okay,' and that's been interesting, how nice that feels" (para. 86).

Opal is still learning how to deal with being told no but appreciates it as "direct

communication" with her Dominant. She also spoke about balancing vanilla and D/s:

When there's too much vanilla life going on, I fight submission. I think I have to grab the reins. Again, in my home, there's a vanilla atmosphere, and that makes it very difficult for me to give over when it's time. I'm in a 24/7 relationship and yet, 
I have to make so many decisions, and it's hard to go back and forth for me. I'm feeling like I really am opening my heart and opening myself up to submission, that I knew I needed a while back, but have in the meantime fought so much that I'm frustrated. (opal, para. 72)

These stories demonstrate the struggles that women have to accept and navigate their submissive identity and desires, particularly when they seemingly conflict with their own feminist values of equality and freedom, and when they do not fit in easily with "vanilla" life. The women also struggle with external issues and entities.

Many of the conflicts the participants experienced involved interactions with other people; with their expectations of normative sexuality, which the women often internalized as negative feelings about their identity or desires.

Greta recalled a relationship she had while in college, during which her partner called her BDSM and submissive desires weird and freaky. At the time, greta felt like, “this is weird, this isn't something I should talk about, this isn't something normal, this isn't what I should want" (para. 142). Years later, greta enjoys her BDSM and submissive desires and would not be with a partner who thought them weird and freaky. Debby spoke about prioritizing her feminist identity over submissive identity when spending time with her mother, who is a feminist. Debby would act more in line with her feminist identity, out of fear that her mom would become upset.

Other conflicts between the women's' feminist and submissive identities and values related to how the BDSM community and the feminist community accept or reject the identities. Participants had different perceptions about whether the BDSM community accepts feminist identity and values and whether the feminist community accepts submissive identity and values. 


\section{BDSM Community as Generally Accepting of Feminist Identity and Values}

In general, participants perceived the BDSM community as accepting feminist identity and values: 13 perceived it as accepting, seven as somewhat accepting, and three were unsure. Because of this, many felt that their identities and values supported each other and that they did not need to prioritize one identity over the other when in the BDSM community.

Lili believes that the BDSM community accepts feminist identity and values; that "we are a pretty accepting group of people for beliefs and how we view and see and do things" (para. 104). Irma agreed with this sentiment, stating that the BDSM community accepts feminist identity and values because there are women at the Dominant Roundtable and at the Dominants Breakfast. In these ways, "She has equal access, and what she has to say is valued. And they are not patronizing her or anything else" (irma, para. 136). Irma referred specifically to Dommes and to events that are designed to promote communication amongst dominants. Lili and irma's perceptions conveyed little nuance in terms of the broader community. Although 13 women said that the BDSM community does accept feminist identity and values, ella's response of "in general" (para. 86) is a better representation of the women's overall perception.

Three women spoke about the difficulty that dominant women (Dommes) experience in receiving respect, compared to dominant men:

Dommes are given respect, but swear to the Gods, they have to prove themselves more than Dominants. If somebody can come into the community and say "I'm a Dominant," they are given that Dominant status. A Domme comes in and says "I'm a Domme," they have to prove they are a Domme... and God forbid they find somebody they want to submit to a little bit or bottom for. Holy crap, it's just like they have to start all over again. (joan, para. 117) 
Therefore, joan perceived the BDSM community as somewhat accepting of feminist identity and values. Contra joan, claudette and iris perceived the BDSM community as accepting feminist identity and values only in people who are seen as strong:

I think that they accept feminists if they are Dommes. I don't think they accept feminists if they are submissives, because I think they perceive women - they respect them if they are strong, if they are dominant. I don't think they respect feminist submissives because they want submission to be more weak. They want girls to be girls, littles, dependent. (claudette, para. 149)

Claudette described the BDSM community as accepting feminist identity and values only in individuals who should be strong, in a context where submissives should not be strong. Iris echoed this sentiment in relation to slaves:

I don't know - the community, yes, but you'd have to be really specific with that because there are people that believe slaves are doormats and they probably wouldn't be so accepting if a woman [slave] was saying "that's not how you do things" or "that's not right". Some people are into that, I guess, and some people really like that, for women not to speak up for their own rights or where they should be, but I guess it depends on what piece of the pie you are looking at. (iris, para. 76)

Ophelia agreed with the other women, suggesting that feminism is probably accepted in every role except for submissive females, who are seen as passive:

You are not supposed to speak up for yourself. You are supposed to be a doormat and God, you know, your Dominant is all God and can do no wrong and God forbid you should stand up for yourself. Yeah, I definitely get that vibe a lot. (ophelia, para. 112)

Ophelia's perception hinges more on gender than on role. She believes that feminist identity and values are accepted from a male submissive, as he would be seen as supporting his Dominant or Domme. 
Frances perceived the BDSM community as accepting some aspects of feminism, such as the right to make decisions about your own body, or your partner's body, and the right to speak up and engage in activities. However, she views those feminist values to be different from and more widely accepted than feminist identity:

If someone was actively a feminist and advocating and out loud, I think it would depend on who the person was and how they did it. I think that there is, you know, some judgement within the kink community, because the kink community is no different from the general community, in that feminism has a bad reputation for some people. They think of it as, you know, socially or politically correct, always causing problems, always blaming people for oppressions. (frances, para. 73)

These stories illustrate that the BDSM community is perceived mostly as accepting feminist identity and values, such as freedom to choose D/s, communication, and informed consent, but only to a certain extent and not by all members and groups.

\section{Feminist Community Not Very Accepting of Submissive Identity and Values}

In general, participants had much stronger opinions about the feminist community's acceptance of submissive identity and values. Only two women perceived the feminist community as accepting submissive identity and values, four as somewhat accepting, 10 as not accepting, and seven were unsure.

Many women were adamant that the feminist community does not accept submissive identity and values, or more broadly, D/s relationships. Some responses were clear and simple: "No" (gloria) and "Fuck no" (joan). Joan continued:

It's a battle. When I actually sit with a bunch of feminists at a table and talk about it, and I have to remind them that old school feminism gave me the right to make that decision. But "Why would you do it, because you are bowing down to a man?" But what I do notice is that if you bow down to a woman and you are a woman, it's okay. It's not as okay, but it's better. It's the whole man thing. (para. 135) 
Claudette echoed this sentiment and recalled working at a call center for women who had been abused. Her colleagues could not understand or accept why she would choose to kneel before a man; they could not separate $\mathrm{D} / \mathrm{s}$ from violence and abuse. Cleo perceived the recent focus on consent as being a divisive factor in some feminists' resistance to perceiving D/s as acceptable, "it's hard for feminists and people in general to understand that people can consent to - fake rape, let's say - can consent to having age play, no matter how feminist or liberal they say they are (cleo, para. 94). This is also why michelle believes that most communities, feminist or not, do not accept $\mathrm{D} / \mathrm{s}$ as anything other than deviant:

Most of them can get behind a little role play in the bedroom, but I think that particularly feminists - or maybe not particularly feminists - think that submission is viewed as a defect in our society and even more so in the feminist society because in order to create the awareness that women were not treated equally, they had to really fight against any piece of themselves that might tend toward providing some of the submissive type things. Qualities like service to others and things like that. I think that they saw it as flip-flopped and that the only way they could do that was to advocate and to be very vocal and to sort of take the femininity part of feminism and deny it, until people as a whole were more willing to acknowledge that there was more to it than just the femininity piece and that women were equal on all levels and equally capable on all levels. (para. 126)

These stories speak to participants' experiences and struggles to find acceptance in various environments, including work, families, friends, and feminist groups.

Four women perceived the feminist commuinty as somehwat accepting of submissive identities and values and 11 were unsure. Lili and frances expressed a common perception: that it depends on how individuals or the groups in the community view feminism:

The feminist community or the feminists who think that people have the right to their own agency and to understanding their sexual identities, behaviors and desires - yes, I think they accept submissive identity. I think it comes down to, do you really think about why you desire BDSM? Why you desire submission? Is it healthy? Does it come from a place of pathology where you have, you know, a 
history of abuse or some other kind of violence or illness that makes you want to do these things? Because for some people, it can be abuse. That's the way they set it up. But I think for other people, even if they have had trauma or abuse or violence in their past - just because of that, that doesn't mean you go into BDSM from a place of illness or abuse or victimhood. I think a lot of it comes down to, "Do you think about it? Do you knowingly choose it?" and that's your agency. (frances, para. 81)

In addition to reflecting on why they engage in $\mathrm{D} / \mathrm{s}$ and if it is healthy, some women sought feminist groups that accept D/s.

Cindy recognizes that the broad feminist community is too large for a simple "yes" or "no" response to whether it accepts submissive identity. However, the feminist

community in which she engages consists of groups that accept BDSM as a viable choice that someone can freely make (e.g., Lesbian Sex Mafia, The Hard Pink Sisterhood, Women of Leather Florida). These are "very strong feminine presence groups and they are very accepting of D/s roles. And whether that's women in the dominant world or women in the submissive world, it doesn't matter" (cindy, para. 107).

\section{Being Out as Feminist; Being Out as Submissive}

Most women stated that they do not hide their feminist identity; rather, they are "out" as a feminist: 20 are out to their immediate family, 20 are out to their vanilla friends, 19 are out to their coworkers, and 17 are out to their doctors and nurses. Many women valued authenticity and being comfortable in their own skin. However, most also discussed reasons for choosing to hide or downplay parts of their identities, values, or preferred behaviors.

Four women hid their feminist identity or values at work. Greta, who works in higher education, was looking for a job in a private school, due to the silencing that 
occurs within the public school where she worked (e.g., not being allowed to have certain things in her office or have political discussions with students). The women also spoke about not speaking up when someone was being oppressed or discriminated against for three reasons: speaking up can be exhausting, speaking up can be dangerous, or the women are actively engaged in the oppressive behavior. Frances spoke about exhaustion:

I don't always have those conversations. For example, if I am invited to a baby shower for a friend, then sure, maybe I'll say it, but if it's a family member, I might not even go there. Like, you know, what can I do, to really make a difference? If I think it will be helpful, productive: great, I will, but I can't do it all the time: it's exhausting. (para, 74)

Irma spoke about fear and danger:

When fear comes, yes, because I opened my friggen' mouth in a doughnut shop at 3:30 in the morning and there were three White guys there complaining about the Asian doctor being dragged off the plane and he probably deserved it because he was a bad doctor anyway, and I opened my mouth and said, "So that person is allowed to be beat up because they did something bad 10 years ago?" And then the person turned on me and he's like, "You people." And that's when I promptly shut my mouth 'cause I realized: three white guys, me. It's like: oh, yeah, and I shut up 'cause of fear. (para. 52)

Julia spoke about participating in activities that go against her values:

Where you have friends who say, like stupid shit, racist stuff, sexist things and you play along because, like, okay, it's funny. You can be ironic about things to a degree, and maybe you shouldn't be, and maybe I'm just permissive to some extent. Where like, I get that it's not cool, but I'll participate in that conversation sometimes. (para. 85)

These stories about hiding or downplaying feminist identity and values when at work, when afraid, when exhausted, and when involved were rare occurrences. The women shared many more stories about hiding or downplaying submissive identity. 
Participants hid or downplayed their submissive identity with certain people or in certain environments: nine are out to their immediate family, 14 are out to their vanilla friends, seven are out to their coworkers, and 13 are out to their doctors and nurses. When discussing reasons for hiding or downplaying their submissive identity, 13 women said that they hid it from their family members, coworkers, and supervisors to avoid potential negative consequences and 10 to avoid awkward conversations or making other people feel uncomfortable.

Debby said that she hides her submissive identity from her parents, but that her brother knows a little bit about it because he's married to one of her best friends. However, three months after the interview, debby gave me an update: she told her mom about being polyamorous and submissive. Debby's mom demonstrated easy acceptance of both identities, except for asking "You don't do that choking stuff, do you?" Debby does enjoy choking, but because the question was prompted by concern for debby's safety rather than judgement, debby lied, "No, of course not." Opal mentioned how difficult it can be to hide the submissive part of herself, particularly in her own home, "I'm not comfortable and so I struggle with that a lot. So I'm trying to find ways to indicate 'Yes, Sir,' without saying it" (para. 74). The women's need to hide this part of themselves is frustrating and painful, especially related to the women's need to be authentic; however, they will continue to do what they feel is best for the other people in their lives. Fortunately, not all of the hiding is so difficult.

Iris believes that her submissive identity does not have a place at work, as there is no one there that she would choose to serve: 
At work, you wouldn't find all of that patience and all that, because there's no one there that I'm trying to lift, in any which way or form. That kind of gets put aside. Unfortunately, in the workplace I've found that all women have to be a little bit more masculine. (para. 53)

While Iris sets aside her submissive identity at work, michelle expresses her identities and values differently in different environments:

Sometimes I express them by being bossy as hell. But the intrinsic values of caring for others and wanting to take care of others comes out differently. It comes out as being bossy and demanding and controlling sometimes in my vanilla life because I'm the person that's in charge of everything and so it almost like a set-up, like that's how I have to come across. The values of loving and caring for people and advocating for people and wanting them to be healthy and happy and all of those things. None of those values are any different between my submissive self and my vanilla self or my feminist self. They are all the same value (para. 98)

Gabrielle expressed well what many women discussed in terms of not wanting to make other people uncomfortable:

I don't hide, or set it aside, but I do alter my gestures when we are out in public, because it's not everybody's cup of tea and it's not up to me to put it out there for people who are not interested. So it doesn't change me, who I am, but it makes other people feel more comfortable if I don't. Maybe I'll say "Master" when we are at dinner or, you know, there are certain protocols that we have, that when we are around people who are not in the Lifestyle, that I temper, so that it's not obvious. It doesn't change me, intrinsically, but do I hide it a little, to make other people feel more comfortable? Yeah. (para. 59)

Like gabrielle's desire to reduce discomfort, helene hides her submissive identity or activities to avoid awkward conversations, and for potential loss of opportunities. She has disclosed some activities related to her submissive identities to doctors, because the activities cause bruises and other marks on her body. However, she only discloses when necessary; otherwise, she said "I don't want to deal with it" (helene, para. 80). She is also 
interested in running for local government in a few years, and public knowledge of her involved in BDSM or D/s can be used against her.

Several women spoke about how freeing it is to spend time with other kinksters with whom they can be their authentic selves and where "it feels so good to be allowed and expected to have some protocols" (opal, para. 117). Nicole would like to have more friends with whom she can be herself:

Oh my God, it's the most annoying thing that I'm experiencing right now in relation to kink and poly and all of these things. I desperately want to be able to have these kinds of conversations and be part of this kind of active, in-person community because I am a talkative person. I like talking about things, and talking through them and kind of seeing if the way that I think about it is the same way that other people think about it. And if not, how do they think about it? I like the different perspectives and I don't have that right now. (para. 97)

In sharing these stories about hiding or downplaying their identities, values, or behaviors, participants spoke about choosing to make other people comfortable and avoiding potential consequences in employment, family, and society. In doing so, they demonstrated a level of self-awareness while covering up a part of who they are; some women found this painful, as it conflicts with their desire to be authentic, while other women were not bothered at all because it does not impact the core of who they are.

\section{Discussion}

Women's identities and values as feminist and submissive intersect, and sometimes create polyrhythmic realities (Sheared, 1999), where the women do "different, seemingly contradictory things, simultaneously" (Brown, 1989, p. 929). For example, many of the participants advocated for freedom, equality, and women's rights to be heard, while consensually yielding authority to a Dominant partner, to make decisions for 
them, command them to be silent, and even tell them how to dress or interact with other people. Within the intersecting borderlands of feminism and submission, these women have experienced conflict internally (e.g., struggling to accept and reconcile their desires) and from external entities (e.g., defending their freedom and choice to engage in $\mathrm{D} / \mathrm{s}$, to other people). Sometimes, participants chose to prioritize one identity over the other, whether for safety, to avoid making other people uncomfortable, or to avoid negative consequences at work, home, or another environment. However, these findings show that participants' feminist and submissive identities and values are not necessarily in opposition. In fact, their values are consistent across identities. Sometimes, participants might decide to hide or downplay an identity or value, and sometimes, a woman who likes to debate and ask questions when told to do something struggles to keep silent. However, she comes back to her shared core values of being authentic, being comfortable in her own skin, being strong, and choice, autonomy, and freedom.

These findings provide insight into how women in the BDSM community who are feminist and submissive perceive their feminist identity, their submissive identity, and their navigation of these identities.

\section{Feminist Identity}

All participants identified as women, feminists, and submissives; however, when delving into what it means to be a feminist, only 18 women perceived themselves as having a distinct feminist identity, while 5 related more to feminist values.. Feminist values were identified as equality; challenging oppressions; autonomy, freedom, and choice; strong; and authentic. This supports prior research on the BDSM community that shows how feminism provides space for women to claim agency in choosing to submit 
(Hébert \& Weaver, 2015), self-awareness (Martinez, 2011), empowerment (Raab, 2013; Rivoli, 2015; Surprise, 2012), and transgression of social boundaries (Newmahr, 2011). Another finding was that some women could not articulate what a feminist community is or where it could be found. This aligns with prior research showing that feminist identity and feminist attitudes or values are distinct constructs (Eisele \& Stake, 2008; Ramsey et al., 2007; Zucker \& Bay-Cheng, 2010).

These findings contribute to feminist discourse by broadening the understanding of how feminist identity and values are perceived and employed, particularly outside of socially sanctioned normative sexual practices (i.e., BDSM and D/s). These findings also highlight issues that feminists and the feminist community need to address if they want to be seen as advocating for all women, not just those who fit within a limited perspective of good, normal, and accepted feminism and sexuality.

\section{Submissive Identity}

Participants found it much easier to describe their submissive identity than their feminist identity, because submissive was more visible, more action-oriented, and more salient than feminist identity. It was more complex. Submissive identity encompassed a broad range of behaviors and expectations and was often based on roles and partners; ranging from submissive in a one-to-one relationship to submissive to friends or community, and from intimate, sexual relations to service and citizenship within the BDSM community. Submissive values was discussed in terms of service; choice; trust; communication; consent and negotiation; authenticity; strong; and deferring to others. This supports prior research on the BDSM community, which describes submissive 
women "as integrated, well-balanced, and powerful, women" (Prior, 2013, p. 18) who find empowerment through consent (Rivoli, 2015).

These findings contribute to discourse on sexuality, D/s, and intimate relationships by expanding the understanding of how feminism influences power exchange and how D/s dynamics influences a submissive's feminist identity and behaviors. These findings also highlight the importance of sexual education, by illustrating how the women's lack of knowledge about D/s, consent, and negotiation contributed to their difficulty in accepting submissive desires and their (sometimes negative) experiences with unintentional power exchange in intimate relationships. Navigation of Feminist and Submissive Identities

In general, participants perceived their feminist and submissive identities as mutually supportive. However, most women recalled times when they struggled to understand, accept, and reconcile their identities. This supports prior research about feminism and submission, as discussed in Walter's (2012) exploration of how female sex bloggers discuss BDSM and construct their identities:

Thanks to this blog and that support from everyone who's read it over the last few years, I've gotten exactly what I wanted: I no longer feel overwhelmingly ashamed or afraid of my desires; I feel confident in my sexuality; I have a better understanding of different BDSM subcultures and histories and can articulate both defenses and critiques of them. (Subversive Submissive, in Walters, 2012, pp. 157-158).

This was just one example of a woman's success at accepting and reconciling her desires, sexuality, and identities. Some women are not so fortunate, and continue to struggle, as a woman in Raab's (2013) study who described her feminist identity as "not something which I fully manage to reconcile. It makes it harder to bottom, it makes it harder to 
submit, it definitely makes it harder to accept discipline" (p. 53). This echoes findings of the current study where women spoke about struggling to balance their inclinations to speak up, debate, and ask questions when given a command from their Dominant partner; even when they want to obey, it can be hard to keep quiet and proceed without discussion. Some submissive women experience difficulty doing what their Dominants command, dropping whatever they are doing to attend to their Dominants, and accepting decisions made for them by their Dominants (Hébert \& Weaver, 2015).

Participants described the BDSM community as mostly accepting of feminist identity and values, while recognizing that not every member or group are accepting. The participants described the feminist community as not very accepting of submissive identity. In fact, many of the struggles the women experienced related to their perception that other feminists and the feminist community consider their submission to be inherently anti-feminist and a form of abuse that the women perpetuate.

One way that the women navigate their feminist and submissive identities is by hiding or downplaying the identity, desires, or behaviors, as presented in Table 7. This occurred more often with their submissive identity, due to social stigma about BDSM as deviant sexuality.

Table 4. "Out” about Feminist and Submissive Identities

\begin{tabular}{|l|c|c|c|c|}
\hline Out Status & $\begin{array}{c}\text { To } \\
\text { Immediate } \\
\text { Family }\end{array}$ & $\begin{array}{c}\text { To } \\
\text { Vanilla } \\
\text { Friends }\end{array}$ & $\begin{array}{c}\text { To } \\
\text { Coworkers }\end{array}$ & $\begin{array}{c}\text { To } \\
\text { Healthcare } \\
\text { Providers }\end{array}$ \\
\hline "Out" as Feminist & 20 & 20 & 19 & 17 \\
\hline "Out" as Submissive & 9 & 14 & 7 & 13 \\
\hline
\end{tabular}


These findings support prior research showing that members of the BDSM community intentionally choose the conditions under which to disclose BDSM-related identities and employ various strategies to manage the BDSM-related stigma (Bezreh, Weinberg, \& Edgar, 2012).

Most participants would like for other people to understand their identities and experiences better, particularly healthcare professionals (13), family members (10), educators (8), law enforcement (7) or other government/state officials (6), LGBTQ groups (6), friends (5), their Dominant partners (4), and their employers (3). However, three women stated that they do not care if anyone understands their identities.

These findings contribute to discourse on identity development, healthy relationships, and adult education by identifying challenges that women experience in accepting, reconciling, and navigating their identities. These challenges can influence the health of the women's intimate relationships, as they struggle to create and maintain a D/s dynamic that meets their needs while supporting their values. The challenges of being out or hiding one's identities can inform discourse in adult education, as they illustrate the need for healthcare professionals, educators, law enforcement, and other public officials to better understand these experiences.

\section{Role Identity, Social Identity, and Person Identity}

Submissive identity was described as more complex and salient than feminist identity. Participants gave much more thought to their submissive identity and shared more examples of how they actively engage with other people as a submissive, through service, deferring to others, communication, and negotiating consent than as a feminist. 
A role identity refers to the internalized meanings that an individual applies to a specific role that she claims. Participants clearly perceived their submissive identity as strong and important. Submissive identity was described in a variety of ways, but all women could define what their submissive identity was like. However, even though all the women considered their feminist values as important, only 18 perceived of themselves as having a distinct feminist identity. A social identity refers to an individual's identification with a social group. Similarly, all participants identified as members of the BDSM community, and most felt that it was important to have a sense of belonging to the community. However, less than a third of the women felt that it was important to have a sense of belonging to the feminist community, in part because some of them could not even describe what the feminist community is. A person identity refers to the set of meanings that define an individual as unique, rather than a role-holder or group member (Stets, 1995; Stets \& Burke, 1994). A key theme that emerged was women's core values (e.g., agency, power, consent, choice, strength, authenticity) are consistent across all their identities. No matter what role or social identity was salient at any given moment, their values remained the same. However, in some environments, many participants made a conscious decision to hide or downplay an identity or behavior in lieu of another. This often occurred with the submissive identity, when they choose to alter their behavior or otherwise hide that part of themselves to avoid making someone uncomfortable, avoid awkward explanations, or avoid potential negative judgements or consequences.

When an individual's multiple identity standards have opposing meanings, the standards must shift, as the identities change to remove the conflict. These findings 
demonstrate how participants experienced such shifts in identity standards, particularly as they came to accept their submissive desires and identity and learned to navigate their feminist and submissive identities. Negative emotions, such as frustration, anger, and depression can manifest if an identity is not verified or accepted by other people (Burke, 2007). These findings demonstrate this through participants' discussions about opposing oppressions, advocating for equal rights, choosing to hide or downplay their identities, and the need for other people to understand their experiences better, especially healthcare professionals.

These findings also demonstrate that both feminist and submissive identities and values are important to these women and their values. However, participants' submissive identity tends to be more salient, or active, and the women are much more closely embedded within the social structure of the BDSM community than the feminist community. Unfortunately, the stigma related to BDSM and potential negative consequences of "being out" as a submissive cause many women to hide or downplay their submissive identities. Based on these findings, one might expect that when the women's feminist and submissive identities are activated at the same time, their submissive identity will guide their behavior, but only in an environment where BDSM and submissive identity are accepted.

\section{Implications for Future Research and Practice}

To participate in this study, individuals had to identify as a feminist, a submissive, active in the BDSM community, and living in Florida. This limited the study by excluding women who identify as switch (i.e., switching between submissive and dominant roles), women who are not active in the BDSM community, and women living 
outside of Florida. The current study has set the stage for future research to explore these facets of identity: How do switches navigate their feminist, submissive, and dominant identities? Do women who are active in the BDSM community perceive and navigate their identities differently from women who are active in the BDSM community? Do women outside of Florida perceive and navigate their identities differently?

There is an obvious lack of racial and cultural diversity within the BDSM community (Manewitz, 2015). Therefore, locations of oppression (e.g. race, income, age) can enhance the understanding of how feminism and submission are perceived and navigated when intersecting with other identities. In other words, do submissive, switch, and dominant Women of Color in the BDSM community experience feminism and D/s differently than White women? Do women of low socioeconomic status experience feminism and D/s differently than women of mid- or high socioeconomic status?

Future research can enhance our knowledge about advocacy, agency, consent, and abuse by exploring how women who are feminist and submissive challenge oppressions and understand and negotiate consent. Research can also enhance our awareness of sexual desires and behaviors by exploring how individuals learn about, develop, and engage in BDSM practice and in D/s relationships.

Another area for future research is to explore how college women experience these identities. On average, the women in this study recognized their feminist identity at age 14 and their submissive identity at age 24. In fact, six participants recognized their submissive identity between 18-24. Additionally, 22 of the 23 woman attended college. Thus, many of the women attended college already having a feminist identity, though it was probably still developing, while many were likely just beginning to learn about, and 
perhaps struggle with, their submissive identity and desires. Research on feminism and submission, and how consent is understood, negotiated, and violated can enhance college educators' ability to help women develop as healthy individuals. Research on college women who participate in $\mathrm{D} / \mathrm{s}$ might also provide insights into how these concepts are understood and operationalized, particularly on college campuses, where consent, abuse, and assault are critical concerns.

The knowledge gained from such research can inform educational resources for individuals on topics such as feminism, identity, sexual desires, orientations, and health; healthy relationships; and self-awareness. The knowledge can also be utilized by teachers, advisors, and counselors who speak with students about these topics.

Participants were asked if any other questions should have been asked during the interview. Their responses included questions about sexual orientation, polyamorous relationships, and sadism and masochism (SM). Based on these interests from women in the BDSM community, future research might explore the following topics through a variety of methods (e.g., case studies, interviews, and surveys):

a) How does sexual orientation influence the way that women engage in $\mathrm{D} / \mathrm{s}$ dynamics, specifically, do the desires, behaviors, and levels of submission change based on their partner's sexual orientation?

b) How do feminism and feminist values influence how the women participate in polyamorous relationship? How do polyamorous relationships influence how women think and behave as feminists?

c) How do sadism and masochism influence women's feminist and submissive identities and values? For example, is it more difficult for sadistic women to feel submissive or to be perceived as submissive because of their top role? Is it easier for them to feel feminist because of their top role? Is it easier for masochistic women to feel submissive or to be perceived as submissive because of their bottom role? Is it more difficult for them to feel feminist because of their bottom role? 
Participants also expressed a desire to learn about how the BDSM community has changed over the last 10 years and if being a submissive, and/or being involved in the BDSM community, has been a positive experience for members. The women believe that this knowledge can help educate new community members by providing insights into how to have healthy and positive experiences in BDSM.

\section{Summary}

This paper was a part of a larger dissertation to explore how women who are feminist and submissive perceive and navigate these identities. This exploration advances the discussion about feminism, sexuality, BDSM, learning, and identity development. The findings provide insight for healthcare providers, law enforcement, policy makers, educators, and other professionals who work with and for this population to provide better services for the women, their families, and their communities. These findings can be applied to the fields of adult education and human resource development through incorporation into curriculum, training, and policies.

Two studies were conducted as a part of this research: a structured literature review and a phenomenology. The following concluding chapter consists of four sections: (a) a summary of study \#1, the structured literature review; (b) a summary of study \#2, the phenomenology, (c) an overview of the findings of the collected papers; and (d) the overarching implications of this collected papers dissertation for theory, research, and practice. 


\section{References}

Anzaldúa, G. (2007). Borderlands: The new mestiza = La frontera. San Francisco, CA: Aunt Lute Books.

Badran, M. (2009). Feminism in Islam: Secular and religious convergences. Oxford, UK: Oneworld Publications.

Beasley, C. (1999). What is feminism? An introduction to feminist theory. London, UK: Sage.

Berg, B. L. (2001). Qualitative research methods for the social sciences. Boston, MA: Allyn and Bacon.

Bezreh, T., Weinberg, T. S., \& Edgar, T. (2012.). BDSM Disclosure and stigma management: Identifying opportunities for sex education. American Journal of Sexuality Education, 7, 37-61. doi: 10.1080/15546128.2012.650984

Bogdan, R. C. \& Biklen, S. K. (2007). Qualitative research for education: An Introduction to theories and methods (5th ed.). Boston, MA: Pearson Education.

Boyatzis, R. E. (1998). Transforming qualitative data: Thematic analysis and code development. Thousand Oaks, CA: Sage.

Brown, E. (1989). African-American women's quilting: A Framework for conceptualizing and teaching African-American women's history. Signs, 14, 921 929. Retrieved from http://www.jstor.org/stable/3174693

Browne, K. (2005). Snowball sampling: Using social networks to research nonheterosexual women. International Journal of Social Research Methodology, 8, 47-60. doi: 10.1080/1364557032000081663

Burke, P. J. (2007). Identity control theory. In G. Ritzer, (Ed.), The Blackwell encyclopedia of sociology (pp. 2202-7). Oxford, UK: Wiley-Blackwell. Retrieved from http://wat2146.ucr.edu/Papers/05d.pdf

Burke, P. J., \& Stets, J. E. (2009). Identity theory. Oxford, UK: Oxford University Press.

Califia, P. (2002). Speaking sex to power: The politics of queer sex. San Francisco, CA: Cleis Press.

Creswell, J. W. (2009). Research design: Qualitative, quantitative, and mixed methods approaches. Los Angeles, CA: Sage. 
Creswell, J. W. (2013). Qualitative inquiry \& research design: Choosing among five approaches. Los Angeles: SAGE Publications.

Deckha, M. (2011). Pain as culture: A Postcolonial feminist approach to S/M and women's agency. Sexualities, 14, 129-150. doi: 10.1177/1363460711399032

Downing, L. (27 July 2012). What is 'sex critical' and why should we care about it? Sex Critical. [Blog]. Retrieved from http://sexcritical.glogsopt.co.uk/2012/07/what-issex-critical-and-why-should-we.html

Durex. (2005). Global Sex Survey. Retrieved from http://www.data360.org/pdf/20070416064139.Global\%20Sex\%20Survey.pdf

Dworkin, A. (1974). Woman hating. New York, NY: Dutton.

Dworkin, A. (1989). Pornography: Men possessing women. New York, NY: Plume.

Dworkin, A., \& MacKinnon, C. (1985). The reasons why: Essays on the new civil rights law recognizing pornography as sex discrimination. Pornography Resource Center: Minneapolis, MN.

Erikson, E. H. (1968). Identity: Youth and crisis. New York, NY: Norton.

Ferber, A. L., Holcomb, K., \& Wentling, T. (2013). Sex, gender, and sexuality: The New basics: An anthology. Oxford, UK: Oxford University Press.

Freedman, E. B. (2002). No turning back: The History of feminism and the future of women. New York, NY: Ballantine Books.

Griffin, S. (1982). Sadomasochism and the erosion of self: A critical reading of Story of O. In R. R. Linden (Ed.), Against sadomasochism: A radical feminist analysis (pp. 184-201). San Francisco, CA: Frog in the Well.

Guest, G., Bunce, A., \& Johnson, L. (2006). How many interviews are enough? An experiment with data saturation and variability. Field Methods, 18(1), 59-82. doi:10.1177/1525822X05279903

Harrington, L., \& Williams, M. (2012). Playing well with others: Your field guide to discovering, exploring and navigating the kink, leather and BDSM communities. San Francisco, CA: Greenery.

Janus, S., \& Janus, C. (1993). The Janus report on sexual behavior. New York, NY: John Wiley \& Sons. 
Jeffreys, S. (2003). Unpacking queer politics: A lesbian feminist perspective. Cambridge, MA: Polity Press in association with Blackwell Publishers.

Kinsey, K. (2012, December 11). Guest post: A Feminist submissive by Kate Kinsey, Lady Smut (Web log post). Retrieved from http://ladysmut.com/2012/12/11/guest-post-a-feminist-submissive-by-kate-kinsey/

Langdridge, D., \& Barker, M. (2007). Safe, sane, and consensual: Contemporary perspectives on sadomasochism. London, UK: Palgrave Macmillan.

Lincoln, Y. S., \& Guba, E. G. (1985). Naturalistic inquiry. Newbury Park, CA: Sage.

Linden, R. R. (1982). Against sadomasochism: A radical feminist analysis. East Palo Alto, CA: Frog in the Well.

Lowe, W. (1983). The Playboy reader's sex survey. Chicago, IL: Playboy Foundation.

Lugones, M. (1997). Playfulness, "world"-travelling, and loving perception. In D. T. Meyers (Ed.), Feminist social thought: A reader, (pp. 147-159). New York, NY: Routledge.

MacKinnon, C. (1987). Feminism unmodified: Discourses on life and law. Cambridge, MA: Harvard University Press.

Makai, M. (2014). Domination \& submission: The BDSM relationship handbook. eBook, Los Gatos: Smashwords Edition.

Manewitz, S. (2015, January 12). Kink, race, privilege. Beyond safewords. Retrieved from http://www.beyondsafewords.com/kink-race-privilege/

Martinez, K. (2011). Bound in theory and practice: A mixed-methods exploration of consensual sadomasochism (3468405). Available from ProQuest Dissertations \& Theses A\&I; ProQuest Dissertations \& Theses Global. (887901416). Retrieved from http://ezproxy.fiu.edu/login?url=https://search.proquest.com/docview/88790 $\underline{1416 \text { ? accountid }=10901}$

McCall, G. J., \& Simmons, J. L. (1978). Identities and interactions: An examination of human associations in everyday life. New York, NY: Free Press.

McCarthey, S. J., \& Moje, E. B. (2002). Identity matters. Reading Research Quarterly, 37, 228-238. Retrieved from http://ezproxy.fiu.edu/login?url=http://search.proquest.com.ezproxy.fiu.edu/docvi ew/212133561? accountid=10901 
Merriam, S. B. (2009). Qualitative research: A guide to design and implementation. San Francisco, CA: Jossey-Bass.

Miller, D. C., \& Salkind, N. J. (2002). Handbook of research design \& social measurement. Thousand Oaks, CA: Sage.

Moustakas, C. E. (1994). Phenomenological research methods. Thousand Oaks, CA: Sage.

Ortmann, D. \& Sprott, R. A. (2012). Sexual outsiders: Understanding BDSM sexualities and communities. New York, NY: Rowman and Littlefield.

Patton, M. Q. (2002). Qualitative research and evaluation methods. Thousand Oaks, CA: Sage.

Peshkin, A. (1988). In search of subjectivity - one's own. Educational Researcher, 17, 17-21. doi: 10.3102/0013189X017007017

Powers, W. T. (2005). Behavior: The control of perception ( $2^{\text {nd }}$ ed.). New Canaan, CT: Benchmark.

Powers, W. T., Clark, R. K., \& McFarland, R. L. (1960). A general feedback theory of human behavior. Part II. Perceptual and Motor Skills, 11, 309-323. Retrieved from http://www.pctweb.org/Powers\%20et\%20al\%201960\%20part2.pdf

Prior, E. (2013) Women's perspectives of BDSM power exchange. Electronic Journal of Human Sexuality, 16. Retrieved from http://www.ejhs.org/volume16/BDSM.html

Reinisch, J. M., Beasley, R., Kent, D., \& Kinsey Institute for Research in Sex, Gender, and Reproduction. (1990). The Kinsey Institute new report on sex: What you must know to be sexually literate. New York, NY: St. Martin's Press.

Richters, J., de Visser, R. O., Rissel, C. E., Grulich, A. E., \& Smith, A. M. A. (2008). Demographic and psychosocial features of participants in bondage and discipline, "sadomasochism" or dominance and submission (BDSM): Data from a national survey. Journal of Sexual Medicine, 5(7), 1660-1668. doi:http://dx.doi.org.ezproxy.fiu.edu/10.1111/j.1743-6109.2008.00795.x

Rossman, G., \& Rallis, S. E. (1998). Learning in the field: An Introduction to qualitative research. Thousand Oaks, CA: Sage.

Rubin, G. (2011). Deviations: A Gayle Rubin reader. Durham, NC: Duke University Press. 
Rubin, G.. (1984). Thinking sex: Notes for a radical theory of the politics of sexuality. In Carole S. V. (Ed.), Pleasure and danger (pp. 267-319). Boston, MA: Routledge.

Rubin, H. J., \& Rubin, I. S. (2005). Qualitative interviewing: The art of hearing data. Thousand Oaks, CA: Sage.

Seidman, I. (2006). Interviewing as qualitative research: A guide for researchers in education and the social sciences ( $3^{\text {rd }}$ ed). New York, NY: Teachers College Press.

Shrage, L., \& Stewart, R. S. (2015). Philosophizing about sex. Tonawanda, NY : Broadview Press.

Smash. (2013, January 27) BDSM is violence against women. [Blog post]. Retrieved from https://liberationcollective.wordpress.com/2013/01/27/bdsm-is-violenceagainst-women/

Stets, J. E. (1995). Role identities and person identities: Gender identity, mastery identity, and controlling one's partner. Sociological Perspectives, 38(2), 129-150. doi: $10.2307 / 1389287$

Stets, J. E., \& Burke, P. J. (1994). Inconsistent self-views in the control identity model. Social Science Research, 23, 236-262. doi:10.1006/ssre.1994.1010

Strauss, A., \& Corbin, J. (1998). Basics of qualitative research (2nd ed.). Thousand Oaks, CA: Sage.

Swanson, E. (2013, April 16). Poll: Few identify as feminists, but most believe in equality of sexes. The Huffington Post. Retrieved from http://www.huffingtonpost.com/2013/04/16/feminism-poll_n_3094917.html

Tesch, R. (1990). Qualitative research: Analysis types and software tools. New York, NY: Falmer Press.

Thorn, C. (2012). The S\&M feminist: Best of Clarisse Thorn. CreateSpace Independent Publishing Platform.

Tong, R. (2009). Feminist thought: A more comprehensive introduction. Boulder, CO: Westview Press.

Valenti, J. (2007). Full frontal feminism: A young woman's guide to why feminism matters. Emeryville, CA: Seal Press.

Van Manen, M. (1997). Researching lived experience: Human science for an action sensitive pedagogy. London, UK: Althouse Press. 
Walters, C. J. (2012). Discourses of heterosexual female masochism and submission from the 1880s to the present day (Order No. U575177). Available from ProQuest Dissertations \& Theses A\&I; ProQuest Dissertations \& Theses Global. (1124095062). Retrieved from http://ezproxy.fiu.edu/login?url=https://search.proquest.com/docview/112409506 2? accountid $=10901$

Weinberg, M. S., Williams, C. J., \& Moser, C. (1984). The social constituents of sadomasochism. Social Problems, 31, 379-389. Retrieved from http://www.jstor.org/stable/800385

Weinberg, T. S. (1995). S\&M: Studies in dominance \& submission. Amherst, N.Y: Prometheus Book.

Weiss, M. D. (2011). Techniques of pleasure: BDSM and the circuits of sexuality. Durham, NC: Duke University Press.

Willis, E., \& Aronowitz, N. W. (2014). The essential Ellen Willis. Minneapolis, MN: University of Minnesota Press

Wollstoncraft, M. (1972/2011). A vindication of the rights of women. In Wayne, T. (Ed.), Feminist writings from ancient times to the modern world: A Global sourcebook and history (pp. 162-165). Westport, US: Greenwood.

Women Against Men (2014.) Retrieved on December 29, 2014 from http://www.womenagainstmen.com/about

Wright, S. (2008). Second National Survey of Violence \& Discrimination Against Sexual Minorities. Retrieved from: https://ncsfreedom.org/images/stories/pdfs/BDSM_Survey/ 2008 bdsm_survey_analysis_final.pdf

Young, M. (2012). Submissive: A personal manifesto. In T. Taormino (Ed.), The ultimate guide to kink: BDSM, role play and the erotic edge (pp. 297-308). Berkeley, CA: Cleis Press. 


\section{CHAPTER IV}

\section{CONCLUSION}

This concluding chapter answers the research questions of the collected papers dissertation. The first section provides an overview of the findings related to the purpose of studies. The next section answers the questions: How are feminism and submission discussed in the scholarly literature on BDSM, particularly related to women who identify as feminist and submissive? How do women in the BDSM community who identify as feminist and submissive perceive these identities? How do women in the BDSM community who identify as feminist and submissive navigate these identities? The final section discusses the implications for future research and practice.

\section{Overview of the Findings Related to Purpose of the Collected Papers}

The purpose of this collected papers dissertation was to explore how women in the BDSM community who are feminist and submissive perceive and navigate these identities.

Study \#1, the structured literature review, uncovered four themes that were discussed in the scholarly literature about women in the BDSM community who identify as feminist and submissive: (a) feminism in the context of BDSM; (b) normalization of BDSM, (c) navigating feminist and submissive identities, and (d) BDSM power as transgressive. Study \#2, the phenomenological inquiry, uncovered six themes related to BDSM women's experiences perceiving and navigating their feminist and submissive identities: (a) feminist identity is distinct from feminist values; (b) the complexity of submissive identity; (c) women learn to accept their submissive identity in different ways; (d) the BDSM community is perceived as generally accepting of feminist identity; 
(e) the feminist community is perceived as not very accepting of submissive identity; and

(f) being out as feminist and as submissive.

\section{How Feminism and Submission are Discussed in the Scholarly Literature on BDSM, Related to Women who Identify as Feminist and Submissive}

Feminism within the context of BDSM is enacted through women's agency, power, and consent. Agency refers to an individual's ability to freely make decisions. Power refers to a dynamic process; a "characteristic of interaction" that is not owned by anyone (Newmahr, 2006, p. 57). Consent refers to "an ongoing, relational, negotiation in which the conditions under which a 'no' is possible need to be created, by everyone involved, in order for a 'yes' to count" (Barker, 2013b, p. 908). Consent is complicated by the fact that, "the real, pre-existing power dynamics that exist between players will always frame and partially determine the meaning of what happens in a scene" (Marion, 2016, p. 189). Of critical importance in this discourse is how individuals perceive and enact the ability to replicate, simulate, and/or transgress boundaries and oppressions through BDSM play; how they sandbox, or play around with, power dynamics and fashion tools such as negotiation, safewords, contracts, consensual non-consent, and positive consent to eroticize and tame issues of power that were not previously pleasurable (pepomint, 2007a).

"Safe, Sane, and Consensual" operates within the BDSM community as a set of guiding principles that establish which BDSM practices are established and which are not. This normalization is perceived as both beneficial, in focusing on health, safety, and the creation of ethical subjectivity (Weiss, 2011) and as negative, in creating a disciplinary mechanism used to police the BDSM community and members from within 
by distinguishing acceptable practices from unacceptable practices (Dymock, 2012). In this way, the normalization of BDSM marginalizes those who fall outside of accepted norms, and some practitioners experience discrimination based on their roles and activities, such as women who claim a slave identity or who engage in race play. Women who are feminist and submissive transgress boundaries when their activities and relationships fall outside of normative BDSM.

Feminist identity was discussed as distinct from feminist values. For example, the literature showed that some women who have feminist values do not claim a feminist identity, which supports prior research that identifies feminist identity and feminist attitudes as distinct constructs (Zucker \& Bay-Cheng, 2010). Also, some women who have feminist values may not claim a feminist identity because they perceive feminism as racist and classist (Allison, 1994; hooks, 2000; Hurtado, 1989).

Submissive identity were discussed as a natural, inherent part of self; as a replication of negative relationships and oppressions; as a simulation of power imbalance; and as a feminist choice. Additionally, women recognized the importance of self-awareness; being aware of what you want and why, both as a BDSM practitioner and as a submissive.

\section{How Women in the BDSM Community who Identify as Feminist and Submissive Perceive These Identities}

The findings from both studies supported the concept of feminist identity as distinct from feminist values. In study \#2, all 23 women had feminist values, but only 18 perceived themselves as having a distinct feminist identity. Also, some women perceived themselves as distant from the feminist community; in fact, some women could not 
articulate what a feminist community is. This supports prior research that identified feminist identity and feminist attitudes or values as distinct constructs (Eisele \& Stake, 2008; Ramsey et al., 2007; Zucker \& Bay-Cheng, 2010). Feminist identity was described in terms of equality; challenging oppressions; autonomy, freedom, and choice; strength; and authenticity. This supports prior research demonstrating feminism provides space for BDSM women to claim agency in choosing to submit (Hébert \& Weaver, 2015), selfawareness (Martinez, 2011), empowerment (Raab, 2013; Rivoli, 2015; Surprise, 2012), and transgression of social boundaries (Newmahr, 2011).

Submissive identity was described in terms of service; choice; trust; communication, consent, and negotiation; strength; and authenticity. These values were shared across a wide range of submissive relationships and activities. Submissive identity is complex, as women are submissive in different ways, based on their roles and partners. For example, some women were submissive to a single Dominant only, while other women had multiple Dominants, and different levels of consent and activities within their different relationships. Also, submissive identity was not restricted to sexual activity; rather it also involved providing service to other people, groups, or community, through volunteering, teaching, and leading a group. In fact, while some women were only submissive to a Dominant partner, other women perceived themselves as submissive to people they care about (e.g., friends, community) or in general (e.g., at home, with friends, at work). Most of the women perceived their submissive identity as something that has always existed, even when they are not in any type of relationship or group where they provide submission or service. Submissive identity was also presented as more salient and action-oriented than feminist identity, as the women think about 
submission more often than feminism and comport themselves as submissive (e.g., kneeling, serving drinks to their Dominant) more often than feminist (e.g., marching, advocating for equality).

\section{How Women in the BDSM Community who Identify as Feminist and Submissive Navigate These Identities}

Women reconcile and navigate their feminist and submissive identities in different ways. The findings of these studies demonstrated that some women experienced no need to navigate or reconcile these identities, as they perceived the identities as mutually supportive:

I embrace my submission and feel empowered and humbled at the same time by these experiences. I feel that any woman who is embracing her sexuality and actively pursuing genuine pleasure for both herself and her partners is participating in a form of feminism. (Young, 2009, p. 60)

Other women struggled to accept their submissive desires, and struggled to reconcile these desires with their feminist values. For the women in study \#2, these struggles often began before the women even knew what submission was. On average, the women recognized their submissive identity at age 24 , but many had fantasies about submission at a much younger age. Their initial experiences with submission were discussed in four ways: (a) as inherent or always existing, (b) as beginning when they became sexually active, (c) as beginning with erotica or pornography, and (d) as unknowingly played out in relationships. The women struggled the most with their attraction to erotica and pornography, because they became sexually aroused by images of women being

dominated in situations where consent was not explicitly given and where activities were not negotiated. Many of the women recalled being turned on by their mother's romance 
novels, where the swashbuckling pirate takes a "captive bride". The women worry that these types of novels contribute to readers' ignorance regarding consent.

Some women experienced the reconciliation and navigation of feminist and submissive identities as a difficult, even violent, process that they learned to overcome. This was particularly connected to reconciling their desire to yield authority with their belief in freedom and equality. The women had to reframe this seemingly dichotomous understanding of feminism into a broader understanding, where choosing to yield authority was perceived as agentic and being submissive did not equate to being less than or inferior to someone else. For example, Queen (2002) spoke about her "Inner Feminist" who struggled with her desires and pleasure in taking a subordinate sexual position, especially when submitting to a man. Her understanding of feminism (at that time) fostered self-doubts "in a petri dish of sex-negativity" and as "ignorant of much of human life's sexual possibility" (Queen, 2002, p. 170). Over time, Queen's understanding of feminism changed to become more accepting of diverse sexuality and of submission.

Some women consider the reconciliation and navigation as an ongoing struggle. This was expressed as having difficulty accepting the consequences of their chosen roles, such as having to do what their Dominants command, dropping whatever they were doing to attend to their Dominants' wishes, and accepting some of the decisions that were made for them. Additionally, some women recognized a trend within the BDSM community "to define 'submissive' in a particular way, and to cast all those not fitting in with that definition as 'not real submissives"” (Walters, 2012, p. 160). Many women struggled with this limited view of submissive identity, particularly when their desire to be seen as a submissive caused them to hide or downplay their feminist values; which kept them from 
being their authentic selves. This struggle to reconcile and navigate identities can be a feminist process in itself, where "getting what we want sexually helps us move towards what Maslow termed self-actualization" (Queen, 2002, p. 176) and where a woman's strength and self-esteem are reinforced.

Much of the ongoing struggles that women experience stem from external sources, particularly related to social stigma.

The BDSM community is perceived by some practitioners as a space where feminism and feminist values are not supported, and where both sexism and racism thrive. BDSM practitioners questioned if people are just replicating gender norms that they are used to, without critically thinking about their desires and choices. Other BDSM practitioners perceived the community as accepting feminism and feminist values, as it supports spaces where personal, social, and ethical boundaries can be transgressed (Newmahr, 2011).

One strategy that women employed in navigating their feminist and submissive identities was to choose when to be out about an identity or to hide or downplay it. The findings from study \#2 show that submissive identity was hidden or downplayed more often than feminist identity, as presented in Table 5. The women would alter their submissive behavior or otherwise hide that part of themselves in order to avoid making someone else uncomfortable, avoid awkward explanations, or avoid potential negative judgements or consequences. These findings support prior research showing that members of the BDSM community intentionally choose the conditions under which to disclose BDSM-related identities and employ various strategies to manage the BDSMrelated stigma (Bezreh, Weinberg, \& Edgar, 2012). 
Table 5. "Out" about Feminist and Submissive Identities

\begin{tabular}{|l|c|c|c|c|}
\hline Out Status & $\begin{array}{c}\text { To } \\
\text { Immediate } \\
\text { Family }\end{array}$ & $\begin{array}{c}\text { To } \\
\text { Vanilla } \\
\text { Friends }\end{array}$ & $\begin{array}{c}\text { To } \\
\text { Coworkers }\end{array}$ & $\begin{array}{c}\text { To } \\
\text { Healthcare } \\
\text { Providers }\end{array}$ \\
\hline "Out" as Feminist & 20 & 20 & 19 & 17 \\
\hline "Out" as Submissive & 9 & 14 & 7 & 13 \\
\hline
\end{tabular}

Both feminist and submissive identities and values are important to the women, and the women are committed to these values regardless of what role is salient or active at a given time. However, submissive identity was presented as more salient than feminist identity, as the women spent more time reflecting on how they think and act as a submissive. Yet, the stigma related to BDSM and potential negative consequences of being out as kinky or submissive cause many women to hide or downplay their submissive identities and behaviors. Choosing to hide or downplay feminist identity and values occurred much less frequently. The findings suggest that in environments where both feminist and submissive identity are accepted, women should not experience any conflict between their feminist and submissive identities or values, and should not need to hide an identity or prioritize one over another.

Despite the potential challenges of claiming, reconciling, and navigating feminist and submissive identities, both feminism and submission were perceived as enriching, empowering, and providing space to feel on a deeper level.

\section{Discussion and Implications for Future Research and Practice}

Both feminism and submission were important to the women's experiences because they created space for self-awareness, empowerment, choice, strength, and authenticity, and opportunities for the women to learn about themselves and find a voice 
with which to speak. Being self-aware was critical to establishing healthy behaviors and relationships; this included being aware of what they wanted, why they wanted it, and why they made choices.

Choice was important in understanding that their decisions are freely made and founded on self-awareness of their desires and values, and on being empowered to make those choices. Strength was important because the women recognized that yielding authority to someone else requires a backbone, to agree to go along with their Dominant's decisions and interests, even when they conflict with their own. Strength was also important when holding true to their values, particularly when someone else did not respect those values. Examples of this occurred within the feminist community, when debating that choosing to be submissive was a feminist choice and within the BDSM community, when arguing that just because someone is assertive does not mean that she is not a submissive. These findings echo prior research describing submissive women "as integrated, well-balanced, and powerful, women," (Prior, 2013, p. 18) who find empowerment through consent (Rivoli, 2015). Being self-aware, strong, and empowered helped the women to be authentic and true to their values. Ophelia shared, "it's just so important for us all to really know who we are, where we fit, you know, how we identify, and be very true to that" (para. 90) and for women to not let anyone take them away from their authenticity.

Women's core values are consistent, but their identity standards (set of meanings that define the character of an identity) shifted as women came to accept their submissive desires and learned to navigate their identities. The women described their submissive identity as more salient than feminist identity; and the women were more closely 
embedded within BDSM community than the feminist community. However, BDSMrelated stigma caused many to hide or downplay their submissive identity or behaviors. Even though submissive identity might be more salient, the identity would only guide behavior in environments where $\mathrm{D} / \mathrm{s}$ was accepted.

Boundaries are transgressed by reimagining social norms related to sex, gender, sexual orientation, and other identities. Boundaries are also transgressed through the utilization of BDSM scenes as catharsis, where BDSM appears to have the potential to be psychically and psychologically therapeutic (Easton, 2007; Lindemann, 2011; Woody, 2014) and through cultural trauma play, where people work through painful experiences such as assaults and incidents of discrimination and racism (Weiss, 2006). These opportunities to transgress can help women to employ their feminist values while rescripting painful memories, increasing self-awareness, and finding empowerment. Of critical importance in this discourse is how people perceive and enact the ability to replicate, simulate, and/or transgress boundaries and oppressions, and sandbox (or isolate) power dynamics and create tools such as negotiation, safewords, contracts, and consent to eroticize and tame issues of power (pepomint, 2007a).

These collected papers studies focused on individuals identified as women, feminist, submissive, and active in the BDSM community. Based on these limitations, several factors were not taken into consideration. Future research can address these limits by exploring: (a) the psychological meanings of switching (claiming both dominant and submissive roles), particularly the relationship between one's dominant and submissive selves (Marion 2016); (b) women who are feminist and dominant; (c) practitioners who only play in private or in sex/gender-specific venues (Martinez 2011); (d) participants 
from a full range of racial, sexual, and socio-economic backgrounds (Prior 2013); (e) multiple locations of oppression (race, income, age) with the aim of better understanding how feminism and submission are perceived and navigated.

The current study has set the stage for future research to ask: How do switches navigate their feminist, submissive, and dominant identities? Do women who are active in the BDSM community perceive and navigate their identities differently from women who are not active in the BDSM community? Do women outside of Florida perceive and navigate their identities differently? There is an obvious lack of racial and cultural diversity within the BDSM community (Manewitz, 2015). Therefore, locations of oppression (e.g. race, income, age) can enhance the understanding of how feminism and submission are perceived and navigated when intersecting with other identities. In other words, future research can ask: Do submissive, switch, and dominant Women of Color in the BDSM community experience feminism and D/s differently than White women? Do women of low socioeconomic status experience feminism and D/s differently than women of mid- or high socioeconomic status?

Research and practice can focus on exploring consent, transgression, and diversity within the BDSM community. Members can apply a sex-critical lens to reflect on these concepts, particularly how individuals learn about them and employ them, and how groups and sub-communities support or restrict them. Research can examine how race and gender are experienced, and how racism and sexism are employed. BDSM normalization benefits the community through a focus on health, safety, and ethical practices (Weiss, 2011). However, this normalization comes with a cost (Dymock, 2012), as it works as a disciplinary mechanism to police the BDSM community and practices, 
therefore marginalizing those who fall outside of accepted norms. Research can explore if women who identify as slave or who engage in types of play deemed outside of acceptable (e.g., race play, rape play, age play) perceive the normalization as positive, negative, or both. Qualitative studies, such as phenomenologies and case studies, might be most helpful in uncovering the depth and nuances of these issues; then once adequately explored, large scale surveys can provide a more global perspective. A suggestion for researchers is that academics and bloggers "bring the kinds of critical considerations of consent within BDSM communities to bear on reports of abuse in other forms of relationships (including recent high profile cases), and on relationships and human interactions more widely" (Barker, 2013, p. 909). Perhaps practices from within the BDSM community and D/s relationships can inform, and perhaps improve, practices in other communities and relationship dynamics.

Research and practice can focus on helping women to understand and navigate their identities. The BDSM community is a community of practice (Busbee 2008) with a thriving public pedagogy (Sandlin, Schultz, Burdick 2010). Women benefit from this by gaining access to peers and education, including the ability to learn about roles, practices, consent, power, and self-advocacy. Research can examine how women learn within the BDSM community. Members of the BDSM community and organizations such as The National Coalition for Sexual Freedom (NCSF, https://www.ncsfreedom.org/) can continue to create "a political, legal and social environment" that advances education and equal rights for adults who engage in alternative forms of sexual expressions. Qualitative studies, using interviews, and focus groups can provide rich detail about these topics. 
Content analysis of documents can also illuminate what education is occurring. For example, the conference proceedings can be examined, for large annual BDSM events around the world where attendees learn, socialize, and play (e.g., Beat Me in St. Louis, US; DomCon in Louisiana, US; Kinkfest in Oregon, US; Leather Leadership Conference in Georgia, US; Lupercalia in Alberta, CAN; German Fetish Ball in Berlin, GER; Rome BDSM Conference, IT; The Fetish Ball in Auckland, NZ).

Research and practice can focus on reducing BDSM social stigma through education. The need for professionals to be educated about BDSM has been recognized by the BDSM community, as demonstrated by the Kink Aware Professionals Directory (NCSF), where individuals can find psychotherapeutic, medical, legal, and other professionals who are sensitive to diverse expressions of sexuality. Research can explore the challenges that BDSM practitioners experience while learning about their identities and desires and while engaging in them. Awareness of BDSM can be applied in the field of adult education through incorporation into curriculum and training for psychologists, doctors, nurses, attorneys, and law enforcement officers. Continuing education, as provided by associations such as the American Psychological Association and the Academy of Human Resource Development, also provides sites for increased awareness. Additionally, this knowledge can inform educational platforms for parents, friends, and colleagues who interact with BDSM practitioners, and can be significant to all members of the BDSM community, in terms of understanding multiple identities. In addition to the research and policy work being conducted by the National Coalition for Sexual Freedom (e.g., Kink Aware Professionals Directory; Violence and Discrimination Survey; Consent Counts, comprehensive analysis and education about current laws and court decisions, 
development of legal arguments, participating in court cases, and grassroots activism) other researchers can focus on exploring BDSM in non-pathological ways, from a wide array of frameworks.

Research and practice can focus on healthy relationships and sexual education on college campuses. On March 12, 2018, the New York Times published an article titled "How Does Submissive Sex Work in the Age of \#MeToo?" (Phelan, 2018). The author wrote "there are the memories of being brusquely, and without permission, pushed up against a wall — and loving it. In fact, those were the steamiest moments I could recall. I wondered if I would ever experience such an unscripted embrace again — and then immediately worried: Did my secret desires make me a traitor to \#MeToo and what it stands for?" (Phelan, 2018, n.p.). In light of recent campaigns to end sexual violence, such as \#MeToo, a movement to support survivors and end sexual violence and harassment, and It's On Us, a national movement to end sexual assault, active on over 500 campuses, how do we educate people about consensual BDSM?

On average, the women in study \#2 recognized their feminist identity at age 14 and their submissive identity at age 24 . Six of the women recognized their submissive identity between the ages of 18 and 24. Additionally, 22 of the 23 woman attended college. Thus, many of the women attended college already having a feminist identity, though it was probably still developing, while many were likely just beginning to learn about, and perhaps struggle with, their submissive identity and desires. Research on feminism and submission, and how consent is understood, negotiated, and violated can enhance college educators' ability to help students develop as healthy individuals. Research on college students who participate in D/s might also provide insights into how 
these concepts are understood and operationalized, particularly on college campuses, where consent, abuse, and assault are critical concerns. The knowledge gained from such research can inform educational resources for individuals on topics such as feminism; identity; sexual desires, orientations, and health; healthy relationships; and selfawareness. The knowledge can also be utilized by teachers, advisors, and counselors who speak with students about these topics. Research on these topics at college campuses might be difficult to conduct, particularly if the researchers do not want to focus on people who already identify with the BDSM community. The researchers might want to connect with local TNG (The Next Generation, for people 18-35 years old) groups, whose members might attend college.

The women in study \#2 were asked if any other questions should have been asked, that related to the topic. Their responses involved sexual orientation, polyamorous relationships, and sadism and masochism, suggesting that future research might explore:

a) How does sexual orientation influence the way in which women engage in $\mathrm{D} / \mathrm{s}$ dynamics? Specifically, do their desires, behaviors, and levels of submission change based on their partner's sexual orientation or gender expression?

b) How do feminism and feminist values influence the women's polyamorous relationships? How do polyamorous relationships influence how women think and behave as feminists?

c) How do sadism and/or masochism influence women's feminist and submissive identities and values? For example, is it more difficult for sadistic women to feel submissive, or to be perceived as submissive because of their top role? Is it easier for sadistic women to feel feminist because of their top role? Is it easier for masochistic women to feel submissive or to be perceived as submissive because of their bottom role? Is it more difficult for masochistic women to feel feminist because of their bottom role? 
Researchers who explore BDSM hope that their findings can have a positive impact on the effectiveness of educators, counselors, therapists, doctors, and other professionals who interact with members of the BDSM community (Barker, 2007; Nichols, 2006; Rehor, 2015). A key to increasing this effectiveness is to educate the professionals about BDSM so that they have a better understanding of BDSM interests and identities. This education can occur within higher education, professional training and associations, and other settings where adults learn. For example, knowledge about feminism and submission, and how consent is understood, negotiated, and violated can enhance college educators' ability to help women develop as healthy individuals.

\section{References}

\#MeToo. (n.d.). Retrieved from https://metoomvmt.org/

Allison, D. (1994). Skin: Talking about sex, class \& literature. Ithaca, NY: Firebrand Books.

Barker, M. (2007). Turning the world upside down: Developing a tool for training about SM. In D. Langdridge \& M. Barker, (Eds.), Safe, sane and consensual contemporary perspectives on sadomasochism (pp. 261-270). London, UK: Palgrave Macmillan.

Barker, M. (2013). Rewriting the rules: An integrative guide to love, sex and relationships. New York, NY: Routledge.

Bezreh, T., Weinberg, T. S., \& Edgar, T. (2012). BDSM disclosure and stigma management: Identifying opportunities for sex education. American Journal of Sexuality Education, 7, 37-61. doi: 10.1080/15546128.2012.650984

Boyatzis, R. E. (1998). Transforming qualitative data: Thematic analysis and code development. Thousand Oaks, CA: Sage.

Brown, T. O. L. (2010). If someone finds out you're a perv (Masters thesis). Retrieved from OhioLINK ETD Center. (Document number: ohiou1279225927)

Creswell, J. W. (2013). Qualitative inquiry \& research design: Choosing among five approaches. Los Angeles, CA: Sage. 
Deckha, M. (2011). Pain as culture: A postcolonial feminist approach to S/M and women's agency. Sexualities, 14(2), 129-150. doi: 10.1177/1363460711399032

Downing, L. (27 July 2012). What is "sex critical" and why should we care about it? Sex Critical. [Blog]. Retrieved from http://sexcritical.glogsopt.co.uk/2012/07/what-issex-critical-and-why-should-we.html

Dworkin, A. (1974). Woman hating. New York, NY: Dutton.

Dworkin, A. (1989). Pornography: Men possessing women. New York, NY: Plume.

Dworkin, A., \& MacKinnon, C. (1985). The reasons why: Essays on the new civil rights law recognizing pornography as sex discrimination. Pornography Resource Center: Minneapolis, MN.

Dymock, A. (2012). But femsub is broken too! On the normalisation of BDSM and the problem of pleasure. Psychology \& Sexuality, 3(1), 54-68.

doi:10.1080/19419899.2011.627696

Eisele, H., \& Stake, J. (2008). The differential relationship of feminist attitudes and feminist identity to self-efficacy, Psychology of Women Quarterly, 32(3), 233244. doi: 10.1111/j.1471-6402.2008.00432.x

Goffman, E. (1963). Stigma: Notes on the management of spoiled identity. Englewood Cliffs, NJ: Prentice-Hall.

Hébert, A., \& Weaver, A. (2015). Perks, problems, and the people who play: A qualitative exploration of dominant and submissive BDSM roles. The Canadian Journal of Human Sexuality, 24(1), 49-62. Retrieved from http://ezproxy.fiu.edu/login?url=https://search-proquestcom.ezproxy.fiu.edu/docview/1667326462? accountid=10901

hooks, B. (2000). Feminist theory: From margin to center. Boston, MA: South End Press.

Hurtado, A. (1989). Relating to privilege: Seduction and rejection in the subordination of white women and women of color. Signs: Journal of Women in Culture and Society, 14, 833-855.

It's On Us. (n.d.). Retrieved from http://www.itsonus.org/

Joffe, H., \& Yardley, L. (2004). Content and thematic analysis. In D. Marks \& L. Yardley (Eds.), Research methods for clinical and health psychology (pp. 56-68). London, UK: Sage. 
Klein, M., \& Moser, C. (2006). SM (sadomasochistic) interests as an issue in a child custody proceeding. Journal of Homosexuality, 50(2-3), 233-242. doi: $\underline{10.1300 / J 082 v 50 n 02 \_11}$

Linden, R. R. (1982). Against sadomasochism: A radical feminist analysis. East Palo Alto, CA: Frog in the Well.

Marion, J. (2016). Please hurt me: A feminist psychoanalytic study of women's consensual sadomasochistic sexual practices (Ph.D.). Available from ProQuest Dissertations \& Theses A\&I. (1812552153). Retrieved from http://ezproxy.fiu.edu/login?url=https://search.proquest.com/docview/181255215 $\underline{3 \text { ? accountid }=10901}$

Martinez, K. (2011). Bound in theory and practice: A mixed-methods exploration of consensual sadomasochism (3468405). Available from ProQuest Dissertations \& Theses A\&I; ProQuest Dissertations \& Theses Global. (887901416). Retrieved from http://ezproxy.fiu.edu/login?url=https://search.proquest.com/docview/88790 1416 ? accountid=10901

Moustakas, C. E. (1994). Phenomenological research methods. Thousand Oaks, CA: Sage.

Musser, A. J. (2015). BDSM and the boundaries of criticism: Feminism and neoliberalism in fifty shades of grey and the story of O. Feminist Theory, 16(2), 121-136. doi:http://dx.doi.org.ezproxy.fiu.edu/10.1177/1464700115585723

Newmahr, S. (2006). Experiences of power in SM: A challenge to power theory. Berkeley Journal of Sociology, 50, 37-60. Retrieved from http://www.jstor.org.ezproxy.fiu.edu/stable/41035611

Newmahr, S. (2011). Rethinking kink: Sadomasochism as serious leisure. Qualitative Sociology, 33, 313-331.

Nichols, M. (2006). Psychotherapeutic issues with "kinky" clients: Clinical problems, yours and theirs. Journal of Homosexuality, 50(2-3), 281-300. doi:http://dx.doi.org.ezproxy.fiu.edu/10.1300/J082v50n02_14

pepomint. (11 June 2007a). "Towards a general theory of BDSM and power" posted on the blog freaksexual. Retrieved from https://freaksexual.com/2007/06/11/towardsa-general-theory-of-bdsm-and-power/

pepomint. (28 February 2007b). "Your kink does not get a free pass". Posted on the blog freaksexual. Retrieved from https://freaksexual.com/2007/02/28/your-kink-doesnot-get-a-free-pass/ 
Phelan, H. (12 March 2018). "How Does Submissive Sex Work in the Age of \#MeToo?" Retrieved from https://www.nytimes.com/2018/03/12/style/submissive-sex-metoo.html

Prior, E. (2013) Women's perspectives of BDSM power exchange. Electronic Journal of Human Sexuality, 16. Retrieved from http://www.ejhs.org/volume16/BDSM.html

Queen, C. (2003). Real live nude girl: Chronicles of sex positive culture, San Francisco, CA: Cleis.

Raab, S. M. (2013). The perpetuation and subversion of gender-power dynamics in BDSM: An interview study in Central Pennsylvania. Dickinson College Honors Theses. Paper 50. Retrieved from http://scholar.dickinson.edu/cgi/viewcontent.cgi?article=1049\&context=student $\mathrm{h}$ onors

Ramsey, L. R., Haines, M. E., Hurt, M. M., Nelson, J. A., Turner, D. L., Liss, M., \& Erchull, M. J. (2007). Thinking of others: Feminist identification and the perception of others' beliefs. Sex Roles, 56, 661-616.

Rehor, J. E. (2015). Sensual, erotic, and sexual behaviors of women from the 'kink' community. Archives of Sexual Behavior, 44(4), 825-836. doi:http://dx.doi.org.ezproxy.fiu.edu/10.1007/s10508-015-0524-2

Richards, L. (2002). Qualitative computing - A methods revolution? International Journal of Social Research Methodology, 5(3), 163-276.

Rivoli, L. R. (2015). Liberation Through Domination: BDSM Culture and SubmissiveRole Women. Student Publications, 318. Retrieved from http://cupola.gettysburg.edu/student_scholarship/318

Rocco, T. S., Stein, D., \& Lee, C. (2003). An exploratory examination of the literature on age and HRD policy development. Human Resource Development Review, 2(2), 155-180. doi: 10.1177/1534484303002002004

Simula, B. L. (2012). A 'Different economy of bodies and pleasures'?: Gender, power, and sexuality in BDSM interactions (Order No. 3522289). Available from ProQuest Dissertations \& Theses A\&I; ProQuest Dissertations \& Theses Global. (1037419865). Retrieved from http://ezproxy.fiu.edu/login?url=http://search.proquest.com.ezproxy.fiu.edu/docvi ew/1037419865?accountid $=10901$

Sprott, R. A. (January 2014). Who are these leather people, and why do we need to include them? Kink history, culture, communities and dilemmas. Paper presented at the National Conference on LGBT Equality. Houston, TX. Retrieved on 
September 23, 2016 from

https://carasresearch.org/images/uploads/main/Who_are_these_leather_people_A n_overview_and_introduction.pdf

Surprise, O. (2012). Screaming green: A topography and bourdieusian analysis of the model of sexual consent utilized by BDSM community members (1509152). Available from ProQuest Dissertations \& Theses A\&I; ProQuest Dissertations \& Theses Global. (1012364302). Retrieved from http://ezproxy.fiu.edu/login?url=https://search.proquest.com/docview/101236430 $\underline{2 \text { ? accountid }=10901}$

Valenti, J. (2007). Full frontal feminism: A Young woman's guide to why feminism matters. Emeryville, CA: Seal Press.

Van Manen, M. (1997). Researching lived experience: Human science for an action sensitive pedagogy. London, UK: Althouse Press.

Walters, C. J. (2012). Discourses of heterosexual female masochism and submission from the 1880s to the present day (Order No. U575177). Available from ProQuest Dissertations \& Theses A\&I; ProQuest Dissertations \& Theses Global. (1124095062). Retrieved from http://ezproxy.fiu.edu/login?url=https://search.proquest.com/docview/112409506 2?accountid=10901

Weiss, M. D. (2011). Techniques of pleasure: BDSM and the circuits of sexuality. Durham, NC: Duke University Press.

Women Against Men. (2014). Retrieved from http://www.womenagainstmen.com/about

Wright, S. (2005). Discrimination of SM-identified individuals. Journal of Homosexuality, 50, 217-231. doi: 10.1300/J082v50n02_10

Wright, S. (2008). Second national survey of violence \& discrimination against sexual minorities. Retrieved from: https://ncsfreedom.org/images/stories/pdfs/BDSM_Survey/ 2008 bdsm_survey_analysis_final.pdf

Young. M. (2009). Thoughts on rope, submission and feminism. In L. Harrington (Ed.), Rope, bondage, and power, (pp. 51-60). Las Vegas, NV: Nazca Plains.

Zucker, A. N., \& Bay-Cheng, L. Y. (2010). Minding the gap between feminist identity and attitudes: The behavioral and ideological divide between feminists and nonlabelers. Journal of Personality, 78(6), 1895-924. doi: 10.1111/j.14676494.2010.00673.x 


\title{
APPENDICES
}

\section{Appendix A \\ Feminist and Submissive Women \\ Adult Verbal Consent}

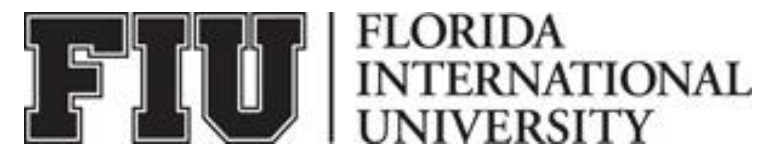

\section{ADULT VERBAL CONSENT TO PARTICIPATE IN A RESEARCH STUDY}

\author{
Negotiated Self: An Exploration of Women's Perceptions of Their Feminist and \\ Submissive Identities
}

Hello, my name is Carolyn Meeker. You have been chosen to be in a research study about the experiences of women who identify as: (a) 18 years or older, (b) feminist, (c) submissive, and (d) active in the bondage/discipline, dominance/submission, sadism/masochism (BDSM) community, though you may prefer the term Fetish, Kink, Leather, or Power Exchange.

The purpose of this study is to explore the identities and related experiences of women as they navigate their feminist and submissive identities. If you decide to participate in this study, you will be 1 of 15 participants. Participation will take approximately 2 hours (60 to 90 minutes for the interview, plus follow up communication). You may choose to spend additional time in this study; for example, you might want to review your interview transcript or my interpretation of the data. If you agree to be in the study, I will ask you to do the following things:

1. Meet one time for approximately 60 to 90 minutes to reflect upon your identities and experiences during an interview, which will be recorded by a digital voice recorder.

2. Verbally consent to be interviewed, and for your voice to be recorded during the interview.

3. Provide background information, such as age and sexual orientation.

4. Reflect upon your identity and experiences as a woman.

5. Reflect upon your identity and experiences as a feminist.

6. Reflect upon your identity and experiences as a submissive.

7. Reflect upon how you navigate your identities as a feminist and as a submissive:

a. Within the BDSM/Leather/Kink/Power Exchange community

$b$. Within your Dominance and submission (D/s), or power exchange, relationship(s)

c. Within non-kink environments 
There are no foreseeable risks or benefits to you for participating in this study. All identifiable information, such as your name, email address, phone number, or similar data will remain confidential and will be kept separate from the interview transcript.

It is expected that this study will benefit society by helping individuals who provide services for women to understand women's experiences better. For example: health care professionals who offer physical, psychological, and spiritual support will benefit from a more in-depth understanding of women's experiences. So will legal professionals who inform and enforce laws and policies, and educators who teach about identity, relationships, sexuality, feminism, and the professions listed above. Additionally, learning about sexual identities allows the creation of new knowledge about ourselves and other people; therefore, this study might help you and the people in your life understand you better.

There is no cost or payment to you for participating in this study. If you have questions while taking part, please stop me and ask.

Your answers are confidential. In any sort of report I might publish, I will not include any information that will make it possible to identify you as a subject. Research records will be stored securely and I am the only person who will have access to them.

Interviews will be recorded using a digital voice recorder. The interviews will be transcribed verbatim by a professional transcriber and the transcriptions will be stored on my personal computer.

I am the only researcher for this study. If you have questions for me, you may contact me at 305-989-8898.

If you would like to talk with someone about your rights of being a subject in this research study or about ethical issues with this research study, you may contact the FIU Office of Research Integrity by phone at 305-348-2494 or by email at ori@fiu.edu.

Your participation in this research is voluntary, and you will not be penalized or lose benefits if you refuse to participate or decide to stop.

Do you consent to participate in this project? 


\section{Appendix B \\ Feminist and Submissive Women \\ Background and Demographic Survey}

1. How old are you?

2. What is your sexual orientation?

3. How do you identify, in terms of race and/or ethnicity?

4. What is your highest level of education?

5. What is your occupation? If a student, what are you studying? If retired, what was it?

6. How would you describe your political philosophy? (i.e. left/liberal, right/conservative, middle of the road)

7. Were you raised in an environment where you were comfortable talking about sex or related topics?

8. How old were you when you first realized that you might be submissive?

9. How many D/s or power exchange relationships have you been in? (beyond just casual play partners)

10. Were you raised in an environment where you were comfortable talking about feminism or related topics?

11. How old were you when you first realized that you might be feminist? 


\section{Appendix C \\ Feminist and Submissive Women \\ Interview Guide}

\section{Negotiating self: An exploration of women's perceptions of their feminist and submissive identities}

The purpose of this study is to explore the perceptions of women who identify as feminist and submissive and who are active in the BDSM community, regarding your experiences navigating these identities. Please consider this more of a conversation than a Q\&A.

Before we start, I want to confirm a few things:

- What is your pseudonym for this study?

- You can end this interview at any time, or skip a question if you feel unconformable.

- Let's test the audio recorder to make sure that it picks up our voices clearly.

\section{Woman Identity (3 questions)}

1. What does being a woman mean to you?

2. How do you perceive, or understand, your identity as a woman?

3. How important is your identity as a woman, to your sense of self?

\section{Feminist Identity (7 questions)}

4. What does feminism mean to you?

5. How do you perceive, or understand, your feminist identity?

6. What are your feminist values?

7. How do you act as a feminist? What kinds of things do you do or say?

8. When and how did you first recognize that you were a feminist?

9. How important is your feminist identity to your sense of self?

10. Are there times when you hide or set aside your feminist identity or values? Please explain.

\section{Submissive Identity (7 questions)}

11. What does Dominance and submission mean to you?

12. How do you perceive, or understand, your submissive identity?

13. What are your submissive values?

14. How do you act as a submissive? What kinds of things do you do or say?

15. When and how did you first recognize that you were a submissive?

16. How important is your submissive identity to your sense of self?

17. Are there times when you hide or set aside your submissive identity or values? Please explain. 


\section{Navigating Feminist and Submissive Identities (7 questions)}

18. Please describe how your feminist and submissive identities relate to each other.

19. Do you ever have to navigate between your feminist and submissive identities? Please explain.

20. How do you incorporate, or navigate, your feminist identity within your D/s relationship?

21. How do you incorporate, or navigate, your feminist identity within the BDSM community?

22. Do you think that the BDSM community, in general, accepts feminist identity? Please explain.

23. How do you incorporate, or navigate, your submissive identity in vanilla environments or situations?

24. Do you think that the feminist community, in general, accepts D/s relationships? Please explain.

\section{Final Questions (3 questions)}

25. Do you have any other identities or values that impact what we've discussed? Please explain.

26. Should any other questions have been asked? What are they?

27. Do you have anything else to add? 


\section{Appendix D \\ Feminist and Submissive Women Follow Up Questions}

1. When in a D/s relationship, which best describes your dynamic?
a. $24 / 7(13)$
b. As often as possible, given the constraints of life (7)
c. Only when in private or with close friends (3)
d. Only in the bedroom (0)
e. Once in a while to spice things up (0)

2. Which best describes your submissive identity?
a. It's who I am (21)
b. It's something I do (2)

3. Which best describes your submissive identity?
a. Only submissive to a Dominant partner(s) (13)
b. Submissive to a Dominant partner(s) AND to people I care about (friends, community) (7)
c. Submissive in general (with friend, at work, etc.) (3)

4. What roles do you have in the BDSM community? (select all that apply)

a. None - I am not currently involved ( 1 - though she was active online)

b. Member - I attend events/groups/parties (21)

c. Educator - I teach classes/topics (10)

d. Leader - I run or help to run groups/events (9)

e. Mentor - I mentor other members (9)

f. Advocate - I actively fight/speak up for rights (11)

5. How important to you is your sense of belonging to the BDSM community?
a. Extremely important (9)
b. Very important (7)
c. Moderately important (4)
d. Slightly important (3)
e. Not at all important (0)

6. Which best describes your feminist identity?

a. I think of myself as a feminist (18)

b. I do not think of myself as a feminist, though I do have feminist values (5)

7. Which best describes your feminist identity/values?

a. It's who I am (21)

b. It's something I do (2) 
8. What roles do you have in the feminist community? (select all that apply)

a. None - I am not currently involved (9)

b. Member - I attend events/groups (9)

c. Educator - I teach classes/topics (4)

d. Leader - I run or help to run groups/events (4)

e. Mentor - I mentor other members (3)

f. Advocate - I actively fight/speak up for rights (12)

9. How important to you is your sense of belonging to the feminist community?
a. Extremely important (2)
b. Very important (5)
c. Moderately important (8)
d. Slightly important (5)
e. Not at all important (3)

10. Do your submissive and feminist identities/values support each other?
a. Yes (16)
b. No (2)
c. Sometimes (5)

11. Do your submissive and feminist identities/values conflict with each other?
a. Yes (1)
b. No (14)
c. Sometimes (8)

12. Do you agree with this? A theme from the interviews is that your core values are always a part of who you are, threaded throughout each identity like a tapestry. Sometimes, certain colors (identities/values) are more visible, but the other colors (identities/values) are still there in the background. In essence, your values are consistent, regardless of what you're doing, where you're at, or who you're with.
a. Strongly agree (21)
b. Agree (2)
c. Neither agree nor disagree (0)
d. Disagree (0)
e. Strongly disagree (0)

13. List your identities (roles, groups, characteristics) that are very important to you.

14. What advice would you give to a submissive woman who is just learning about $\mathrm{D} / \mathrm{s}$ and the BDSM community, if she asked for advice?

15. Who do you wish understood your identities and experiences better?

16. What does consent mean to you? How do you negotiate consent with your Dtype $(\mathrm{s})$ ?

17. How has your identity as a submissive/slave changed over time? 


\section{Appendix D \\ Key Terms and Concepts}

BDSM. Acronym for bondage/discipline (BD), Dominance/submission (D/s), sadism/masochism (SM or S\&M) and slavery/mastery (sM). BDSM can refer to the kink community as a whole or to any kink activity in general (Harrington \& Williams, 2012). Other terms often used interchangeably are SM, Kink, Leather, and Power Exchange.

BDSM/Kink/Leather community. BDSM incorporates a wide array of activities and groups; however, there appears to be enough commonality to suggest that SM is "constituted by a set of five social features which sustained a particular class of fantasies with erotic meanings: dominance and submission, role playing, consensuality, a sexual

context, and mutual definition" (Weinberg, Williams, \& Moser, 1984, p. 380). For many people, the kink community is a place to escape the "real world," where they can engage in fantasy, role play, and other experiences outside of the norm. For others, the kink community is the real world, where they can be themselves and choose their family, community, and identities. Yet others seem to move between these worlds without boundaries (Harrington \& Williams, 2012).

Consent. "An ongoing, relational, negotiation in which the conditions under which a 'no' is possible need to be created, by everyone involved, in order for a 'yes' to count" (Barker, 2013b, p. 908). When negotiating consent, partners discuss various topics and answer questions such as: Who will be involved or observed? What will we be doing? Why are we doing this? Where is it okay to touch? Is there a risk of injury or a 
health issue? How can we stop what is happening? (National Coalition for Sexual Freedom, 2015). Partners operationalize consent in different ways and establish together what consent means to them. This might include relationships involving consensual nonconsent, or agreement that consent is not required for future interactions.

D/s (See also Power Exchange). "An erotic play or relationship style that focuses on power exchange. (aka $d / s, D / s$, Dominance/Submission)" (Harrington \& Williams, 2012, p. 238), where participants consensually assume or yield authority.

Discrimination. "The unequal allocation of valued goods and resources based on one's social position and group membership, which includes limiting access of some groups to full benefits and rights" (Ferber, Holcomb, \& Wentling, 2009, p. 554).

Dominance. "the state of assuming psychological or physical control over another in a power-exchange relationship, a state in which orders may be executed or services performed. The state of Dominance can last for the length of a brief, negotiated scene or for the entire length of a relationship (Ortmann \& Sprott, 2013, p. 15).

Dominant. “(1) adj. The quality of asserting authority or influence. (2) noun. An individual who exercises control in a power exchange dynamic. (aka Dom, Domme)" (Harrington \& Williams, 2012, p. 239). 
Ethnicity. "A socially constructed category based on characteristics, such as national origin, heritage, geography, language, customs, or cultural practices" (Ferber et al., 2009, p. 555).

Feminism. "An understanding that women have suffered forms of subordination or oppression because of their sex, and an advocacy of ways to overcome them to achieve better lives for women, and for men, within the family and society" (Badran, 2009, p. 18). Also, "a wide range of theoretical and political perspectives that value women and their experiences. Feminism is committed to activism, social change, and equality" (Ferber at al., 2009, p. 555).

Fetish (See also Paraphilia). "Sexual arousal resulting from specific objects, situations, or individuals. (aka fetishism, a kink)" (Harrington \& Williams, 2012, p. 240).

Gender. Socially constructed categories dividing people into groups, such as women and men. The term gender is often used interchangeably with sex (Ferber, Holcomb, \& Wentling, 2009, p. 555).

Heteronormativity. "A social structure that assumes that individuals will be naturally attracted to and enter into romantic/sexual relationships with persons of the other sex or gender" (Ferber et al., 2009, p. 555). 
Identity. "The set of meanings that define who one is when one is an occupant of a particular role in society, a member of a particular group, or claims particular characteristics that identify him or her as a unique person" (Burke \& Stets, 2009, p. 3). Identity shapes how people make sense of the world and their experiences, including their interactions with other people (Burke, 2007). Some identities reinforce each other; others might not (Reitzes \& Mutran, 1995; Thoits, 1983; Wiley, 1991).

Identity standard. Set of meanings that define the character of an identity. Individuals act in ways to verify their identities, where perceived meanings are consistent with an identity standard (Powers, 2005).

Kink. A Variety of sexual activities including, but not limited to, voyeurism, exhibitionism, fetishism, role-playing, cross-dressing, power exchange, swinging, leather identity, erotic restraint, consensual non-monogamy, "naughty sex", and BDSM between consenting adults. "In short, the realm of sexuality perceived to be outside the mainstream" (Harrington \& Williams, 2012, p. 242).

Leather. (See also Old Guard) "A subculture that traces its origin back to gay male leather and kink of the mid-20th century" or "a personal identity based on the constructs of the leather sub-culture" (Harrington \& Williams, 2012, p. 242). 
$M / S$ (See also Power Exchange). "An erotic play or relationship style that focuses on ownership or possession within a power exchange dynamic. (aka $\mathrm{m} / \mathrm{s}, \mathrm{M} / \mathrm{s}$, mastery/slavery, ownership/slavery)" (Harrington \& Williams, 2012, p. 244).

Misogyny. "The hatred of women" (Ferber et al., 2009, p. 556).

Negotiation. "Mutual discussion of and arrangement for the terms of an interaction or relationship" (Harrington \& Williams, 2012, p. 244).

Oppression. "The systematic denial of access to cultural and institutional resources based on membership in social groups, such as race, ethnicity, gender, sexuality, ability, age, religion, and so forth. Oppression is perpetuated by those with privilege and power" (Ferber et al., 2009, p. 556).

Outing. "The non-consensual disclosure of someone's sexual or cultural affiliations, status, identity, or activities" (Harrington \& Williams, 2012, p. 244).

Patriarchy. "A dynamic system of power and inequality that privileges men and boys over women and girls in social interactions and institutions (adapted from Yoder, 2007)" (Ferber et al., 2009, p. 556).

Play. (1) A term often used in the kink community to refer to the actions and interactions within a scene. (2) A term adopted by some people in the swinger or 
anonymous sex communities to refer to sexual interaction between two or more individuals (Harrington \& Williams, 2012, p. 245).

Polyrhythmic realities. Individuals' multiple identities can create polyrhythmic realities (Brown, 1989; Sheared, 1999), where their different understandings of their identities cause them to do "different, seemingly contradictory things, simultaneously" (Brown, 1989, p. 929).

Power exchange (See also $D / S, M / S)$. "An interpersonal association in which the participants mutually consent to assume or yield authority" (Harrington \& Williams, 2012, p. 245).

Privilege. "The systematic access to valued cultural and institutional resources that are denied to others, based on social location in dominant categories of race, gender, sexuality, ability, and so forth. Privilege exists in relation to oppression" (Ferber et al., 2009, p. 556).

Prominence hierarchy of identity. How important an identity is to an individual, based on her desires or ideals, and how she wants to be seen by others (McCall \& Simmons, 1978). Three key concepts are prominence, commitment, and salience. Commitment refers to how invested an individual is in the identity; how embedded she is within the social structure. Salience is the likelihood that an identity will be activated; the more salient an identity, the more likely it is to be activated in any given situation. If 
more than one identity becomes activated in a situation, the identity with the highest prominence and commitment will guide the behavior (Burke \& Stets, 2009; McCall \& Simmons, 1978).

Protocol. "A code of behavior that delineates expectations. Protocols may be used within a community or power exchange dynamic to standardize etiquette" (Harrington \& Williams, p. 245).

Queer. "A political project and/or an identity that describes people who identify or live outside heteronormative notions of sex, gender, and sexuality as well as hegemonic constructions of race, ethnicity, ability, class, and so on" (Ferber et al., 2009, p. 556).

Racism. "An institutional system of oppression based on socially constructed categories of race. Racism privileges those with greater social power and oppresses others through everyday practices, attitudes, assumptions, behaviors, cultures, and institutional rules and structures" (Ferber et al., 2009, p. 557).

Risk Aware Consensual Kink (RACK). A common acronym to describe what people do in the BDSM community (Medlin, 2001). Risk means that things can go wrong, even with careful planning and experience. Aware means knowing that things can go wrong and accepting that there is risk involved. Consensual means that two or more adult partners are informed about what they plan to do and have agreed to do it without 
duress. Kink means that what happens is outside of the mainstream. RACK places the responsibility for one's actions on the individual and "empowers each person to define their own risk profile" (Cross, 2010, n.p.).

Safe, Sane, and Consensual (SSC). SSC is the most common phrase used to describe what people do in the BDSM community (Cross, 2010). Safe means being free from harm and knowledgeable about the skills, techniques, and risks related to one's activities. Sane means able to recognize the difference between fantasy and reality, thus distinguishing consensual BDSM from abuse and mental illness. Consensual means that adults negotiate and respect the limits established by each partner. Consent is considered a key difference between rape and abuse and consensual BDSM activities. The standards of Safe, Sane, and Consensual are seen by many practitioners as allowing the community to focus on health, safety, and the creation of ethical subjectivity (Weiss, 2011). However, recent discourse incorporates a critique of how SCC is used to police the BDSM community, members, and practices. Some practitioners prefer the term RACK (Risk Aware Consensual Kink) because (a) they view SSC as subjective and (b) they want to acknowledge that what they do involves risk. RACK is seen as more accurate because it "empowers each person to define their own risk profile" (Cross, 2010, n.p.).

Scene. "(1) An umbrella term for the kink community as a whole. (e.g., 'We are part of the scene.") (2) (aka scenario, session) A kink encounter that has a delineated beginning, middle, and end. (e.g. 'They had a scene.')" (Harrington \& Williams, 2012, p. 247). 
Sexism. "A system that oppresses women through everyday practices, attitudes, assumptions, behaviors, culture, and institutional rules and structures (adapted from Yoder, 2007)" (Ferber et al., 2009, p. 557).

Sexual orientation. "A concept and set of categories (bisexual, heterosexual, homosexual, and the like) denoting sexual preference and desire that implies that sexual object choice is an essential, unchanging, inborn characteristic" (Ferber et al., 2009, p. $557)$.

Sexuality/Sexual identity. "Refers to sexual desire, attraction, and practice, based on sexual object choice. Common forms of sexual identity in contemporary Western culture include heterosexual, homosexual, gay, lesbian, bisexual, pansexual, queer, and asexual" (Ferber et al., 2009, p. 557).

Slave. "An individual who practices consensual servitude to another human within the structure of a power exchange dynamic. An individual may identify as a Slave regardless of relationship status" (Harrington \& Williams, 2012, p. 247).

Submission. The state "in which an indivdiaul willingly and consensually sublimates or bequeaths his or her power to a Dominant partner in a power-excahgen relationship. In doing so, the submissive allows the Dominant to take pscyological or physical control over him or her" (Ortmann \& Sprott, 2013, p. 16). As with Dominance, submission can last for a brief, negotiated scene or for the entire length of a relationship. 
Submissive. "(1) adj. The quality of ceding authority or influence. (2) noun. An individual who surrenders control in a power exchange dynamic. (aka sub)." (Harrington \& Williams, 2012, p. 248).

Vanilla. "Slang for individuals who are not kink-identified, not actively engaged in BDSM activities, or not part of the kink lifestyle. May refer to non-kink activities. This term is sometimes used in a derogatory fashion" (Harrington \& Williams, 2012, p. 249). 
VITA

\section{CAROLYN MEEKER}

1996

1999

2001

2009

2015

2016

07/2013 -

Present

Fall 2015

2012

2010

$12 / 2009-$ $06 / 2015$
A.A. Humanities

College of the Canyons

Valencia, California

B.A. Spanish cum laude

Minor in Education Studies | Coordinator, Peer Advising Program

Concentration in Community Education Leadership

Outstanding Participation in Education Studies Minor

University of California, Los Angeles

Westwood, California

M.Ed. Counseling in Student Affairs

Internship, Bruin Leaders Program

University of California, Los Angeles

Westwood, California

Strong Interest Inventory Certification

Strengths-Based Education Instructor Certificate

Myers Briggs Type Indicator (MBTI) Certified Practitioner

Assistant Director, Career and Talent Development

Florida International University, Biscayne Bay Campus

North Miami, Florida

Teaching Assistant, ADE 6945 Internship in Adult Education and Human Resource Development

Florida International University

Miami, Florida

Instructor, SLS 1501 First Year Experience (FYE)

Florida International University

Miami, Florida

06/2008 - Assistant Director, Career and Talent Development

06/2013 Florida International University, Engineering Center

Miami, Florida

07/2004 - Resident Director

05/2008 University of California, Riverside

Riverside, California 
06/2002 - Resident Director

05/2004 Binghamton University (SUNY)

Binghamton, New York

2014

FIU LGBTQA Staff Award in recognition of support and service to the community.

2011 United Stated Air Force Recruiting Salute for "outstanding support of the Air Force Recruiting Service".

2010 "Outstanding Contributions in Career Services and Organization of Student Events" from American Society of Mechanical Engineers FIU.

2008

"Contribution to the University" from UCR Chancellor Córdova.

PUBLICATIONS AND PRESENTATIONS (Selected)

Meeker, C., McGill, C. M., \& Rocco, T. S. (submitted 2018, March 19). Navigation of Feminist and Submissive Identity by Women in the BDSM Community: A Structured Literature Review. Submitted to Signs: Journal of Women in Culture and Society.

Meeker, C., \& Sharma, D. (2018, March 5). Professional networking via social media and technology. Student Affairs Professionals in Higher Education (NASPA) Annual Conference: Philadelphia, PA.

Meeker, C., \& Belgodere, C. (2017, February 28). Networking and branding with LinkedIn. 38HOT (Helping Others Together) Veterans Workshop. Greater Miami Chamber of Commerce: Miami, FL.

Meeker, C., \& Hernandez, S. (2017, February 17). Advisors' toolkit for helping students choose their major. FIU Council for Undergraduate Academic Advising (CUAA) Spring Advisor's Forum: Miami, FL.

Vega, G., Meeker, C., Serrano, E., \& Hovance, A. (2015, March 6). The Art of Mentoring Sexual Minorities: FIU's LGBTQA Mentors Program. College Student Educators International (ACPA) Annual Convention.

Reio, T. G., Jr., Meeker, C., \& Reio, S. M. (2013). Workplace incivility: What it is, and what we can do. In M. A. Paludi (Ed.), Managing diversity in today's workplace (155168). Santa Barbara, CA: Praeger.

Collins, J. C., Meeker, C., Whitehead, C., Rocco, T. S. (2012). Disclosing "deviance" in the workplace: LGBT, BDSM, convicts, and the disabled. In Dirani, K. M., Wang, J., Gedro, J., Doshy, P. (Eds.), Academy of Human Resource Development Conference Proceedings (p. 50). Denver, CO: Academy of Human Resource Development. 